\title{
Comparison of Waste Feed Delivery Small Scale Mixing Demonstration Simulant to Hanford Waste
}

\author{
BE Wells \\ PA Gauglitz \\ DR Rector
}

September 2011

Pacific Northwest

NATIONAL LABORATORY

Proudly Operated by Battelle Since 1965 


\title{
DISCLAIMER
}

This report was prepared as an account of work sponsored by an agency of the United States Government. Neither the United States Government nor any agency thereof, nor Battelle Memorial Institute, nor any of their employees, makes any warranty, express or implied, or assumes any legal liability or responsibility for the accuracy, completeness, or usefulness of any information, apparatus, product, or process disclosed, or represents that its use would not infringe privately owned rights. Reference herein to any specific commercial product, process, or service by trade name, trademark, manufacturer, or otherwise does not necessarily constitute or imply its endorsement, recommendation, or favoring by the United States Government or any agency thereof, or Battelle Memorial Institute. The views and opinions of authors expressed herein do not necessarily state or reflect those of the United States Government or any agency thereof.

\author{
PACIFIC NORTHWEST NATIONAL LABORATORY \\ operated by \\ BATTELLE \\ for the \\ UNITED STATES DEPARTMENT OF ENERGY \\ under Contract DE-AC05-76RL01830
}

Printed in the United States of America

$$
\begin{aligned}
& \text { Available to DOE and DOE contractors from the } \\
& \text { Office of Scientific and Technical Information, } \\
& \text { P.O. Box 62, Oak Ridge, TN 37831-0062; } \\
& \text { ph: }(\mathbf{8 6 5 )} 576-8401 \\
& \text { fax: (865) 576-5728 } \\
& \text { email: reports@adonis.osti.gov }
\end{aligned}
$$

\author{
Available to the public from the National Technical Information Service \\ 5301 Shawnee Rd., Alexandria, VA 22312 \\ ph: (800) 553-NTIS (6847) \\ email: orders@ntis.gov <http://www.ntis.gov/about/form.aspx> \\ Online ordering: http://www.ntis.gov
}




\title{
Comparison of Waste Feed Delivery Small Scale Mixing Demonstration Simulant to Hanford Waste
}

\author{
BE Wells \\ PA Gauglitz \\ DR Rector
}

September 2011

Prepared for

the U.S. Department of Energy

under Contract DE-AC05-76RL01830

Pacific Northwest National Laboratory

Richland, Washington 99352 


\section{Description of Changes For Revision 1:}

o Bound hard-copies of PNNL-20637 Rev. 0 included illegible y-axis labels for Figures 2.2 and 2.3. The axis labels are now correctly printed as $\tau_{*}$.

o The units for the just suspended impeller speed, $\mathrm{N}_{\mathrm{js}}$, in Figure 4.4, 4.16, 4.19, A.10, A.11, and A.12 as well as in Tables 4.2 and 4.3 were incorrectly provided as rpm. The units for $\mathrm{N}_{\mathrm{js}}$ are now corrected as rps. 


\section{Summary}

The Hanford double-shell tank (DST) system provides the staging location for waste that will be transferred to the Hanford Tank Waste Treatment and Immobilization Plant (WTP). Specific WTP acceptance criteria for waste feed delivery describe the physical and chemical characteristics of the waste that must be met before the waste is transferred from the DSTs to the WTP. One of the more challenging requirements relates to the sampling and characterization of the undissolved solids (UDS) in a waste feed DST because the waste contains solid particles that settle and their concentration and relative proportion can change during the transfer of the waste in individual batches. A key uncertainty in the waste feed delivery system is the potential variation in UDS transferred in individual batches in comparison to an initial sample used for evaluating the acceptance criteria. To address this uncertainty, a number of smallscale mixing tests have been conducted as part of Washington River Protection Solutions' Small Scale Mixing Demonstration (SSMD) project to determine the performance of the DST mixing and sampling systems. A series of these tests have used a five-part simulant composed of particles of different size and density and designed to be equal or more challenging than AY-102 waste. This five-part simulant, however, has not been compared with the broad range of Hanford waste, and thus there is an additional uncertainty that this simulant may not be as challenging as the most difficult Hanford waste. The purpose of this study is to quantify how the current five-part simulant compares to all of the Hanford sludge waste, and to suggest alternate simulants that could be tested to reduce the uncertainty in applying the current testing results to potentially more challenging wastes.

Comparison of the size and density of the particulate comprising the five-part SSMD simulant to that of the characterized Hanford sludge waste particulate was made using metrics for particle mobilization, suspension, settling, transfer line intake, and pipeline transfer where dependence on particle size and density may be different, including:

1. Settling velocity

2. Archimedes number

3. Critical shear stress for erosion of noncohesive particles

4. Just-suspended impeller speed

5. Jet velocity needed to achieve a certain degree of solid suspension

6. PJM critical suspension velocity for noncohesive solids

7. PJM cloud height for noncohesive solids

8. Pipeline critical transport velocity

The five-part SSMD simulant and Hanford sludge waste particulate is represented by particle size and density distributions (PSDDs). Based on comparison of calculated and measured settling velocities, the Hanford sludge waste particles are characterized by particle size distribution (PSD) techniques that likely includes primary particles, hard agglomerates, and soft agglomerates or flocs, and are characterized by particle density by assuming that all particles have a density equal to the UDS compound crystal density regardless of particle size.

The results of this analysis show that, as designed, the five-part SSMD simulant is typically more challenging than the AY-102 waste except for the larger and more dense particulate of the most 
challenging PSDD type, regardless of which metric is considered. The five-part SSMD simulant is also typically more challenging than the waste composites with the exception of the most challenging particulate. The SSMD simulant was not as challenging as the most difficult sludge wastes, and only a limited fraction of the waste has been characterized. Less than $20 \%$ of the Hanford sludge inventory is characterized by the PSDDs. It is also possible that the PSDD variation in the limited characterization of the waste under represents the variation of the entire waste inventory. The analysis results thus indicate that it is possible that at least $50 \%$ by volume of the Hanford sludge UDS particulate may be more challenging than that represented by the five-part SSMD simulant.

Two different example adjustment of the SSMD simulant component concentrations are provided to match the most challenging of the characterized sludge waste. One of the simulants is based on components of the five-part SSMD simulant, while the other includes an additional component. The differences in these example adjusted simulants illustrate the significance of the different dependencies on particle size and density depending on the metric considered.

Previous testing has shown the effect of varying the simulant fluid. A summary of available data shows that a change in fluid properties that decreases the ECR may still increase the amount of settling particles transferred, for example increased viscosity. A simple model showing the roles of suspending fluid density and viscosity on the ECR of the jet mixers was developed. The batch transfer data clearly show that transferring settling stainless steel particles in water is more challenging than in more viscous and dense fluids. The predicted ECR is higher in water, but the increased density and/or viscosity of the other fluids improves the overall suspension and transfer of particles.

The coupled behavior of particle erosion, suspension, and settling, and the roles of particle and fluid properties, can be investigated with appropriate computational tools. The ability of the ParaFlow code to address this physical behavior was presented. ParaFlow may be used to quantify simulant selections as discussed, not only for the particulate selection, but also in consideration of the effects of the characteristics of the suspending fluid on test results. 


\section{Acknowledgments}

The authors thank JA Fort for his independent technical review, SA Suffield for her calculation review, and MK Zimmerschied for the technical editing. 



\section{Acronyms and Abbreviations}

DST

ECR

EM-31

PJM

PNNL

PSD

PSDD

SS

SSMD

UDS

WTP double-shell tank

effective cleaning radius

U.S. Department of Energy Environmental Management Waste Processing Program

pulse jet mixer

Pacific Northwest National Laboratory

particle size distribution

particle size and density distribution

stainless steel

Small Scale Mixing Demonstration

undissolved solids

Hanford Tank Waste Treatment and Immobilization Plant 



\section{Contents}

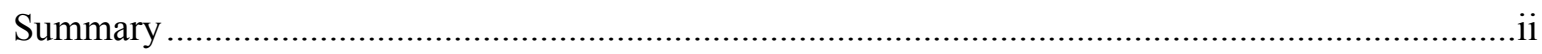

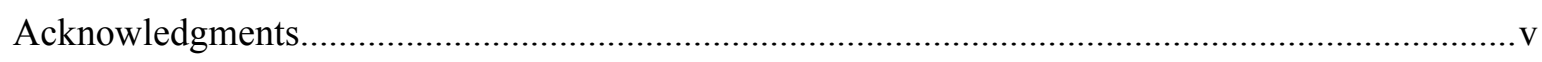

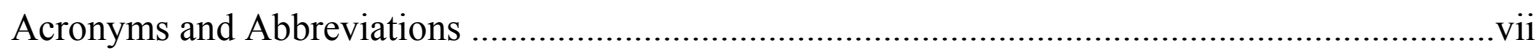

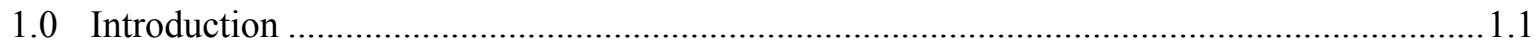

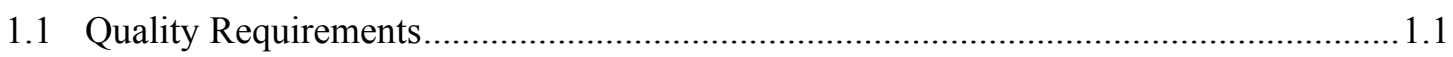

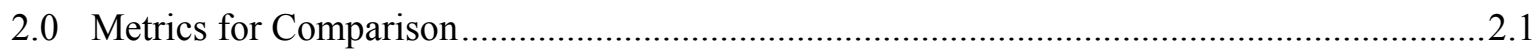

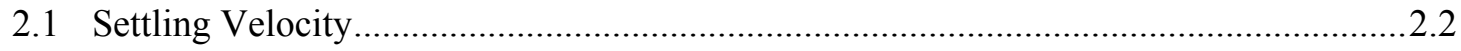

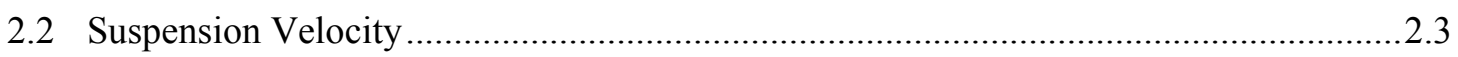

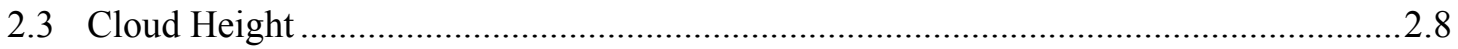

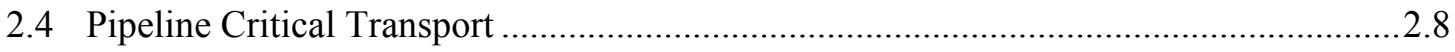

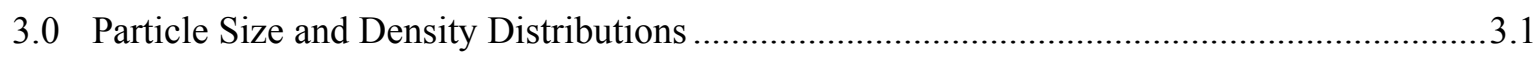

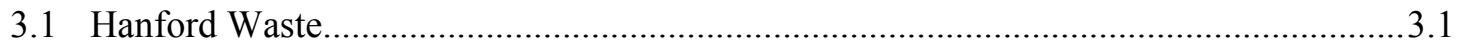

3.1.1 PSDDs: Particle Size and Density Considerations ............................................. 3.1

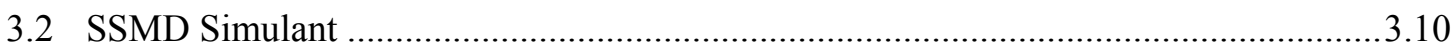

4.0 Comparison of Hanford Waste and SSMD Simulant PSDDs ...............................................

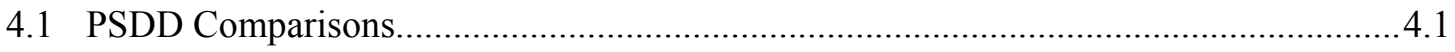

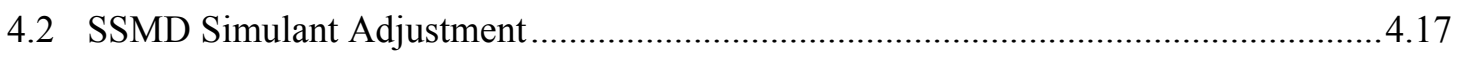

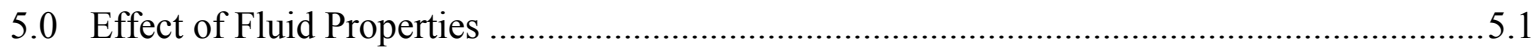

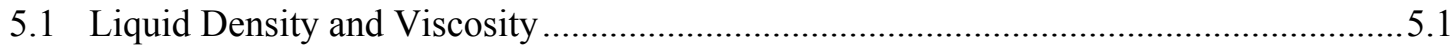

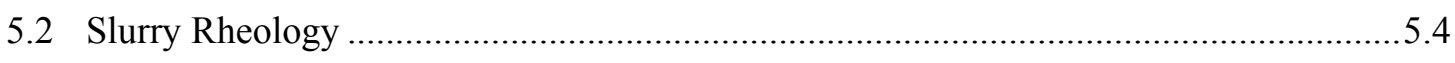

6.0 Computational Fluid Dynamics Tool to Quantify Uncertainty from Simulant Selections......6.1

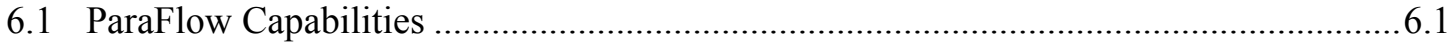

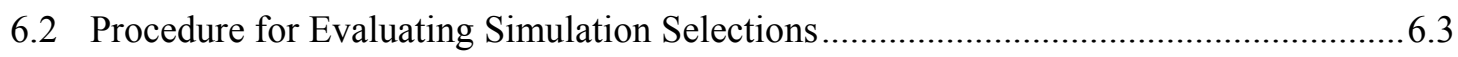

6.2.1 Comparisons of SSMD Simulant in Water and Alternate Liquid .........................6.5

6.2.2 Comparisons of SSMD Simulant and Adjusted Simulant in Water ......................6.5

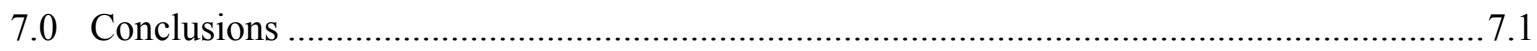

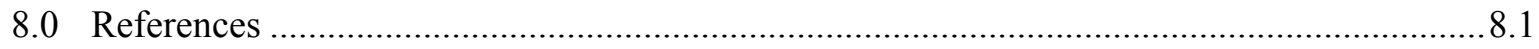

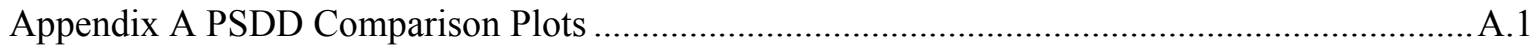




\section{Figures}

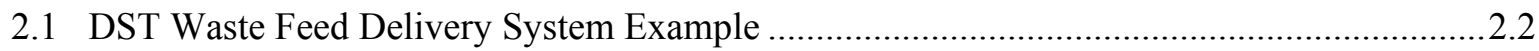

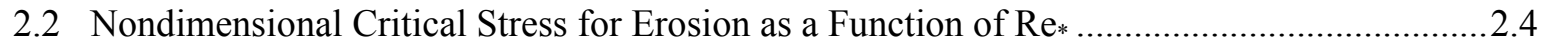

2.3 Nondimensional Critical Stress for Erosion as a Function of $\mathrm{Ar}^{1 / 3}$...................................... 2.6

3.1 Three-Component Simulant Settling Test .......................................................................... 3.3

3.2 Calculated and Measured Settling Velocity: Three-Component Simulant ..............................5

3.3 Interface Velocity for In-Tank Suspended AZ-101 Solids and Particle Velocity Distributions

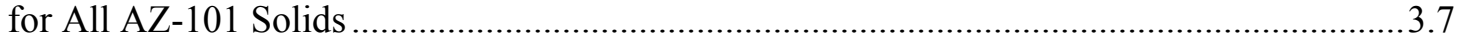

3.4 Interface Velocity for In-Tank Suspended AZ-101 Solids and Particle Velocity Distributions

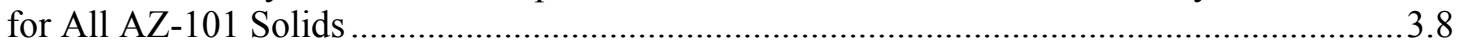

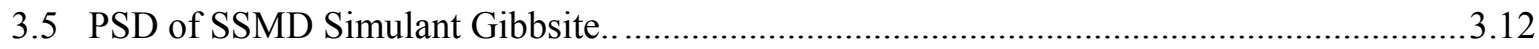

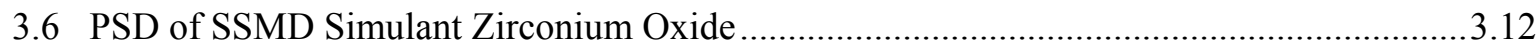

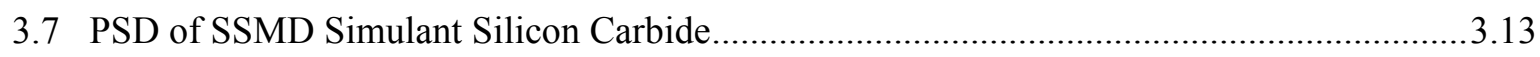

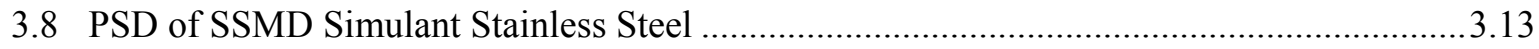

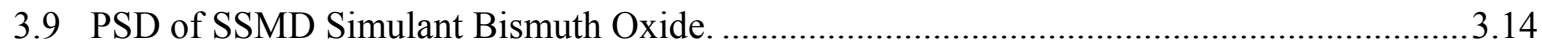

4.1 Settling Velocity Comparison …................................................................................. 4.3

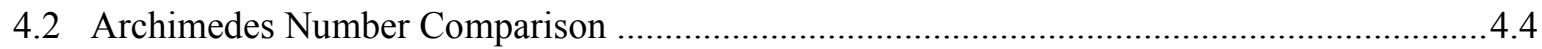

4.3 Critical Shear Stress for Erosion of Non-Cohesive Particles Comparison ............................. 4.5

4.4 Just-Suspended Impeller Speed Comparison .................................................................... 4.6

4.5 Jet Velocity Needed to Achieve a Certain Degree of Solid Suspension Comparison .............4.7

4.6 PJM Critical Suspension Velocity for Non-Cohesive Solids Comparison. .............................4.8

4.7 PJM Cloud Height for Non-Cohesive Solids Comparison .................................................4.9

4.8 Pipeline Critical Transport Velocity Comparison....................................................................10

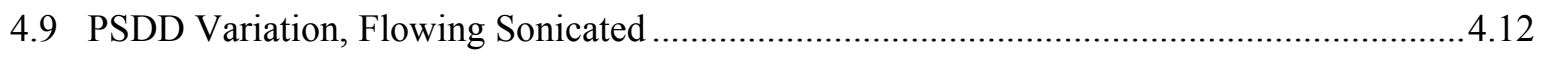

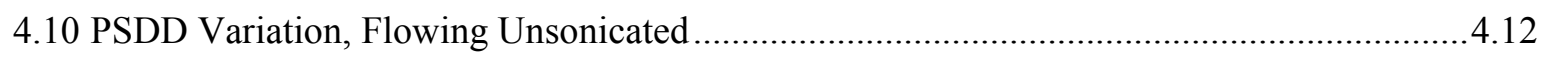

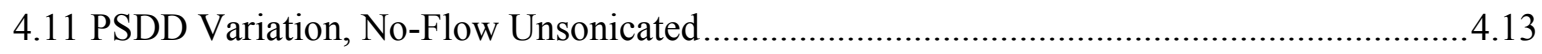

4.12 Summary Metric 1 Example, Archimedes number, Flowing Unsonicated ..........................4.14

4.13 Summary Metric 2 Example, Archimedes number, Flowing Unsonicated .........................4.15

4.14 Archimedes Numbers for SSMD Simulant Adjustment: Original Simulant, Hanford Waste Composite and "Target" Tanks (No-Flow Unsonicated), and Simulant Components...........4.18

4.15 Archimedes Numbers for Example Adjusted SSMD Simulant, No-Flow Unsonicated ........4.19

4.16 Just-Suspended Impeller Speed Comparison for Example Adjusted SSMD Simulant, No-

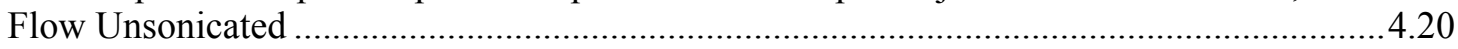

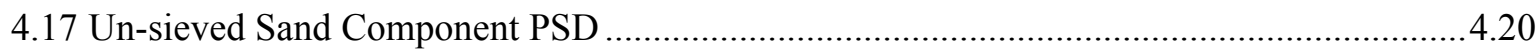

4.18 Archimedes Number for Alternate Example Adjusted SSMD Simulants, No-Flow Unsonicated

4.19 Just-Suspended Impeller Speed Comparison for Alternate Example Adjusted SSMD Simulants, No-Flow Unsonicated 
6.1 Concentration and Sediment Isosurfaces during Waste Feed Delivery Tank Sediment Re-

Suspension

6.2 Suspended Solids Concentration Profile in Terms of Bulk Density for 43.2" Tank at 7.5 GPM......

6.3 Suspended Solids Concentration Profile in Terms of Bulk Density for 120" Tank at 80 GPM6.3

6.4 Suspended Solids Concentration Profile in Terms of Bulk Density for 120" Tank at 80 GPM after First Pumpout

\section{Tables}

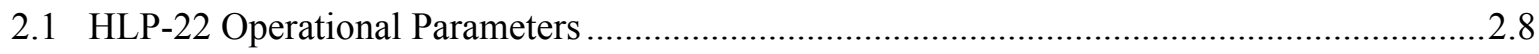

3.1 Hanford Sludge Waste PSDDs Used for Simulant Comparison.............................................11

3.2 5-Part SSMD Simulant Composition and Density ..............................................................

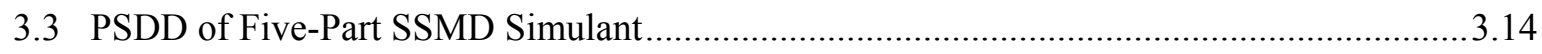

4.1 Hanford UDS Volume Characterized by PSDDs .......................................................... 4.11

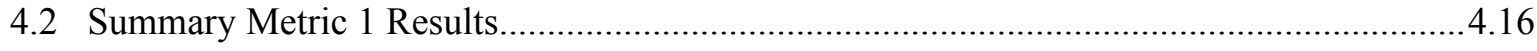

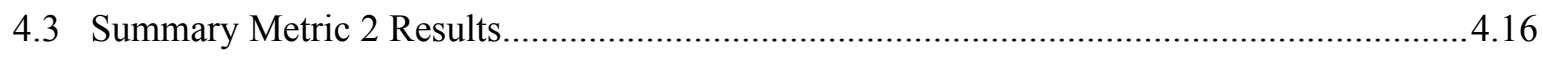

4.4 Example Adjusted SSMD Simulant Composition and Density .........................................4.19

4.5 Alternate Example Adjusted SSMD Simulant Composition and Density ...........................4.21

5.1 Effective Cleaning Radius with Different Suspending Fluids in Comparison to Water, and Experimental Observations of ECRs and the Related Metric of Batch Transfer Quantities ...5.5 



\subsection{Introduction}

The Hanford double-shell tank (DST) system provides the staging location for waste feed delivery to the Hanford Tank Waste Treatment and Immobilization Plant (WTP). Olson (2011) includes WTP acceptance criteria that describe physical and chemical characteristics of the waste that must be certified as acceptable before the waste is transferred from the DSTs to the WTP. Details of the activities associated with the initial development of data quality objective requirements to meet waste acceptance criteria for transfer of staged feed from tank farms to the WTP are provided in Arakali (2011). One of the more challenging requirements relates to the sampling and characterization of the undissolved solids (UDS) in a waste feed DST.

The objectives of Washington River Protection Solutions' Small Scale Mixing Demonstration (SSMD) project are to understand and demonstrate the DST sampling and batch transfer performance at multiple scales using slurry simulants comprising of UDS particles and liquid (Townson 2009). WTP feed delivery requires that the DST sampling and batch transfer systems are capable of adequately mixing the waste feed tank contents and retrieving a representative sample. Waste feed delivery from a DST to the WTP proceeds generally as follows:

1. Waste from a DST feed tank is sampled while the mixing system is operated.

2. Upon WTP waste acceptance, the mixing system in the DST is again operated and batch transfers of the slurry are provided to the WTP.

The SSMD project utilizes geometrically scaled DST feed tanks to generate mixing, sampling, and transfer test data. In Phase 2 of the testing (RPP-49740 Rev A.), the five-part simulant defined in (RPP48358) was used as the waste slurry simulant. The Phase 2 test data are being used to estimate the expected performance of the prototypic systems in the full-scale DSTs. As such, understanding of the how the small-scale systems as well as the simulant relate to the full-scale DSTs and actual waste is required.

The focus of this report is comparison of the size and density of the five-part SSMD simulant to that of the Hanford waste. This is accomplished by computing metrics for particle mobilization, suspension, settling, transfer line intake, and pipeline transfer from the characterization of the five-part SSMD simulant and characterizations of the Hanford waste. In addition, the effects of the characteristics of the suspending fluid on the test results are considered, and a computational fluid dynamics tool useful to quantify uncertainties from simulant selections is discussed.

\subsection{Quality Requirements}

Pacific Northwest National Laboratory's (PNNL's) Quality Assurance Program is based on requirements defined in U.S. Department of Energy (DOE) Order 414.1C, Quality Assurance, and U.S. Code of Federal Regulations Title 10, Part 830 (10 CFR 830), Energy/Nuclear Safety Management, Subpart A-Quality Assurance Requirements (a.k.a., the Quality Rule). PNNL has chosen to implement the requirements of DOE Order $414.1 \mathrm{C}$ and 10 CFR 830, Subpart A, by integrating them into the laboratory's management systems and daily operating processes. The procedures necessary to implement the requirements are documented through PNNL's How Do I? (HDI) standards-based management approach. 
The performed calculations as well as the documentation and reporting of results and conclusions were reviewed in accordance with HDI. Internal verification and validation activities were addressed by conducting an independent technical review of the final data report. This review verifies that the reported results are traceable and that inferences and conclusions are soundly based; review materials are documented in project records. 


\subsection{Metrics for Comparison}

Comparison of the particulate of the five-part SSMD simulant to that of Hanford waste is made by computing metrics for mobilization, suspension, settling, transfer-line intake, and pipeline transfer based on characterization of the particulate. The different waste operations are considered, as the dependence of these metrics on particle size and density may be different. Thus, it may be that a simulant that is representative or conservative for one aspect of the feed delivery system may not be so for some other aspect of that system.

The metrics, depicted in Figure 2.1, address various aspects of the feed delivery system. The majority of the Hanford-waste undissolved solid particles are more dense than waste liquids, and thus suspended UDS particles settle. ${ }^{1}$ Under quiescent conditions, therefore, the waste configuration in a DST is a sediment layer under supernatant liquid. The baseline configuration of the mixing and transfer systems in the DSTs consists of two rotating, opposed-nozzle, centrifugal mixer pumps (one nozzle of each pump has flow depicted in Figure 2.1) and an approximately centrally located transfer pump. The mixer pump jets are intended to mobilize the sediment particulate and suspend the particulate in the supernatant liquid. Particles entrained into the intake of the transfer pump are transferred out of the tank and transported via a pipeline to the WTP.

Metrics for the waste operations depicted in Figure 2.1 are defined in this section. The metrics include models for particle settling, mobilization, suspension, and pipeline transfer.

The models were selected as examples, and may not address certain aspects of the Hanford waste. For example, the pipeline transport model considered was not developed for fine cohesive solids, which comprise a fraction of the waste; this particulate may be more specifically addressed by the work of Poloski et al. (2010). Other listed models may not encompass the size and density ranges of the waste and simulant, or may not be directly applicable to the Hanford DST configurations. These model choices are necessitated by the lack of models specifically for Hanford waste and DST configurations. Additionally, as specified in Section 1.0, the objectives of the SSMD project are to understand and demonstrate the DST sampling and batch-transfer performance. The selected metrics may not be directly related to test parameters for sampling and batch-transfer performance, but are phenomena that occur in the waste feed system. Thus, it is the comparison of the metrics for the waste and simulant particulates that is of significance, not the specific results as related to actual sampling and batch transfer performance. To restate, the objective of this work is to determine whether the particulate of the SSMD simulant is challenging relative to Hanford waste with respect to mixing and transfer metrics, not to consider the specific results of a model, e.g. a specific pipeline transfer velocity.

${ }^{1}$ Some tanks have floating crust layers comprising solids, liquids, and gas. The buoyancy of these crusts is due to the retained gas. 


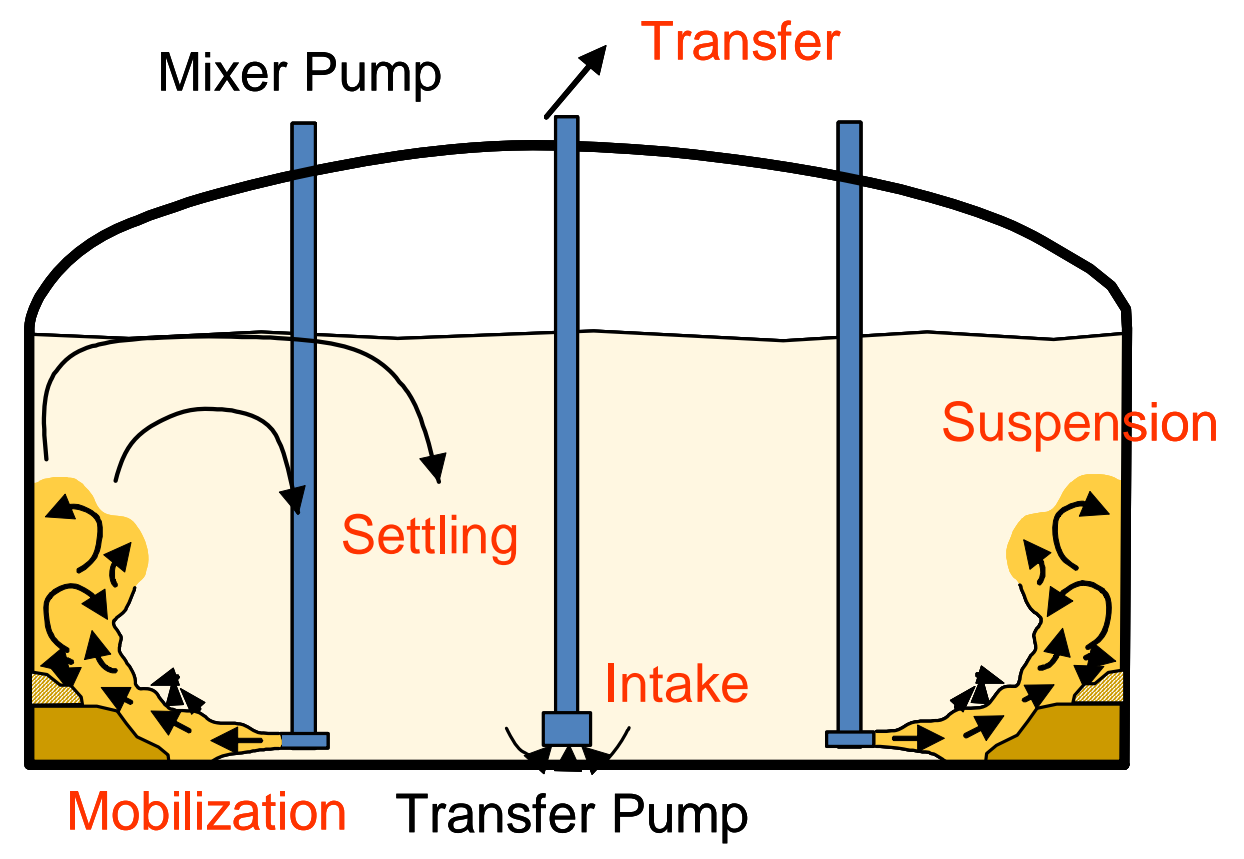

Figure 2.1. DST Waste Feed Delivery System Example

\subsection{Settling Velocity}

Hanford waste UDS particles are more dense than waste liquids and therefore will gravity-settle upon suspension in the liquid. At low solids concentrations, individual particles can settle without interacting with other particles (unhindered settling). At higher solids concentrations, interactions between particles can reduce settling rates (hindering settling). For individual particles in the unhindered settling regime, particle size and density can be used to compute the settling velocity $\left(\mathrm{U}_{\mathrm{T}}\right)$ via an equation such as that of Camenen (2007):

$$
\mathrm{U}_{\mathrm{T}}=\frac{\mu_{\mathrm{L}}}{\rho_{\mathrm{L}} \mathrm{d}}\left[\sqrt{\frac{1}{4}\left(\frac{\mathrm{A}}{\mathrm{B}}\right)^{\frac{2}{\mathrm{~m}}}+\left(\frac{4}{3} \frac{\mathrm{Ar}}{\mathrm{B}}\right)^{\frac{1}{\mathrm{~m}}}}-\frac{1}{2}\left(\frac{\mathrm{A}}{\mathrm{B}}\right)^{\frac{1}{\mathrm{~m}}}\right]^{\mathrm{m}}
$$

where $\mu_{\mathrm{L}}$ is the dynamic viscosity of the liquid, $\rho_{\mathrm{L}}$ is the liquid density, $\mathrm{d}$ is the particle diameter, Ar is the Archimedes number (defined below), and

$$
\begin{aligned}
& \mathrm{A}=\mathrm{a}_{1}+\mathrm{a}_{2}\left[1-\sin \left(\frac{\pi}{2} \mathrm{~S}_{\mathrm{F}}\right)\right]^{\mathrm{a}_{3}} \\
& \mathrm{~B}=\mathrm{b}_{1}+\mathrm{b}_{2}\left[1-\sin \left(\frac{\pi}{2} \mathrm{~S}_{\mathrm{F}}\right)\right]^{\mathrm{b}_{3}}
\end{aligned}
$$




$$
\mathrm{m}=\mathrm{m}_{1} \sin ^{\mathrm{m} 2}\left(\frac{\pi}{2} \mathrm{~S}_{\mathrm{F}}\right)
$$

$\mathrm{a}_{1}=24$

$\mathrm{a}_{2}=100$

$\mathrm{a}_{3}=2.1+0.06 P$

$\mathrm{S}_{\mathrm{F}}=$ Corey shape factor

$\mathrm{b}_{1}=0.39+0.22(6-P)$

$\mathrm{b}_{2}=20$

$\mathrm{b}_{3}=1.75+0.35 P$

$\mathrm{m}_{1}=1.2+0.12 P$

$\mathrm{m}_{2}=0.47$

$\mathrm{P}=$ particle roundness.

The particle roundness $\mathrm{P}$ is a measure of the curvature variations along the grain surface. Smaller distortions of the surface tend to increase the drag coefficient and thus to decrease the settling velocity. Camenen (2007) provides the A, B and $\mathrm{m}$ values for a sphere as 24, 0.4 and 2, respectively, so that Equation (2.1) for a spherical particle is

$$
\mathrm{U}_{\mathrm{T}}=\frac{v}{\mathrm{~d}}\left[\sqrt{15+\sqrt{\frac{\mathrm{Ar}}{0.3}}}-\sqrt{15}\right]^{2}
$$

where Ar is the Archimedes number defined by

$$
\operatorname{Ar}=\frac{\left(\frac{\rho_{\mathrm{S}}}{\rho_{\mathrm{L}}}-1\right) g \mathrm{gd}^{3}}{v^{2}}
$$

and $\rho_{\mathrm{S}}$ is the UDS density, $v$ is the kinematic viscosity of the liquid, and $g$ is the gravitational constant.

\subsection{Suspension Velocity}

The suspension velocity refers to the velocity required to mobilize particles from the surface of a sediment bed. The stress of the induced flow at any given location must overcome the critical shear stress for erosion to mobilize the sediment at that location (Wells et al. 2009). The critical shear stress can be expressed as a relationship between two nondimensional parameters:

$$
\tau_{*}=\frac{\tau_{\mathrm{C}}}{\left(\rho_{\mathrm{S}}-\rho_{\mathrm{L}}\right) \mathrm{gd}} \equiv \text { Nondimensional Critical Shear Stress for Erosion }
$$

and 


$$
\operatorname{Re}_{*}=\frac{u_{*} d}{v}=\frac{\sqrt{\frac{\tau_{B}}{\rho_{L}}} d}{v} \equiv \text { Shear Reynolds Number }
$$

where $\mathrm{u} *$ is the shear velocity, $\tau_{\mathrm{B}}$ is the shear stress acting on the solids surface layer, and $\tau_{\mathrm{C}}$ is the critical shear stress for erosion.

The Shields diagram (e.g. Vanoni 1975, Julien 1998) provides a relationship between Equations (2.4) and (2.5). For non-cohesive solids (particles with negligible surface attractive forces, (Parker 1984)), the Shields diagram uniquely determines the critical shear stress. An expression for the Shields relation provided by Brownlie (1981) is shown Figure 2.2 to represent the data taken from the Shields relation in Vanoni (1975).

For fine cohesive solids, approximately $\mathrm{Re}_{*}<2$ in Figure 2.2, the Shields Diagram provides a qualitative trend of the critical shear stress, but does not provide specific critical shear stress values. The relation of Brownlie (1981) for $\mathrm{Re}_{*}<2$ follows Shields' suggested curve. Mantz (1977) extends the Shields diagram for fine noncohesive particles, as also shown in Figure 2.2. ${ }^{2}$ The difference between the Brownlie (1981) curve and Mantz (1977) is attributed to cohesive effects.

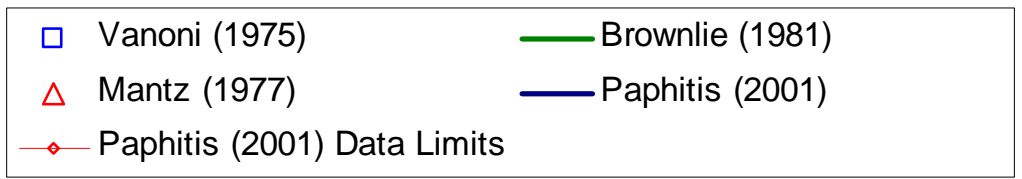

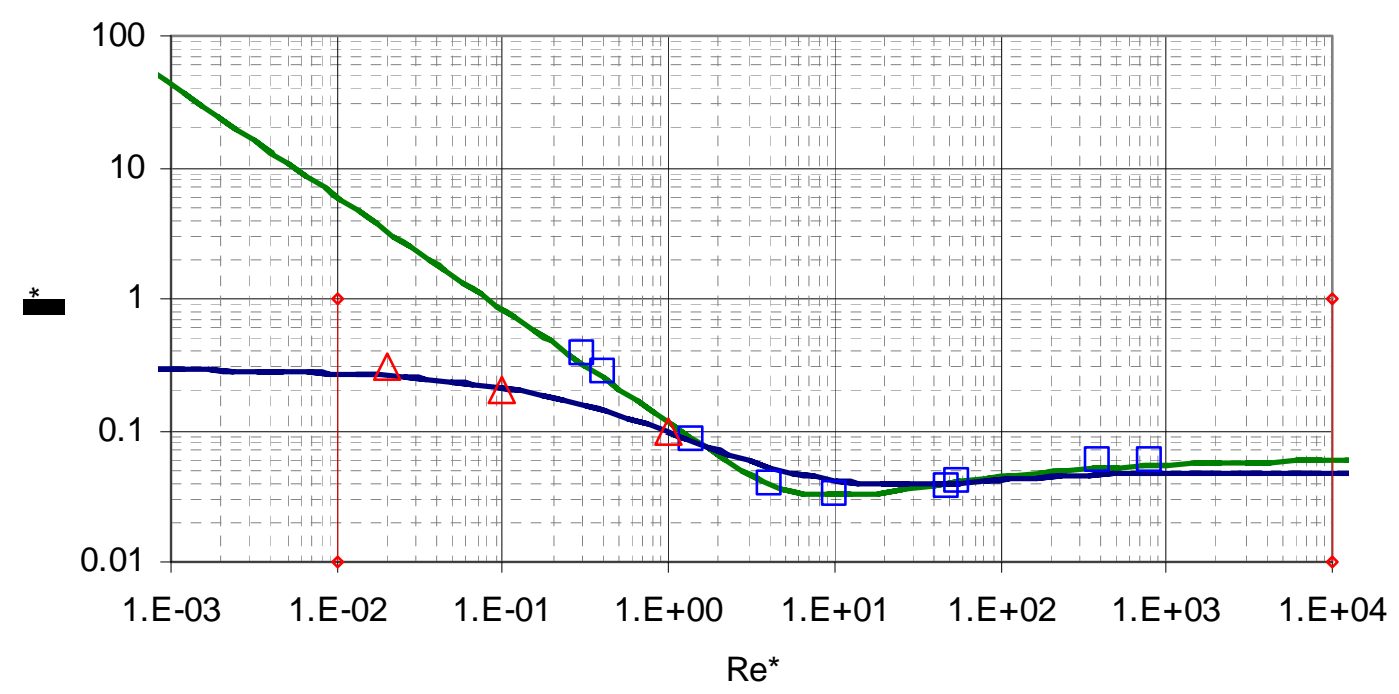

Figure 2.2. Nondimensional Critical Stress for Erosion as a Function of $\mathrm{Re}_{*}$

2 Mantz (1977) achieved different results for non-cohesive flakes, so particle shape is of significance. The data shown in Figure 2.2 are for grains. 
Beheshti and Ataie-Ashatiani (2008) compared proposed empirical curves of the Shields diagram for the threshold conditions and incipient sediment motion. One model comprised of a single relation over a broad range of $\mathrm{Re}_{*}$ that performed well in parity-plot comparisons to observed shear velocity was the mean curve of Paphitis (2001):

$$
\tau_{*}=\frac{0.273}{1+1.2 \mathrm{D}_{*}}+0.046\left(1-0.576 \mathrm{e}^{-0.02 \mathrm{D}_{*}}\right)
$$

where $\mathrm{D}_{*}=\mathrm{Ar}^{1 / 3}$. As shown in Figure 2.2 with $\mathrm{Re}_{*}$ computed from $\mathrm{D} *$ via Equations (2.5) and (2.6) with $\tau_{\mathrm{B}}$ in Equation (2.5) set to $\tau_{\mathrm{C}}$ from Equation (2.4), Paphitis' model reasonably reproduces both Vanoni (1975) and Mantz (1977). The $\mathrm{Re}_{*}$ limits of the data for the Paphitis model are also shown as the vertical red lines at $\mathrm{Re}_{*}=1 \mathrm{E}-2$ and $\mathrm{Re}_{*}=1 \mathrm{E} 4$. The Paphitis (2001) model is used in the current work to represent the critical stress for erosion of non-cohesive particles defined by size and density.

As may readily be observed from Equation (2.6), the critical stress for erosion from Paphitis (2001) shown in Figure 2.2 can be shown as a direct function of size and density via $\mathrm{Ar}^{1 / 3}$. This is illustrated in Figure 2.3. With the direct functionality of the particle size and density as well as the fluid density and viscosity (Equation 2.3), the range of particles and fluids of interest can be compared. From the Hanford sludge waste and SSMD simulant characterizations provided in Section 3 in water, the Ar number for Hanford sludge ranges from approximately 2.8 E5 to 7.4 E-8, and 4.8 E4 to 1.1 E-7 for the SSMD simulant (see Section 4, all particle-size distribution (PSD) types considered for Hanford sludge waste). These ranges are shown on Figure 2.3 as vertical lines, and exceed the lower Paphitis (2001) data limit also shown in Figure 2.3 as a vertical line.

An additional comparison is made for the stainless steel particulate used in the cohesive slurry testing for the SSMD project (Adamson and Gauglitz 2011). The Ar of nominally $100 \mu \mathrm{m}$ stainless steel (8 $\mathrm{g} / \mathrm{mL}$ ) in water is approximately $6.9 \mathrm{E} 1$. As shown by the vertical blue line in Figure 2.3, this corresponds to $\mathrm{D}_{*}=\mathrm{Ar}^{1 / 3} \sim 4$.1. A power-law model for the critical shear stress for $1.5 \leq \mathrm{D}_{*}<10$ provided in Beheshti and Ataie-Ashatiani (2008) is from Chien and Wan (1983). This model approximates that of Paphitis (2001) for the specified $\mathrm{D} *$ range as shown in Figure 2.3. Further discussion of the erosion of the nominally $100 \mu \mathrm{m}$ stainless steel of (Adamson and Gauglitz 2011) is made in Section 5.

$$
\tau_{*}=0.131 \mathrm{D}_{*}^{-0.55}
$$




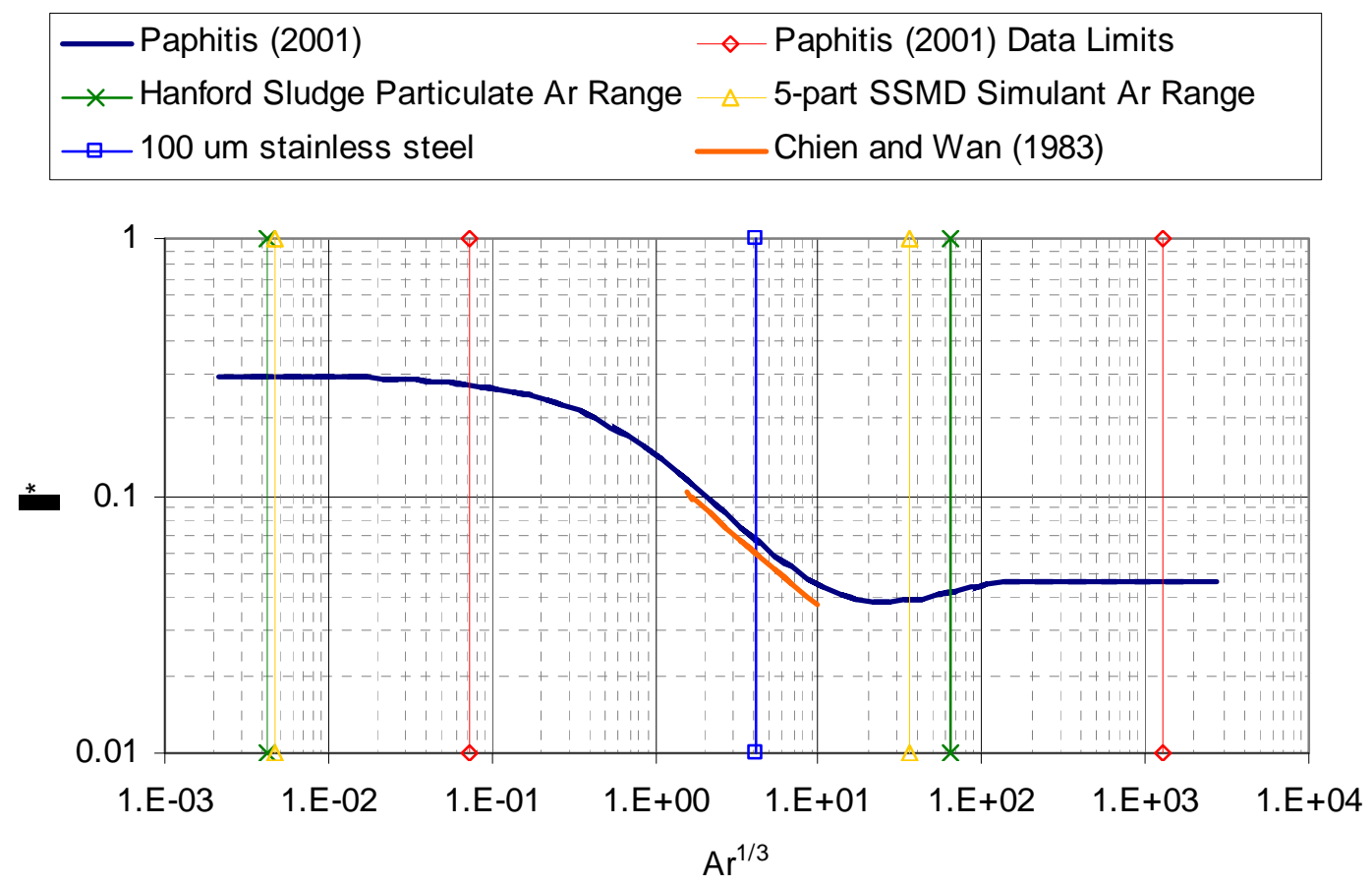

Figure 2.3. Nondimensional Critical Stress for Erosion as a Function of $\mathrm{Ar}^{1 / 3}$

There have been numerous studies that have considered the mobilization of non-cohesive particles under various flow conditions. A common metric is the minimum jet velocity required to suspend all of the particulate in a vessel. A well-known correlation for the just-suspended impeller speed $\mathrm{N}_{\mathrm{js}}$ is that of Zweitering, given in Paul et al. (2004) as

$$
\mathrm{N}_{\mathrm{js}}=\mathrm{S}_{\mathrm{Z}} v^{0.1}\left[\frac{\mathrm{g}\left(\rho_{\mathrm{S}}-\rho_{\mathrm{L}}\right)}{\rho_{\mathrm{L}}}\right]^{0.45} \mathrm{X}^{0.13} \mathrm{~d}^{0.2} \mathrm{D}^{-0.85}
$$

where $S_{Z}$ is a dimensionless number that is a function of impeller type, $\mathrm{X}$ is the mass ratio of solids to liquid, and D is the impeller diameter. To be clear, as stated in Section 2.0, evaluation of Hanford waste and the five-part SSMD simulant via Equation (2.8) is not applicable to DST configurations and the evaluation is conducted solely for particulate comparison purposes. For the comparison, $\mathrm{S}_{Z}$ is set to a nominally typical value of 5 (Paul et al. 2004), $X$ to 10 (nominal solid-to-liquid mass ratio times 100 in AY-102, (Wells and Ressler 2009), and a $1 \mathrm{~m}$ impeller diameter. Equation 2.8 has been shown to reliably fit experimental data between solids loadings of 5 to 170, Paul et al. (2004).

Kale and Patwardhan (2005) provide a correlation for the suspension of solids in 0.5 to $1 \mathrm{~m}$ diameter tanks with radial wall jets. A semi-empirical model to predict the jet velocity needed to achieve a certain degree of solids suspension (e.g., $100 \%$ of the solids suspended, $75 \%$ of the solids suspended) is expressed as a function of the Ar number by 


$$
U_{n}=\frac{v}{d}\left[0.13 X^{0.22} \operatorname{Ar}^{0.38}\left(\frac{D}{d_{j}}\right)^{2}\left(1+0.25\left(\frac{\mathrm{z}}{d_{j}}\right)\right)^{-0.25}\left(1+0.75\left(\frac{\mathrm{z}}{\mathrm{D}}\right)\right)\right]
$$

where $d_{j}$ is the jet nozzle diameter and $\mathrm{z}$ is the nozzle clearance above the tank bottom. As with the Zweitering correlation, Equation (2.8), evaluation of Equation (2.9) for the Hanford waste and the fivepart SSMD simulant is made for comparison, not for specific nozzle velocity in a DST. The solids loading ratio $X$ and tank diameter $D$ are set to the maximum tested by Kale and Patwardhan (2005), 5 and $1 \mathrm{~m}$ respectively, and the nozzle diameter and clearance set to nominal testing values of $0.04 \mathrm{~m}$ and $0.5 \mathrm{~m}$ respectively.

The WTP project is applying pulse jet mixer (PJM) technology for tank mixing applications requiring solids mixing, solids suspension, fluid blending, and release of gases generated by radiolysis and thermal processes. PJMs are non-steady jet mixing devices that use compressed air as the motive force. The WTP defines critical suspension velocity as the lowest jet nozzle velocity that can suspend all solids in a process vessel. The critical suspension velocity model of Fort et al. (2010) depends on waste and jet properties as well as vessel and mixing equipment configuration, i.e., vessel dimensions and the positions, orientations, and number of jets. The hindered settling velocity is represented by

$$
\begin{gathered}
\mathrm{U}_{\mathrm{CS}}=\mathrm{U}_{\mathrm{TH}} 2.302\left(\frac{\mathrm{D}^{*}}{\mathrm{Ar}^{0.673}}\right)^{0.261} \\
\mathrm{U}_{\mathrm{TH}}=\mathrm{U}_{\mathrm{T}}\left(1-\frac{\phi_{\mathrm{S}}}{0.6}\right)^{6}
\end{gathered}
$$

For Equation (2.10), D* is defined by

$$
\mathrm{D}^{*}=\frac{\mathrm{D}(\mathrm{S}-1) \mathrm{g} \phi_{\mathrm{S}}}{\mathrm{DC} \mathrm{U}_{\mathrm{TH}}{ }^{2} \phi_{\mathrm{P}}{ }^{0.898} \phi_{\mathrm{J}}{ }^{1.958}}
$$

where

$$
\begin{aligned}
\mathrm{DC}= & \text { PJM duty cycle } \\
\mathrm{S}= & \rho_{\mathrm{S}} / \rho_{\mathrm{L}} \\
\phi_{\mathrm{J}}= & \text { jet density }\left(=\mathrm{nd}_{\mathrm{j}}^{2} / \mathrm{D}^{2}\right) \\
\mathrm{d}_{\mathrm{j}}= & \text { PJM nozzle diameter } \\
\mathrm{n}= & \text { number of operating jets/pulse tubes } \\
\phi_{\mathrm{P}}= & \text { pulse volume fraction } \\
\phi_{\mathrm{S}}= & \text { Solids volume fraction (volume of UDS per a reference tank } \\
& \text { volume defined as } \left.\frac{\pi}{4} \mathrm{D}^{3}\right) .
\end{aligned}
$$

Calculations for the Hanford waste and the five-part SSMD simulant via Equation (2.10) are conducted using configuration and operational parameters for WTP vessel HLP-22 as specified in Meyer et al. (2009), which are provided in Table 2.1, and $\phi_{\mathrm{S}}=0.1$. 
Table 2.1. HLP-22 Operational Parameters, Meyer et al. (2009)

\begin{tabular}{cc}
\hline Parameter & Value (units) \\
\hline $\mathrm{D}$ & $38(\mathrm{ft})$ \\
$\mathrm{DC}$ & 0.22 \\
$\phi_{\mathrm{P}}$ & 0.05 \\
$\phi_{\mathrm{J}}$ & 0.00208 \\
\hline
\end{tabular}

\subsection{Cloud Height}

During PJM operation in a WTP waste process vessel, some eroded solids are lifted upward, often forming a distinct slurry layer above which a clear liquid exists. The cloud height, $\mathrm{H}_{\mathrm{C}}$, expresses the height of this slurry layer above the vessel bottom, and thus provides the maximum of the vertical distribution of the suspended solids. Fort et al. (2010) provide a model for cloud height as

$$
\ln \left[\mathrm{H}_{\mathrm{C}}^{*} \mathrm{Re}^{-0.143}\right]=8.223\left(\frac{\mathrm{U}}{\mathrm{U}_{\mathrm{TH}}}\right)^{0.1364}
$$

where

$$
\mathrm{H}_{\mathrm{C}}^{*}=\frac{\mathrm{H}_{\mathrm{C}}(\mathrm{S}-1) \mathrm{g} \phi_{\mathrm{S}} \mathrm{N}^{0.658}}{\mathrm{DC} \mathrm{U}_{\mathrm{TH}}{ }^{2} \phi_{\mathrm{P}}{ }^{0.898} \phi_{\mathrm{J}}^{1.662}}
$$

where the Reynolds number $\mathrm{Re}=\mathrm{Ud}_{\mathrm{j}} / v, \mathrm{U}$ is the jet nozzle velocity, and $\mathrm{N}$ is the number of PJMs. For HLP-22, $\mathrm{U}$ is set to $12 \mathrm{~m} / \mathrm{s}$, and $\mathrm{N}=12$ (Meyer et al. 2009). All other parameters are as listed in Section 2.2 for the PJM critical suspension velocity.

\subsection{Pipeline Critical Transport}

Hanford waste slurry will be transferred though pipelines within tank farms, between tank farms, from tank farms to the WTP, and between process vessels within the WTP. It is important that solids do not deposit in pipelines during transfer to avoid plugging. Deposition is prevented by making certain that the pipeline velocity exceeds the deposition or critical transport velocity.

The Oroskar and Turian (1980) model to estimate the critical velocity for coarse, non-cohesive solids is specified by Hall (2006) for use in WTP process piping. The critical velocity is determined via

$$
\mathrm{U}_{\mathrm{C}}=1.85 \sqrt{\mathrm{gd}(\mathrm{S}-1)} \mathrm{C}_{\mathrm{V}}^{0.1536}\left(1-\mathrm{C}_{\mathrm{V}}\right)^{0.3564}\left(\frac{\mathrm{d}}{\mathrm{D}_{\mathrm{P}}}\right)^{-0.378}\left[\frac{\mathrm{D}_{\mathrm{P}} \rho_{\mathrm{L}} \sqrt{\mathrm{gd}(\mathrm{S}-1)}}{\mu_{\mathrm{C}}}\right]^{0.09} \chi^{0.30}
$$

where $\mathrm{C}_{\mathrm{V}}=$ solid volume fraction

$\mathrm{D}_{\mathrm{P}}=$ pipe diameter

$\chi=$ fraction of eddies having velocities equal to or greater than the settling velocity. $\chi$ is set to 0.96 (Wells et al. 2007).

$\mu_{\mathrm{C}}=$ carrier fluid viscosity. 
For the comparison evaluation, $\mathrm{C}_{\mathrm{V}}=0.1, \mathrm{D}_{\mathrm{P}}=3$ inches, and $\mu_{\mathrm{C}}=1 \mathrm{cP}$. 



\subsection{Particle Size and Density Distributions}

The Hanford waste and five-part SSMD simulant particulate can be characterized with respect to size and density by a particle size and density distribution (PSDD) as developed in Wells et al. (2007). The PSDDs provide a volume-based probability for the solid particles in terms of particle size and density.

More specifically, the PSDDs are three-dimensional matrices of the volume probability for each particle size and density pair. PSDDs for Hanford waste are constructed as described in Wells et al. (2007 and 2011) from measured particle size distributions (PSDs) and UDS composition and density determined from the measured waste chemistry and a combination of modeling and analysis.

\subsection{Hanford Waste}

Wells et al. (2011) provides PSDDs for individual Hanford tanks that have PSD data available, for the primary waste types represented by that PSD data, and for sludge and saltcake waste type composites created from the available data. The general waste types, sludge and saltcake, are classified as such based on the relative concentrations of soluble and insoluble UDS. As specified in Weber (2009), a tank's content is classified as sludge if at least $75 \mathrm{vol} \%$ is sludge solids (insoluble UDS), and classified as saltcake if it is at least $75 \mathrm{vol} \%$ saltcake/salt slurry solids (soluble UDS).

For the current work, those tanks and waste types that are primarily sludge are considered because retrieval activities can dissolve the soluble waste. There are up to 15 individual sludge tanks with PSDs available, and up to 3 sludge waste groups from the M12 project that was performed in response to issue M12 (Undemonstrated Leaching Processes) as identified by the External Flowsheet Review Team (CCN 2006) that can be represented by PSDDs in their as-received condition.

Uncertainties in the particulate characterization of the PSDDs include:

1. Particle density. The particle density of the PSDDs is determined by the UDS composition and assumptions about that composition and the density of the particulate as it exists as primary particles, hard agglomerates, and soft agglomerates or flocs.

2. Particle size. In addition to the uncertainty of the PSD measurement techniques themselves, applying a measurement technique under different instrumentation configurations can yield different results.

The effects of assumptions related to particle density and PSD instrument configuration are discussed in Section 3.1.1. Assumptions for the UDS composition and the uncertainty of PSD measurement techniques are discussed in detail in Wells et al. (2011).

\subsubsection{PSDDs: Particle Size and Density Considerations}

As described, PSDDs are three-dimensional matrices of the volume probability for each particle size and density pair, and are constructed from PSD and UDS composition information. A waste operation model such as those presented in Section 2 may be applied to produce a cumulative volume-based probability of a selected model for the particulate comprising the PSDD. This provides a twodimensional means of volume-based probabilistic evaluation and comparison of the PSDDs (as opposed to a size-, density-, and volume fraction-tabulated form of the three-dimensional PSDD). 
The settling velocity of Equation (2.2) can be computed for the PSDD particulate in water $(1 \mathrm{~g} / \mathrm{mL}$, $1 \mathrm{cP})$. The particulate characterization can then be compared to a directly measurable parameter, i.e., settling velocity. In this way, the effects of assumptions related to the density of the particle and the effect of PSD instrument configuration on the measured particle size can be considered.

As an example, the comparison of a PSDD-based calculated particle settling velocity with measured settling rates for a three-component simulant discussed in Wells et al. (2011) is summarized. In support of the M3 PJM testing program, settling tests of three-component simulants were conducted in a column 4' tall with a 3" inner diameter (Beeman 2010). Settling data (interface heights of settled solids and clear liquid) were measured over a period of about $24 \mathrm{hr}$ as depicted in Figure 3.1. Three of the tests used the same simulant at three different concentrations of total solids, $5 \mathrm{wt} \%, 10 \mathrm{wt} \%$, and $15 \mathrm{wt} \%$. The solids in the simulant were $90 \mathrm{wt} \%$ boehmite (median particle size by volume of $8.9 \mu \mathrm{m}$ ), $5 \mathrm{wt} \%$ stainless steel (volume $\mathrm{d}_{50}=140 \mu \mathrm{m}$ ), and $5 \mathrm{wt} \%$ sand (volume $\mathrm{d}_{50}=262 \mu \mathrm{m}$ ), and the liquid was $0.25 \mathrm{M} \mathrm{NaCl}$. 


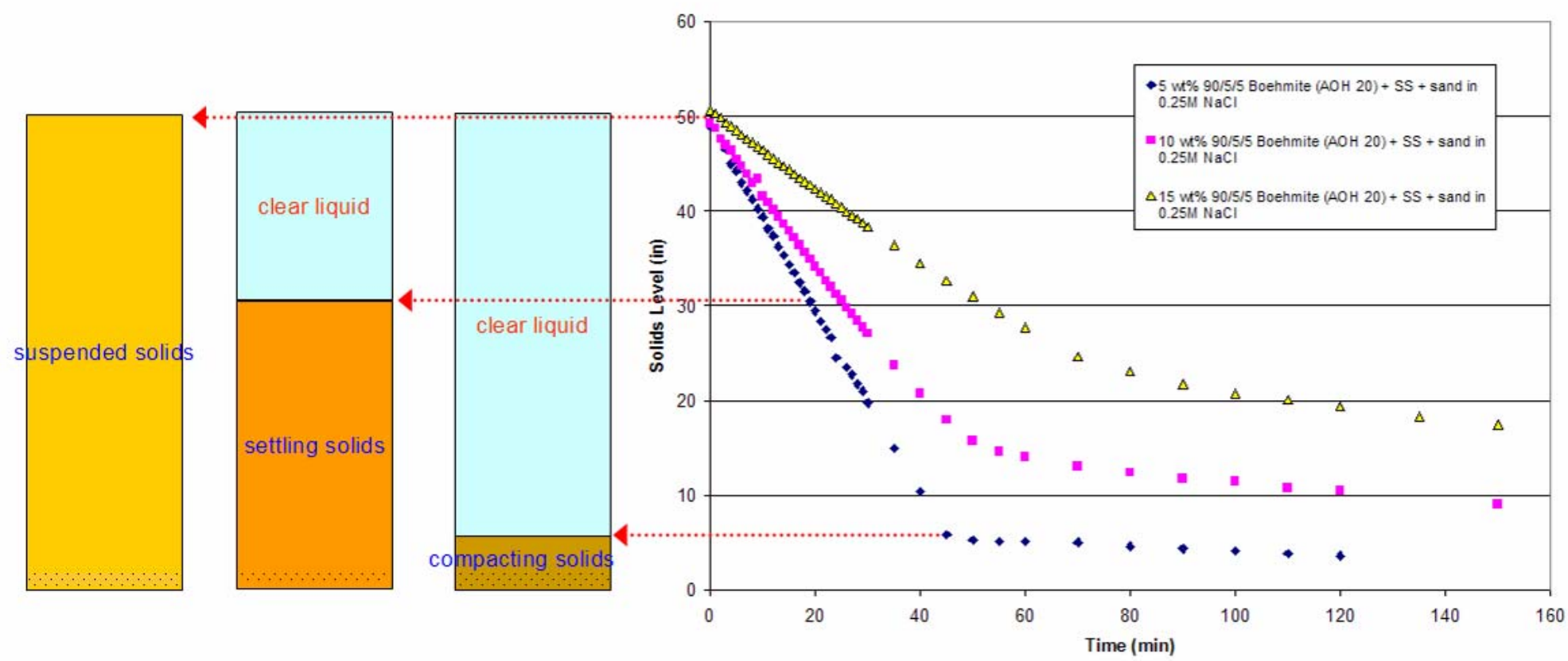

Figure 3.1. Three-Component Simulant Settling Test 
All three of the level-versus-time profiles exhibited a long linear decrease in level (constant interface velocity during settling), followed by a period of smaller change in level as compaction proceeded, Figure 3.1. The "fast" interface velocities of the initial settling periods of the tests were calculated as $5.0 \mathrm{E}-4 \mathrm{~m} / \mathrm{s}$ for the $5-\mathrm{wt} \%$ simulant, $3.6 \mathrm{E}-4 \mathrm{~m} / \mathrm{s}$ for the $10-\mathrm{wt} \%$ simulant, and $1.8 \mathrm{E}-4 \mathrm{~m} / \mathrm{s}$ for the $15-\mathrm{wt} \%$ simulant. The fact that the interface velocities in the three tests with equivalent particulate had three distinct values is assumed to be due solely to the different solids concentrations (i.e., hindered settling effects only, as opposed to unintended differences between tests). The three interface velocities were used to estimate the unhindered velocities of between $8.2 \mathrm{E}-4 \mathrm{~m} / \mathrm{s}$ and $1.1 \mathrm{E}-3 \mathrm{~m} / \mathrm{s}$. The reasonably close match between the three tests' estimates of unhindered velocity suggests that hindrance was the main effect leading to differences in interface velocities.

The estimates of unhindered interface velocity and the distribution of unhindered particle terminal velocities calculated via Equation (2.2) from the simulant PSDD are shown in Figure 3.2. The estimates of unhindered interface velocity are shown as red lines in the figure. The estimated unhindered interface velocity lies at about the $92^{\text {nd }}$ percentile of the particle velocity distribution, which is nearly equal to the velocity of the largest boehmite particles but well below the lowest velocity of the steel and sand particles. Therefore, the lowest velocities calculated from particle properties do not appear to determine the interface velocity. By definition, the observed top interface travels at the settling velocity of the slowest visible particles, but the slowest particles were not settling as slowly as the sizes and densities in the PSDD dictate. This suggests either the presence of one or more phenomena that accelerate the settling rate, such as wake capture of smaller particles by larger ones or agglomeration followed by the formation of convective structures, or that the particulate of the measured settling rate is not accurately characterized the PSDD. 


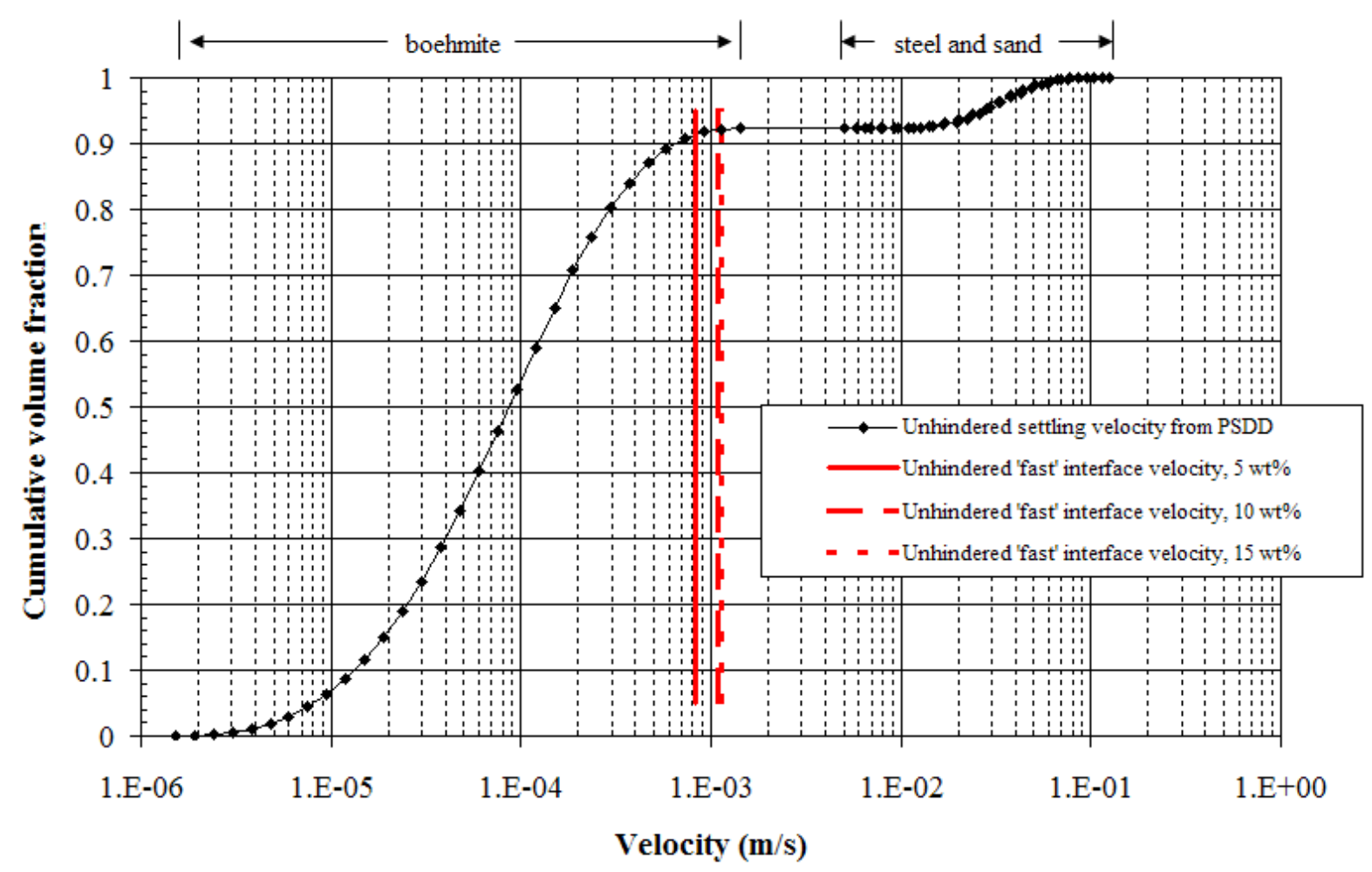

Figure 3.2. Calculated and Measured Settling Velocity: Three-Component Simulant

As discussed in Wells et al. (2011), certain particle-size analyzers suspend and circulate solid samples with adjustable suspension and circulation rates within the instrument during PSD measurements. This configuration is termed a "Flowing" condition. Certain particle-size analyzers can also be operated with the sample contained in a "fraction cell" with minimal agitation and these PSD measurements are designated as "No-Flow."

Sonication may also be employed. Sonication for the Flow condition is accomplished via an ultrasonic generator in the sample tank, which may be operated during the PSD measurement. It is stated in WTP Project Memorandum CCN 186332, “...sonication is a very high energy and irreproducible process...sonication is much more energy intensive than pumping or mixing for many hours and similar to grinding or milling. Its purpose is to reduce the particles to a primary particle size." (Etchells 2007). The solid suspension and circulation of the flowing condition also exert shear forces on the solid particulate. Thus it is assumed that the most energetic PSD measurements with respect to the potential break-up of agglomerates are Flowing Sonicated, followed by Flowing Unsonicated, and the least disturbance is provided by No-Flow Unsonicated.

PSD type, and therefore PSDD type, classifications in Wells et al. (2011) are therefore:

- Sludge, Flowing Sonicated: The data would be expected to include individual primary particles and hard agglomerates but not flocs or soft agglomerates.

- Sludge, Flowing Unsonicated: These data would be expected to include individual primary particles and both soft and hard agglomerates. 
- Sludge, No-flow Unsonicated: The PSD measurement may bias lighter/smaller particles because heavy/large particles may settle to the bottom of the cell and not be measured. The data would be expected to include flocs and soft agglomerates present in the samples.

More detailed descriptions of the PSD measurement types as well as an extensive discussion of PSD uncertainty are provided in Wells et al. (2011). Wells et al. (2011) also compared the PSDD-based calculated particle settling velocity with in situ measured settling rates for mixer pump-suspended sediment AZ-101 (see Carlson et al. (2001) regarding the AZ-101 jet mixer pump test). The "fast" initial interface velocity in AZ-101 was calculated by Wells et al. (2011) from interface measurements as 7.4 E$4 \mathrm{~m} / \mathrm{s}^{(3)}$, and the corresponding unhindered interface velocity was calculated to be $9.6 \mathrm{E}-4 \mathrm{~m} / \mathrm{s}$.

Figure 3.3 and Figure 3.4 plot the "fast" interface velocity calculated from interface measurements and the estimated unhindered velocity in AZ-101 (red lines) together with the distribution of unhindered particle terminal velocities calculated from different types of PSDDs (from the different PSD types) for the waste. The PSDDs used to create Figure 3.3 assume that all particles have a density equal to the UDS compound crystal density regardless of particle size (fractal dimension $\mathrm{D}=3$ designation in the legend). The three PSDD velocity distributions that are shown represent different degrees of energy applied during PSD measurement as previously described.

(3) Because the averaging time was shorter, the "fast" velocity was greater than the 1.5 -hr average of $\sim 6 \mathrm{E}-4 \mathrm{~m} / \mathrm{s}$ of Carlson et al. (2001) 


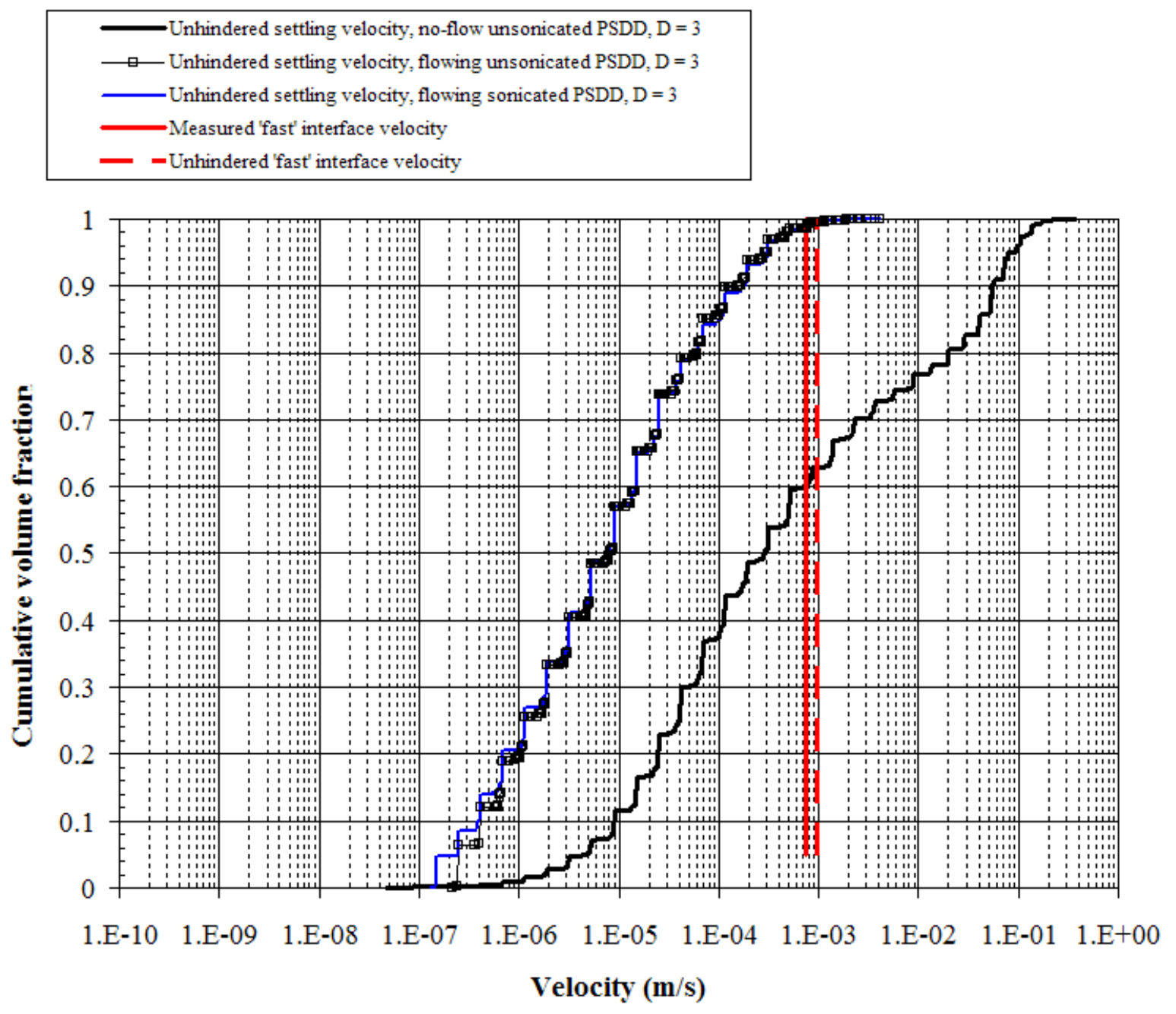

Figure 3.3. Interface Velocity for In-Tank Suspended AZ-101 Solids and Particle Velocity Distributions for All AZ-101 Solids (With All Particles Treated as Primary Particles)

There is essentially no difference in the Flowing Sonicated and Flowing Unsonicated particle velocity distributions in Figure 3.3, which results from the similarity in the PSDs. This similarity suggests that either the particulate exists as primary particles, or the upper range stir and pump settings for the Flowing configuration break up agglomerates as completely as does sonication. The No-flow Unsonicated velocity distribution includes higher velocities because of the substantial fraction of larger particulate, suggesting that agglomerates are present in the solids and that flow breaks up those agglomerates. 

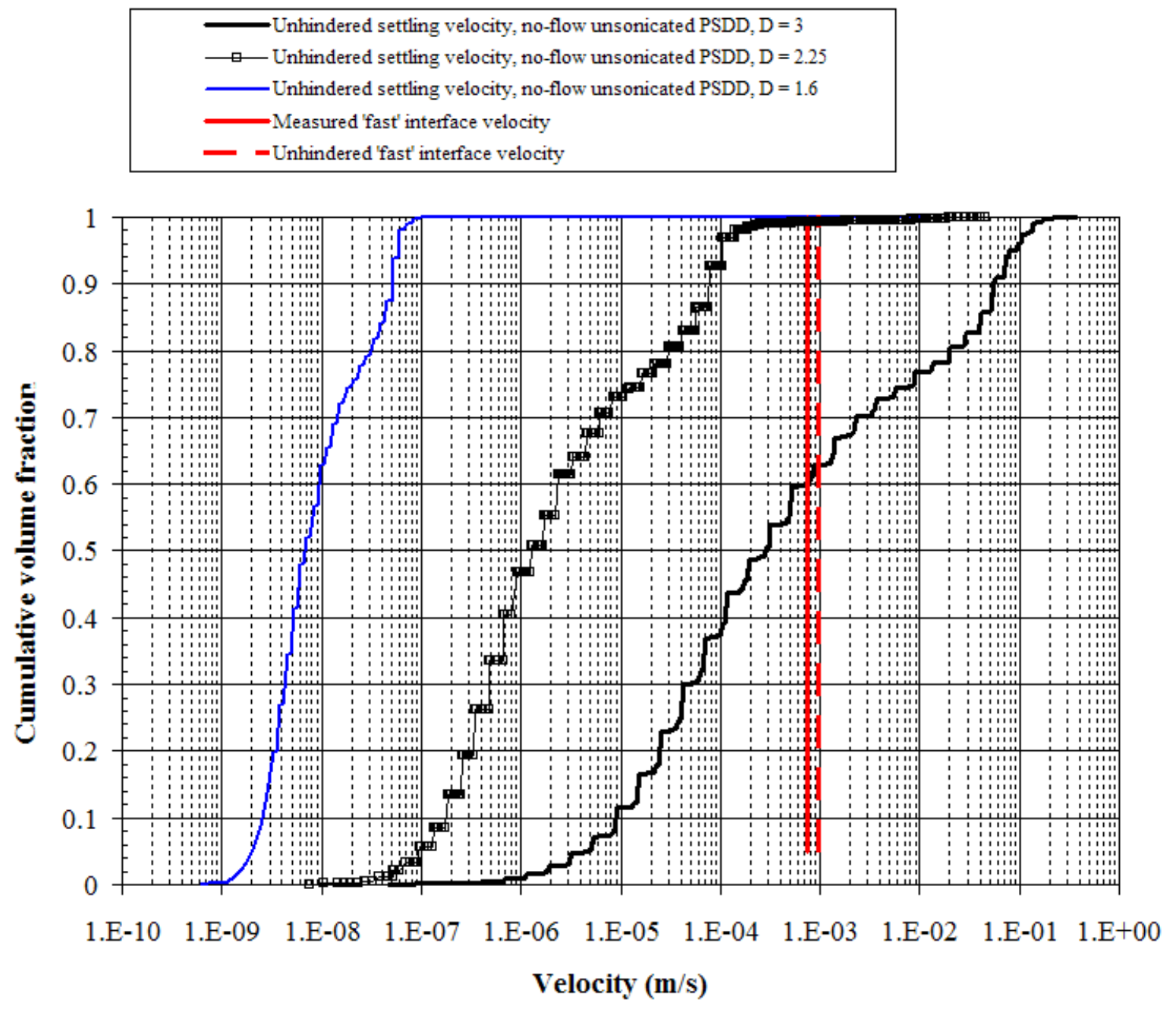

Figure 3.4. Interface Velocity for In-Tank Suspended AZ-101 Solids and Particle Velocity Distributions for All AZ-101 Solids (At No-Flow Condition, Varied Fractal Dimension)

The PSDDs used to create Figure 3.4 use the No-flow Unsonicated PSD and a range of different fractal dimensions as described in Wells et al. (2011). Whereas in Figure 3.3 at fractal dimension D $=3$, particles have a density equal to the UDS compound crystal density regardless of particle size, at lower D, the particles above a certain defined primary particle size are assigned a density as a function of the crystal density, the liquid density, and the agglomerate porosity that is calculated from $\mathrm{D}$. Thus, large particles in the No-flow Unsonicated PSDD with $\mathrm{D}<3$ have a reduced density in comparison to the $\mathrm{D}=3$ PSDD, and therefore a lower calculated settling velocity.

The unhindered interface velocity in Tank AZ-101 lies at about the $98^{\text {th }}$ percentile of the Flowing Sonicated and Unsonicated velocity distributions in Figure 3.3, and at the $63^{\text {rd }}$ percentile of the No-flow Unsonicated distribution. Therefore, as with the three-component simulant example, the lowest velocities calculated from particle properties do not seem to determine the interface velocity.

Based on the preceding discussion of the comparison of calculated and measured settling velocities for the three-component simulant, it is suggested that: 
- There is no conclusive evidence that characterization of the Hanford waste particle size via any of the three PSD techniques over-represents the settling characteristics of particles suspended by jet mixer pump operation. In fact, Bechtold et al. (2002) observed that PSDs of settled material from laboratory tests failed to identify very many large particles despite their being visible during the settling tests. Bechtold et al. (2002) also noted that, in comparison to sieving analysis of particle size, the light-scattering particle-size analyzer was poor at finding particles above $500 \mu \mathrm{m}$ in size. Thus, larger particulates may be under-represented by these instruments.

- There is no conclusive evidence that representing the particle density of Hanford waste particles by assuming that all particles have a density equal to the UDS compound crystal density regardless of the measured particle size over-represents the settling characteristics of particles suspended by jet mixer pump operation.

Thus, for the purposes of comparison with the SSMD simulant, the Hanford waste will be characterized using all three PSD types of Wells et al. (2011) with particle density equal to the UDS compound crystal density independent of particle size. A listing of the tanks, waste groups, and composite PSDDs of Wells et al. (2011) used in the current analysis is provided in 
Table 3.1. ${ }^{(4)}$ Highlighted tanks denote that PSDDs for that tank are available for each PSD type.

\subsection{SSMD Simulant}

The SSMD simulant comprises five components as listed in Table 3.2 (RPP-48358). As specified in (RPP-49740 Rev A), the simulant "...allowed for testing of both the nominal particles within the AY-102 waste and the bounding particles of interest."

The volume-based PSDs for these components are shown in Figure 3.5 through Figure 3.9. The PSDs for silicon carbide and stainless steel (Figure 3.7 and Figure 3.8) are for Lot\# PL-019 and SSMD027 respectively, as noted. Different lots of these components were used in the testing of RPP-49740 Rev $\mathrm{A}$, and these PSDs represent the larger-sized lots.

A volume-based PSDD is constructed from the component composition and density of Table 3.2 and the respective PSDs following Wells et al. (2007 and 2011), and is provided in Table 3.3. The concentration-weighted average particle density of the simulant is $3.96 \mathrm{~g} / \mathrm{mL}$. Given that the constituents are included as specified, the uncertainties of UDS composition and particle density for the Hanford waste PSDDs discussed in Section 3.1 are not applicable. The uncertainty of PSD measurement techniques used for the simulant component characterization is similar to that for the waste which is discussed in detail in Wells et al. (2011).

(4) Wells et al. (2011) provides PSDDs defined using the "combined" PSDs developed in that work. The combined PSDs provide a "best representation" of the particle size for a specific tank, waste type, or composite. Wells et al. (2011) also provides estimates of the lower and upper particle size limits based on percentile minimum and maximums for the tank, waste type, or composite. Thus, PSDDs with larger or smaller PSDs than currently used may be defined for a given tank, waste type, or composite. 
Table 3.1. Hanford Sludge Waste PSDDs Used for Simulant Comparison

\begin{tabular}{ccc}
\hline & PSD Types & \\
\hline Flowing Sonicated & Flowing Unsonicated & No-Flow Unsonicated \\
\hline C-107 & C-107 & C-107 \\
B-203 & B-203 & BX-107 \\
T-203 & T-203 & T-104 \\
T-204 & T-204 & B-201 \\
T-110 & T-110 & B-111 \\
C-106 & C-106 & T-111 \\
AY-102 & AY-102 & AY-102 \\
C-104 & C-104 & C-104 \\
AW-103 & AW-103 & C-103 \\
AZ-101 & AZ-101 & AZ-101 \\
AZ-102 & AZ-102 & AZ-102 \\
AY-101 & AY-101 & U-110 \\
SY-102 & SY-102 & SY-102 \\
S-107 & S-107 & - \\
SX-108 & SX-108 & - \\
- & CWR1 sludge (M12 Group 4) & - \\
CWR1 sludge (M12 Group 4) & TBP sludge (M12 Group 7) & - \\
Composite & PFeCN sludge (M12 Group 8) & - \\
CWR1 sludge: reduction oxidation (REDOX) cladding waste from aluminum clad fuel (1952-1960) \\
PFeCN sludge: Ferrocyanide sludge from in-plant scavenged supernatant \\
TBP sludge: Tributyl phosphate waste from solvent-based uranium recovery operations \\
\hline
\end{tabular}

Table 3.2. 5-Part SSMD Simulant Composition and Density

\begin{tabular}{ccccc}
\hline Component & Density $\mathbf{( g / \mathbf { m L } )}$ & $\begin{array}{c}\text { Median Particle } \\
\text { Size by Volume } \\
(\boldsymbol{\mu} \mathbf{m})\end{array}$ & UDS Mass Fraction & UDS Volume Fraction \\
\hline Gibbsite & 2.42 & 10 & 0.32 & 0.523 \\
Zirconium Oxide & 5.7 & 12 & 0.53 & 0.368 \\
Silicon Carbide & 3.2 & 150 & 0.05 & 0.062 \\
Stainless Steel & 8 & 128 & 0.05 & 0.025 \\
Bismuth Oxide & 8.9 & 38 & 0.05 & 0.022 \\
\hline
\end{tabular}




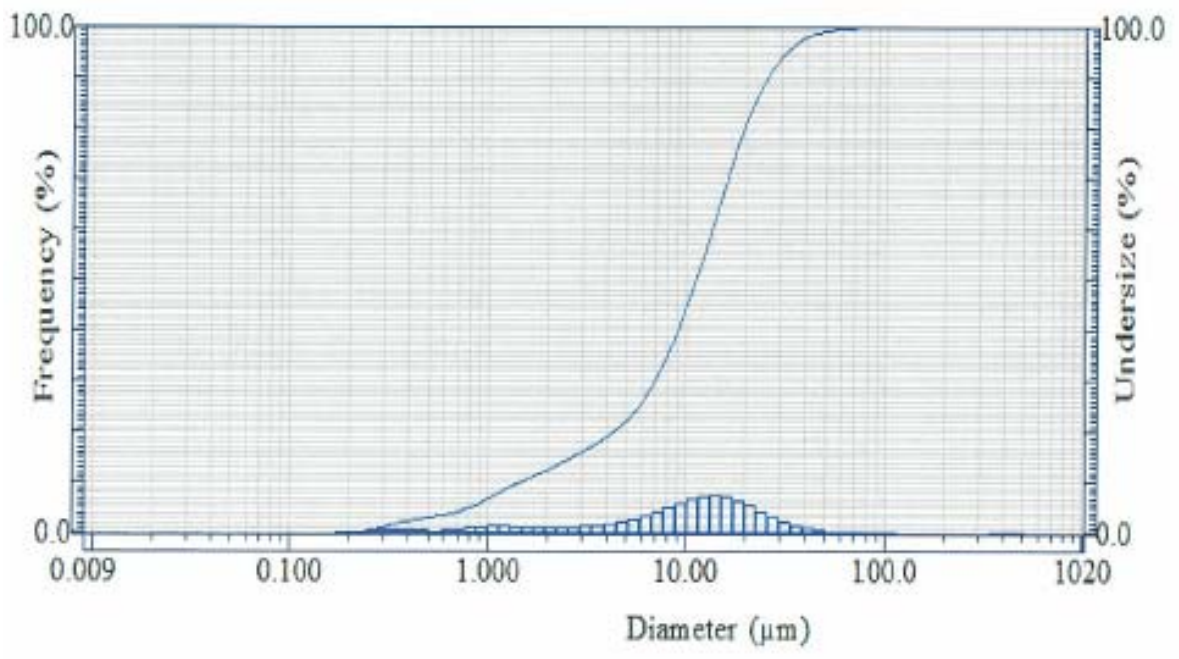

Figure 3.5. PSD of SSMD Simulant Gibbsite. Bars indicate frequency of particles in a size range; the solid line shows the percentage of particles smaller than the associated size.

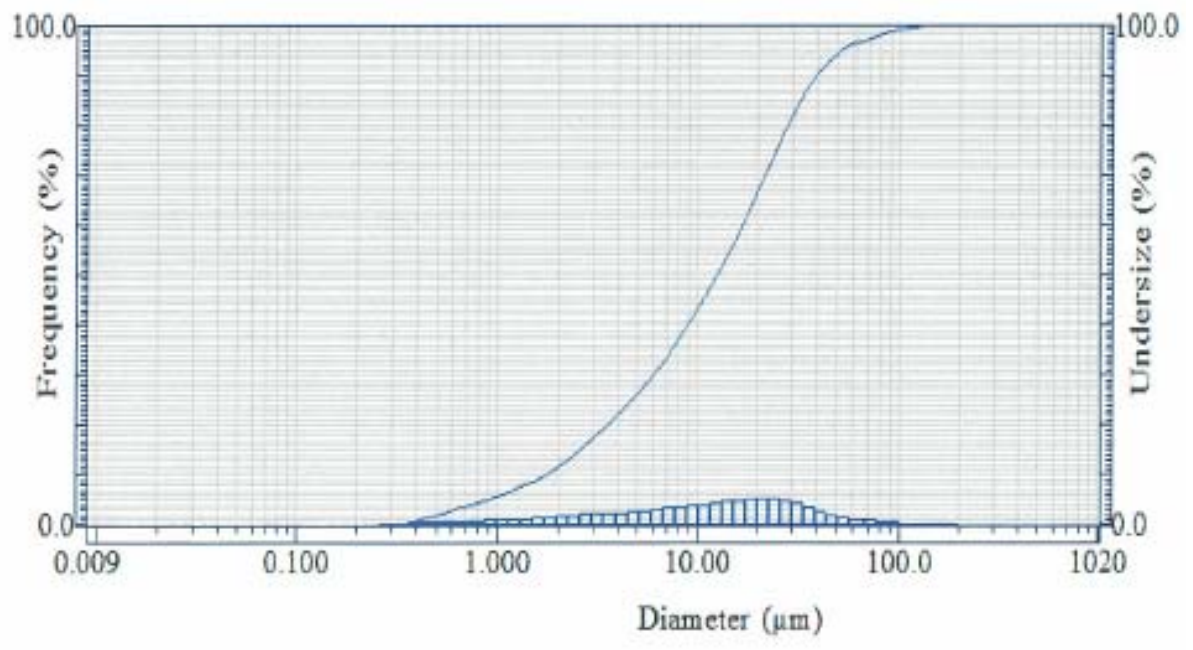

Figure 3.6. PSD of SSMD Simulant Zirconium Oxide 


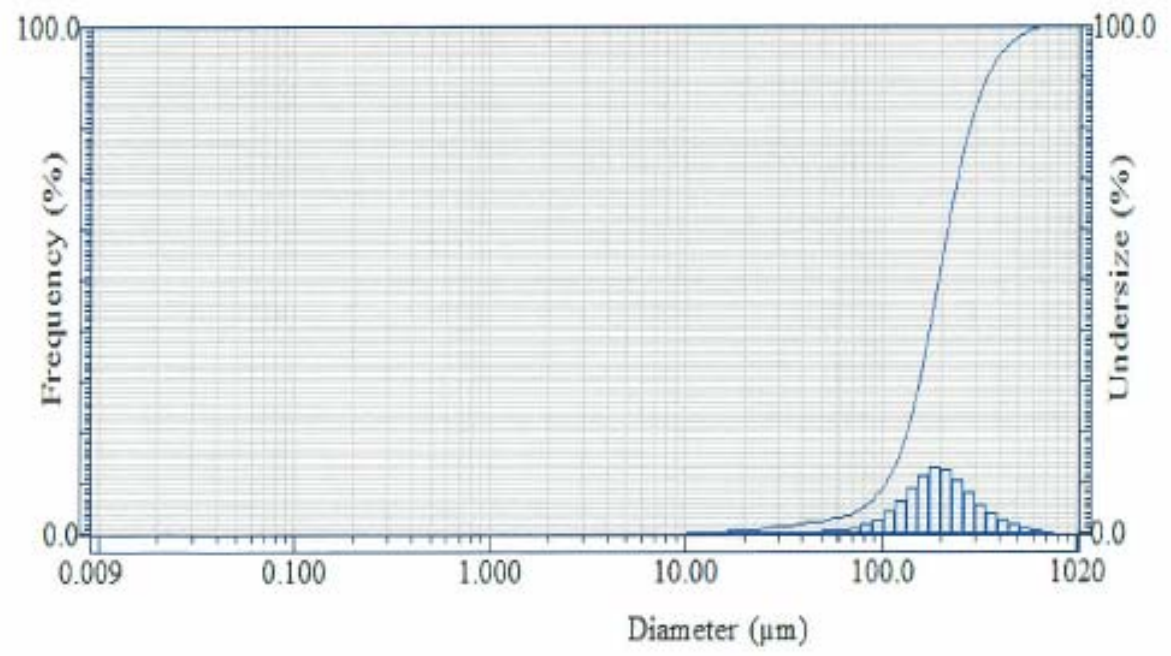

Figure 3.7. PSD of SSMD Simulant Silicon Carbide (SSMD-027)

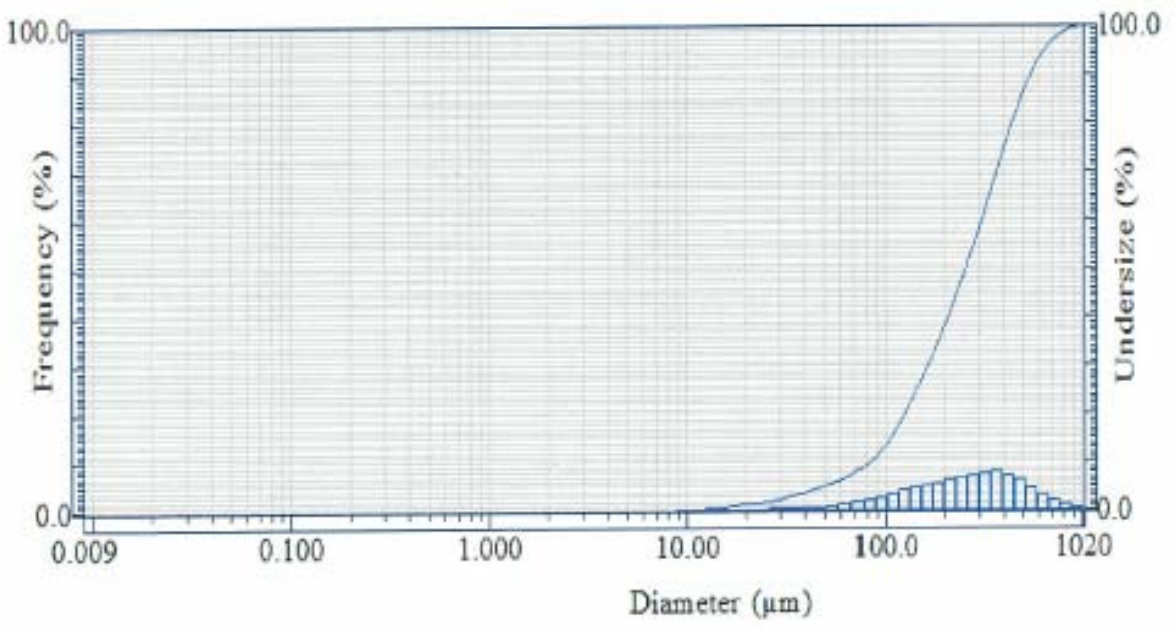

Figure 3.8. PSD of SSMD Simulant Stainless Steel (Lot\# PL-019) 


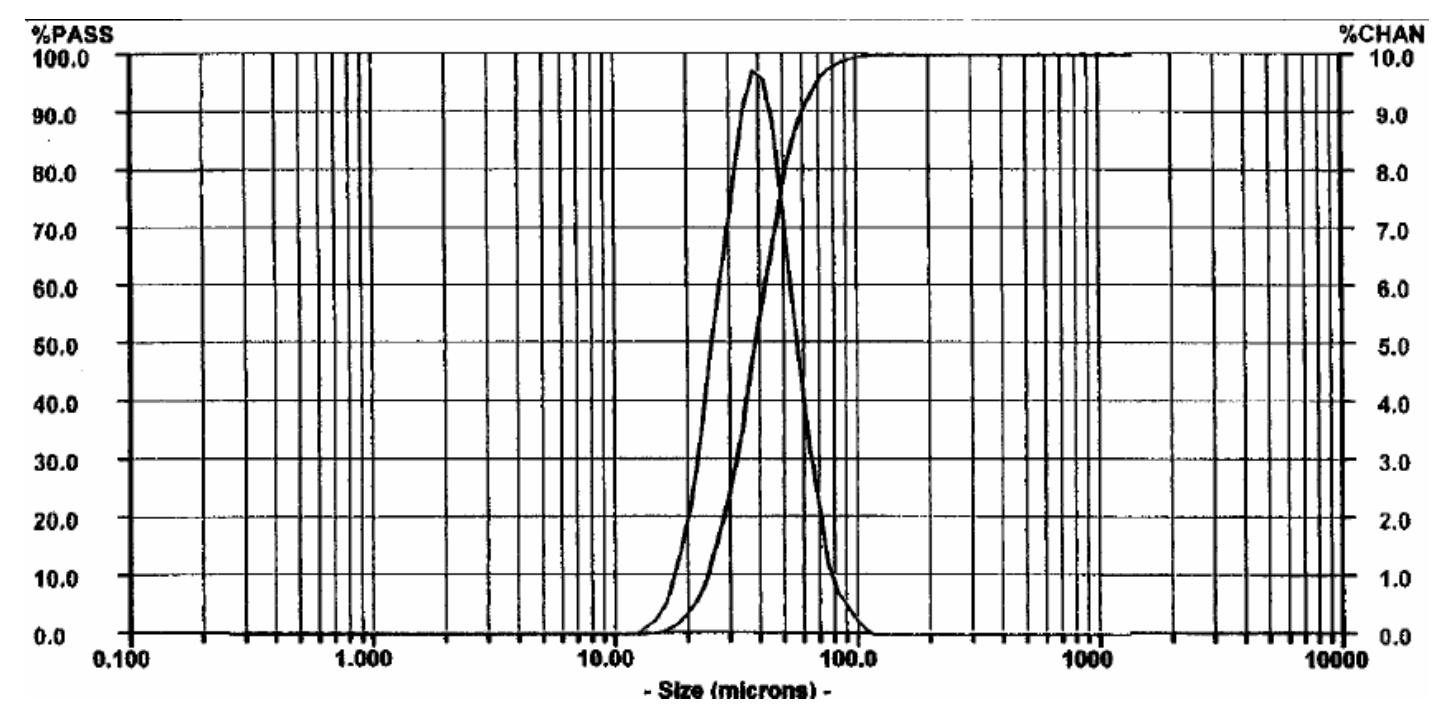

Figure 3.9. PSD of SSMD Simulant Bismuth Oxide. Parabolic line indicates frequency of particles of a given size; asymptotic line shows the percentage of particles smaller than the associated size.

Table 3.3. PSDD of Five-Part SSMD Simulant

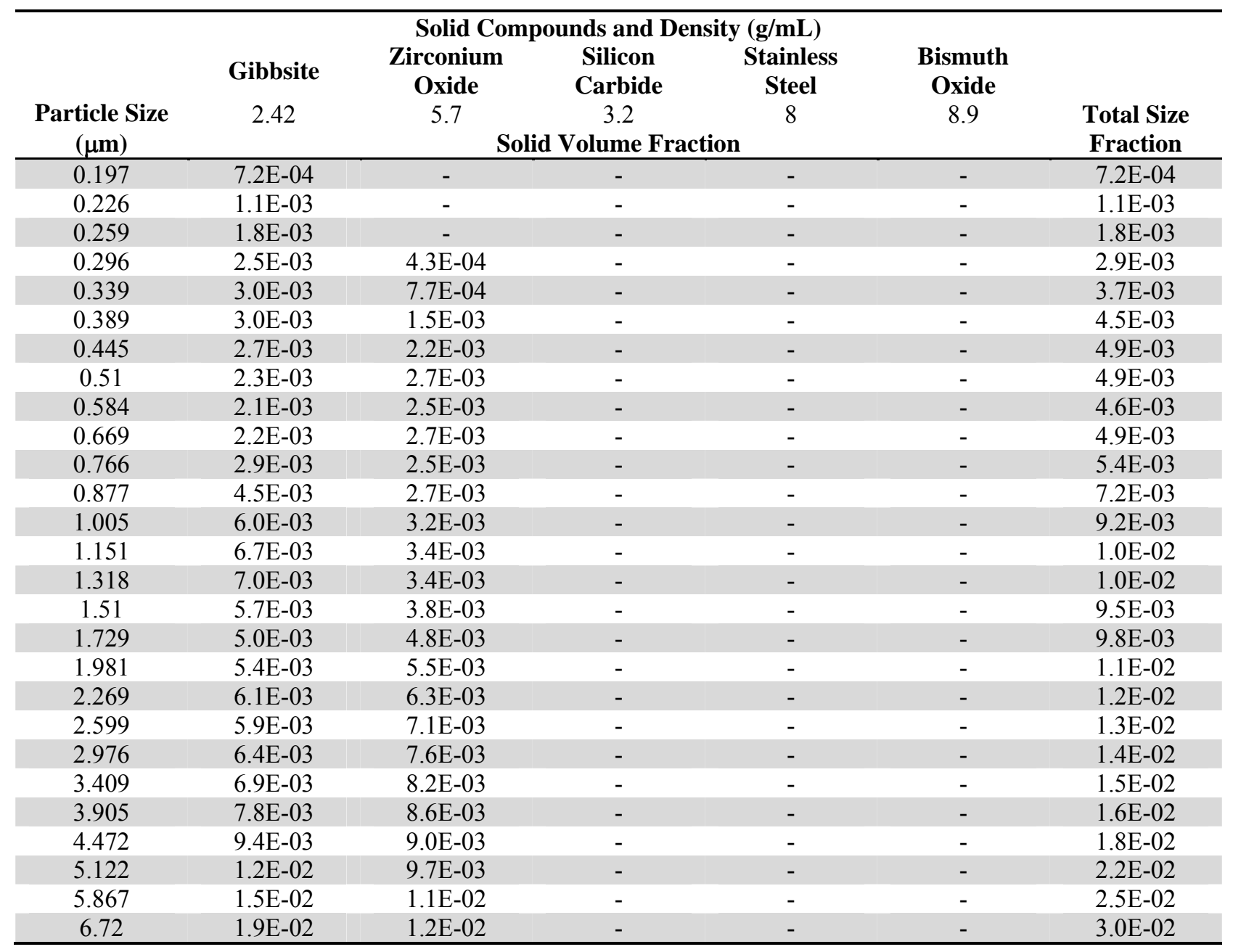




\begin{tabular}{|c|c|c|c|c|c|c|}
\hline \multicolumn{7}{|c|}{ Solid Compounds and Density (g/mL) } \\
\hline \multirow{3}{*}{$\begin{array}{c}\text { Particle Size } \\
(\mu \mathrm{m})\end{array}$} & Gibbsite & \multirow{3}{*}{$\begin{array}{c}\text { Zirconium } \\
\text { Oxide } \\
5.7\end{array}$} & \multirow{2}{*}{$\begin{array}{c}\text { Silicon } \\
\text { Carbide } \\
3.2\end{array}$} & \multirow{3}{*}{$\begin{array}{c}\text { Stainless } \\
\text { Steel } \\
8\end{array}$} & \multirow{3}{*}{$\begin{array}{c}\text { Bismuth } \\
\text { Oxide } \\
8.9\end{array}$} & \multirow{3}{*}{$\begin{array}{c}\text { Total Size } \\
\text { Fraction }\end{array}$} \\
\hline & 2.42 & & & & & \\
\hline & & & Volume $\mathbf{F}$ & & & \\
\hline 7.697 & $2.4 \mathrm{E}-02$ & $1.3 \mathrm{E}-02$ & - & - & - & $3.6 \mathrm{E}-02$ \\
\hline 8.816 & $2.8 \mathrm{E}-02$ & $1.3 \mathrm{E}-02$ & - & - & - & $4.2 \mathrm{E}-02$ \\
\hline 10.097 & $3.2 \mathrm{E}-02$ & $1.4 \mathrm{E}-02$ & - & $3.1 \mathrm{E}-05$ & - & 4.7E-02 \\
\hline 11.565 & 3.6E-02 & $1.5 \mathrm{E}-02$ & 4.3E-05 & 4.0E-05 & - & $5.1 \mathrm{E}-02$ \\
\hline 13.246 & $3.9 \mathrm{E}-02$ & $1.6 \mathrm{E}-02$ & 7.4E-05 & $4.8 \mathrm{E}-05$ & - & $5.5 \mathrm{E}-02$ \\
\hline 14.27 & - & - & - & - & $3.1 \mathrm{E}-05$ & $3.1 \mathrm{E}-05$ \\
\hline 15.172 & $4.0 \mathrm{E}-02$ & $1.7 \mathrm{E}-02$ & 8.3E-05 & $5.7 \mathrm{E}-05$ & - & $5.7 \mathrm{E}-02$ \\
\hline 15.56 & - & - & - & - & $6.4 \mathrm{E}-05$ & $6.4 \mathrm{E}-05$ \\
\hline 16.96 & - & - & - & - & $1.2 \mathrm{E}-04$ & $1.2 \mathrm{E}-04$ \\
\hline 17.377 & $3.8 \mathrm{E}-02$ & $1.8 \mathrm{E}-02$ & 9.3E-05 & $6.5 \mathrm{E}-05$ & - & $5.7 \mathrm{E}-02$ \\
\hline 18.5 & - & - & - & - & 2.1E-04 & $2.1 \mathrm{E}-04$ \\
\hline 19.904 & 3.4E-02 & $1.9 \mathrm{E}-02$ & $1.0 \mathrm{E}-04$ & 7.3E-05 & - & $5.4 \mathrm{E}-02$ \\
\hline 20.17 & - & - & - & - & $3.5 \mathrm{E}-04$ & $3.5 \mathrm{E}-04$ \\
\hline 22 & - & - & - & - & 5.3E-04 & 5.3E-04 \\
\hline 22.797 & 2.9E-02 & $1.9 \mathrm{E}-02$ & $1.1 \mathrm{E}-04$ & 8.3E-05 & - & $4.8 \mathrm{E}-02$ \\
\hline 23.99 & - & - & - & - & 7.6E-04 & 7.6E-04 \\
\hline 26.111 & 2.3E-02 & $1.9 \mathrm{E}-02$ & $1.2 \mathrm{E}-04$ & 9.4E-05 & - & $4.2 \mathrm{E}-02$ \\
\hline 26.16 & - & - & - & - & $1.0 \mathrm{E}-03$ & $1.0 \mathrm{E}-03$ \\
\hline 28.53 & - & - & - & - & $1.3 \mathrm{E}-03$ & $1.3 \mathrm{E}-03$ \\
\hline 29.907 & $1.6 \mathrm{E}-02$ & $1.8 \mathrm{E}-02$ & 1.4E-04 & $1.1 \mathrm{E}-04$ & - & $3.4 \mathrm{E}-02$ \\
\hline 31.11 & - & - & - & - & $1.6 \mathrm{E}-03$ & $1.6 \mathrm{E}-03$ \\
\hline 33.93 & - & - & - & - & $1.8 \mathrm{E}-03$ & $1.8 \mathrm{E}-03$ \\
\hline 34.255 & 1.1E-02 & $1.5 \mathrm{E}-02$ & $1.5 \mathrm{E}-04$ & $1.2 \mathrm{E}-04$ & - & 2.7E-02 \\
\hline 37 & - & - & - & - & $2.0 \mathrm{E}-03$ & $2.0 \mathrm{E}-03$ \\
\hline 39.234 & 7.3E-03 & $1.3 \mathrm{E}-02$ & 1.7E-04 & 1.4E-04 & - & $2.0 \mathrm{E}-02$ \\
\hline 40.35 & - & - & - & - & 2.2E-03 & $2.2 \mathrm{E}-03$ \\
\hline 44 & - & - & - & - & 2.2E-03 & $2.2 \mathrm{E}-03$ \\
\hline 44.938 & $4.6 \mathrm{E}-03$ & $9.8 \mathrm{E}-03$ & $1.9 \mathrm{E}-04$ & $1.7 \mathrm{E}-04$ & - & $1.5 \mathrm{E}-02$ \\
\hline 47.98 & - & - & - & - & $2.0 \mathrm{E}-03$ & $2.0 \mathrm{E}-03$ \\
\hline 51.471 & 2.9E-03 & 7.4E-03 & 2.4E-04 & $2.0 \mathrm{E}-04$ & - & $1.1 \mathrm{E}-02$ \\
\hline 52.33 & - & - & - & - & 1.7E-03 & $1.7 \mathrm{E}-03$ \\
\hline 57.06 & - & - & - & - & $1.4 \mathrm{E}-03$ & $1.4 \mathrm{E}-03$ \\
\hline 58.953 & $1.9 \mathrm{E}-03$ & $5.5 \mathrm{E}-03$ & 3.2E-04 & $2.5 \mathrm{E}-04$ & - & $7.9 \mathrm{E}-03$ \\
\hline 62.23 & - & - & - & - & $1.0 \mathrm{E}-03$ & $1.0 \mathrm{E}-03$ \\
\hline 67.523 & $1.2 \mathrm{E}-03$ & $4.1 \mathrm{E}-03$ & 4.5E-04 & 3.2E-04 & - & $6.0 \mathrm{E}-03$ \\
\hline 67.86 & - & - & - & - & 7.2E-04 & $7.2 \mathrm{E}-04$ \\
\hline 74 & - & - & - & - & 4.8E-04 & $4.8 \mathrm{E}-04$ \\
\hline 77.339 & 8.3E-04 & $3.1 \mathrm{E}-03$ & $6.7 \mathrm{E}-04$ & 4.1E-04 & - & $5.0 \mathrm{E}-03$ \\
\hline 80.7 & - & - & - & - & $3.1 \mathrm{E}-04$ & $3.1 \mathrm{E}-04$ \\
\hline 88 & - & - & - & - & $1.9 \mathrm{E}-04$ & $1.9 \mathrm{E}-04$ \\
\hline 88.583 & $2.8 \mathrm{E}-04$ & $2.4 \mathrm{E}-03$ & $1.1 \mathrm{E}-03$ & 5.4E-04 & - & $4.2 \mathrm{E}-03$ \\
\hline 95.96 & - & - & - & - & $1.2 \mathrm{E}-04$ & $1.2 \mathrm{E}-04$ \\
\hline 101.46 & $2.3 \mathrm{E}-04$ & $1.8 \mathrm{E}-03$ & $1.7 \mathrm{E}-03$ & 7.1E-04 & - & 4.4E-03 \\
\hline 104.7 & - & - & - & - & 7.1E-05 & 7.1E-05 \\
\hline 114.1 & - & - & - & - & 3.6E-05 & 3.6E-05 \\
\hline 116.21 & 1.9E-04 & $1.4 \mathrm{E}-03$ & $2.6 \mathrm{E}-03$ & $9.0 \mathrm{E}-04$ & - & $5.1 \mathrm{E}-03$ \\
\hline 124.5 & - & - & - & - & 1.6E-05 & $1.6 \mathrm{E}-05$ \\
\hline 133.103 & - & $1.0 \mathrm{E}-03$ & 4.0E-03 & $1.1 \mathrm{E}-03$ & - & $6.1 \mathrm{E}-03$ \\
\hline 152.453 & - & $5.9 \mathrm{E}-04$ & $5.6 \mathrm{E}-03$ & $1.2 \mathrm{E}-03$ & - & 7.4E-03 \\
\hline 174.616 & - & $3.5 \mathrm{E}-04$ & 7.1E-03 & $1.3 \mathrm{E}-03$ & - & $8.8 \mathrm{E}-03$ \\
\hline 200 & - & $1.3 \mathrm{E}-04$ & 8.0E-03 & 1.4E-03 & - & $9.5 \mathrm{E}-03$ \\
\hline
\end{tabular}




\begin{tabular}{|c|c|c|c|c|c|c|}
\hline \multicolumn{7}{|c|}{ Solid Compounds and Density (g/mL) } \\
\hline & Gibbsite & $\begin{array}{c}\text { Zirconium } \\
\text { Oxide }\end{array}$ & $\begin{array}{c}\text { Silicon } \\
\text { Carbide }\end{array}$ & $\begin{array}{c}\text { Stainless } \\
\text { Steel }\end{array}$ & $\begin{array}{c}\text { Bismuth } \\
\text { Oxide }\end{array}$ & \\
\hline $\begin{array}{c}\text { Particle Size } \\
(\mu \mathrm{m})\end{array}$ & \multicolumn{5}{|c|}{ Solid Volume Fraction } & $\begin{array}{c}\text { Total Size } \\
\text { Fraction } \\
\end{array}$ \\
\hline 229.075 & - & - & $7.8 \mathrm{E}-03$ & $1.5 \mathrm{E}-03$ & - & $9.3 \mathrm{E}-03$ \\
\hline 262.376 & - & - & $6.6 \mathrm{E}-03$ & $1.7 \mathrm{E}-03$ & - & $8.3 \mathrm{E}-03$ \\
\hline 300.518 & - & - & $5.0 \mathrm{E}-03$ & $1.8 \mathrm{E}-03$ & - & $6.8 \mathrm{E}-03$ \\
\hline 344.206 & - & - & $3.5 \mathrm{E}-03$ & $1.9 \mathrm{E}-03$ & - & $5.4 \mathrm{E}-03$ \\
\hline 394.244 & $1.9 \mathrm{E}-04$ & - & $2.3 \mathrm{E}-03$ & $2.0 \mathrm{E}-03$ & - & $4.5 \mathrm{E}-03$ \\
\hline 451.556 & $2.4 \mathrm{E}-04$ & - & $1.6 \mathrm{E}-03$ & $1.8 \mathrm{E}-03$ & - & $3.6 \mathrm{E}-03$ \\
\hline 517.2 & $3.1 \mathrm{E}-04$ & - & $1.1 \mathrm{E}-03$ & $1.6 \mathrm{E}-03$ & - & $3.0 \mathrm{E}-03$ \\
\hline 592.387 & - & - & $6.1 \mathrm{E}-04$ & $1.2 \mathrm{E}-03$ & - & $1.8 \mathrm{E}-03$ \\
\hline 678.504 & - & - & $3.4 \mathrm{E}-04$ & $8.1 \mathrm{E}-04$ & - & $1.2 \mathrm{E}-03$ \\
\hline 777.141 & - & - & $1.3 \mathrm{E}-04$ & $5.4 \mathrm{E}-04$ & - & $6.7 \mathrm{E}-04$ \\
\hline 890.116 & - & - & - & $3.3 \mathrm{E}-04$ & - & $3.3 \mathrm{E}-04$ \\
\hline 1019.515 & - & - & - & $1.2 \mathrm{E}-04$ & - & $1.2 \mathrm{E}-04$ \\
\hline $\begin{array}{c}\text { Total } \\
\text { Component } \\
\text { Volume } \\
\text { Fraction } \\
\end{array}$ & 0.52 & 0.37 & 0.06 & 0.02 & 0.02 & 1.0 \\
\hline
\end{tabular}




\subsection{Comparison of Hanford Waste and SSMD Simulant PSDDs}

The comparison of the five-part SSMD simulant and Hanford waste particulate PSDDs is made on the following metrics described in Section 2:

1. Settling velocity, $\mathrm{U}_{\mathrm{T}}$, Equation (2.2)

2. Archimedes number, Ar, Equation (2.3)

3. Critical shear stress for erosion of noncohesive particles, $\tau_{c}$, from Equations (2.4) and (2.6)

4. Just-suspended impeller speed, $\mathrm{N}_{\mathrm{js}}$, Equation (2.8)

5. Jet velocity needed to achieve a certain degree of solid suspension, $U_{n}$, Equation (2.9)

6. PJM critical suspension velocity for noncohesive solids, $\mathrm{U}_{\mathrm{CS}}$, Equation (2.10)

7. PJM cloud height for noncohesive solids, $\mathrm{H}_{\mathrm{C}}$, Equation (2.13)

8. Pipeline critical transport velocity, $\mathrm{U}_{\mathrm{C}}$, Equation (2.15)

The PSDDs are compared via these models with all inputs held constant at the values specified in Section 2 except the particle size and density, and water $(1.0 \mathrm{~g} / \mathrm{mL}, 1.0 \mathrm{cP})$ is used as the fluid in all cases. Other parameters that may influence the comparison not encompassed on the model forms (e.g., particle shape, see Section 2), are not addressed.

The eight listed metrics address various phenomena that occur in the waste feed system, but may not be directly related to the SSMD project test objectives to understand and demonstrate the DST sampling and batch transfer performance. The models may not encompass the size and density range of the waste and simulant, and may not be directly applicable to the Hanford DST configurations. Thus, it is the comparison of the metrics for the waste and simulant particulate that is of significance, not the specific results as related to actual sampling and batch transfer performance.

\subsection{PSDD Comparisons}

Comparison plots for the eight listed metrics for each of the three Hanford waste PSDD types (Flowing Sonicated, Flowing Unsonicated, and No-flow Unsonicated) are provided in Figure 4.1 through Figure 4.8. In order to view all three PSDD types concurrently for a given metric, Figure 4.1 through Figure 4.8 are shown reduced in size; the intent of these figures is not so much the specific tanks but as general observed trends. Full-page plots for each comparison are provided in Appendix A so that individual details may be more closely examined.

In Figure 4.1 through Figure 4.8, as for the settling velocity plots of Section 3, the abscissa is the metric, and the ordinate is the cumulative UDS volume \% summed in increasing order of the metric. Thus, for example, the settling velocity at $60 \%$ indicates that $60 \%$ of the particulate by volume has a lower calculated settling velocity, and $40 \%$ by volume has a higher settling velocity. For each metric, the PSDD-based results for the five-part SSMD simulant, indicated by the gold line and symbols, are the same in each plot for the three PSDD types. The black line and symbol on each plot is the composite PSDD result, and the bold lines denote the tanks common to all three PSDD types as indicated in 
Table 3.1.

In Figure 4.1, the five-part SSMD simulant is shown to be to the right of all the Flowing Sonicated waste results (individual samples and composite PSDD) up to approximately the $70^{\text {th }}$ percentile by volume. This observation indicates that the calculated settling velocity of the slowest $70 \%$ by volume of the five-part SSMD simulant particulate is faster than that in the Flowing Sonicated waste characterization. For both the Flowing Unsonicated and No-Flow Unsonicated waste, $100 \%$ by volume of the calculated settling velocity for the five-part SSMD simulant particulate is exceeded by that of some individual samples of the waste. Substantially higher calculated settling velocity results are achieved for the No-Flow Unsonicated waste, at some percentiles exceeding the five-part SSMD simulant by approximately 1.5 orders of magnitude.

For both the Flowing Sonicated and Flowing Unsonicated waste characterization, the calculated settling velocity of the five-part SSMD simulant exceeds that of the composite PSDDs; it exceeds approximately $80 \%$ by volume of the No-Flow Unsonicated composite PSDD and is relatively similar for the upper $20 \%$, Figure 4.1 . The simulant exceeds the calculated settling velocity of AY-102 waste for Flowing Sonicated and Flowing Unsonicated characterizations, and exceeds for the slowest $80 \%$ by volume and is slower than the upper $20 \%$ for the No-Flow Unsonicated waste characterization.

The comparison for the Archimedes number is essentially equivalent to that for the settling velocity, Figure 4.2, as expected from the settling velocity Equation (2.2). As indicated in Section 2, the Archimedes number is also a parameter in other waste operation metrics, including pump intake (see Wells et al. 2011), critical shear stress for erosion (Paphitis (2001), jet suspension velocity (Kale and Patwardhan 2005), critical suspension velocity and suspended particle cloud height (Meyer et al. 2009), and pipeline critical velocity (Poloski et al. 2010).

The comparisons of critical shear stress for erosion of noncohesive particles, Figure 4.3, justsuspended impeller speed, Figure 4.4, jet velocity needed to achieve a certain degree of solid suspension, Figure 4.5, PJM critical suspension velocity and cloud height ${ }^{(5)}$ for non-cohesive solids, Figure 4.6 and Figure 4.7 respectively, and pipeline critical transport velocity, Figure 4.8, all show similar results for a given PSDD type. The simulant exceeds the calculated metrics of AY-102 waste for the Flowing Sonicated and Flowing Unsonicated characterizations, and may under-represent the upper fraction of the AY-102 waste for the No-Flow Unsonicated waste characterization. Thus, it appears that the five-part SSMD simulant comparison to Hanford waste is relatively independent of the metric considered for waste feed delivery system phenomena. This result is unexpected given that the different waste operation metrics considered have different functionalities with particle size and density (e.g., $\mathrm{Ar} \rightarrow(\mathrm{S}-1) \mathrm{d}^{3}, \mathrm{~N}_{\mathrm{js}}$ $\rightarrow(\mathrm{S}-1)^{0.45} \mathrm{~d}^{0.2}$ and $\left.\mathrm{U}_{\mathrm{C}} \rightarrow(\mathrm{S}-1)^{0.545} \mathrm{~d}^{0.167}\right)$.

(5) Cloud height is viewed "opposite" of the other metrics; that is, a more challenging particle with respect to suspension has a lower cloud height. The cloud height plots are truncated beyond a maximum height of $10 \mathrm{~m}$, and thus limited fractions of the particulate are accounted for in Figure 4.7. 

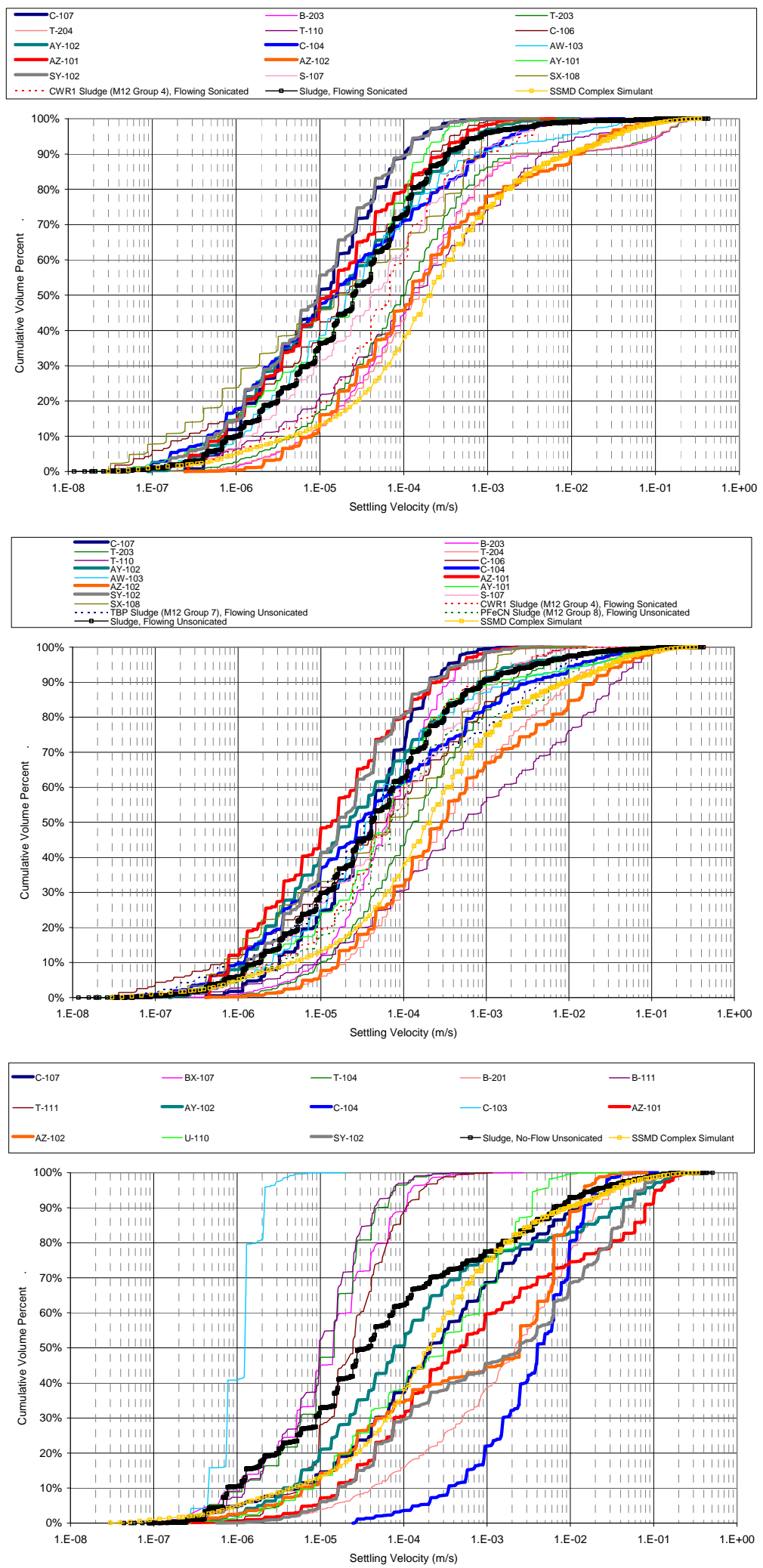

Figure 4.1. Settling Velocity Comparison. Top: Flowing Sonicated; Middle: Flowing Unsonicated; Bottom: No-flow Unsonicated. SSMD simulant, gold line and symbols; composite PSDD, black line and symbol; bold lines denote the tanks common to all three PSDD types. 

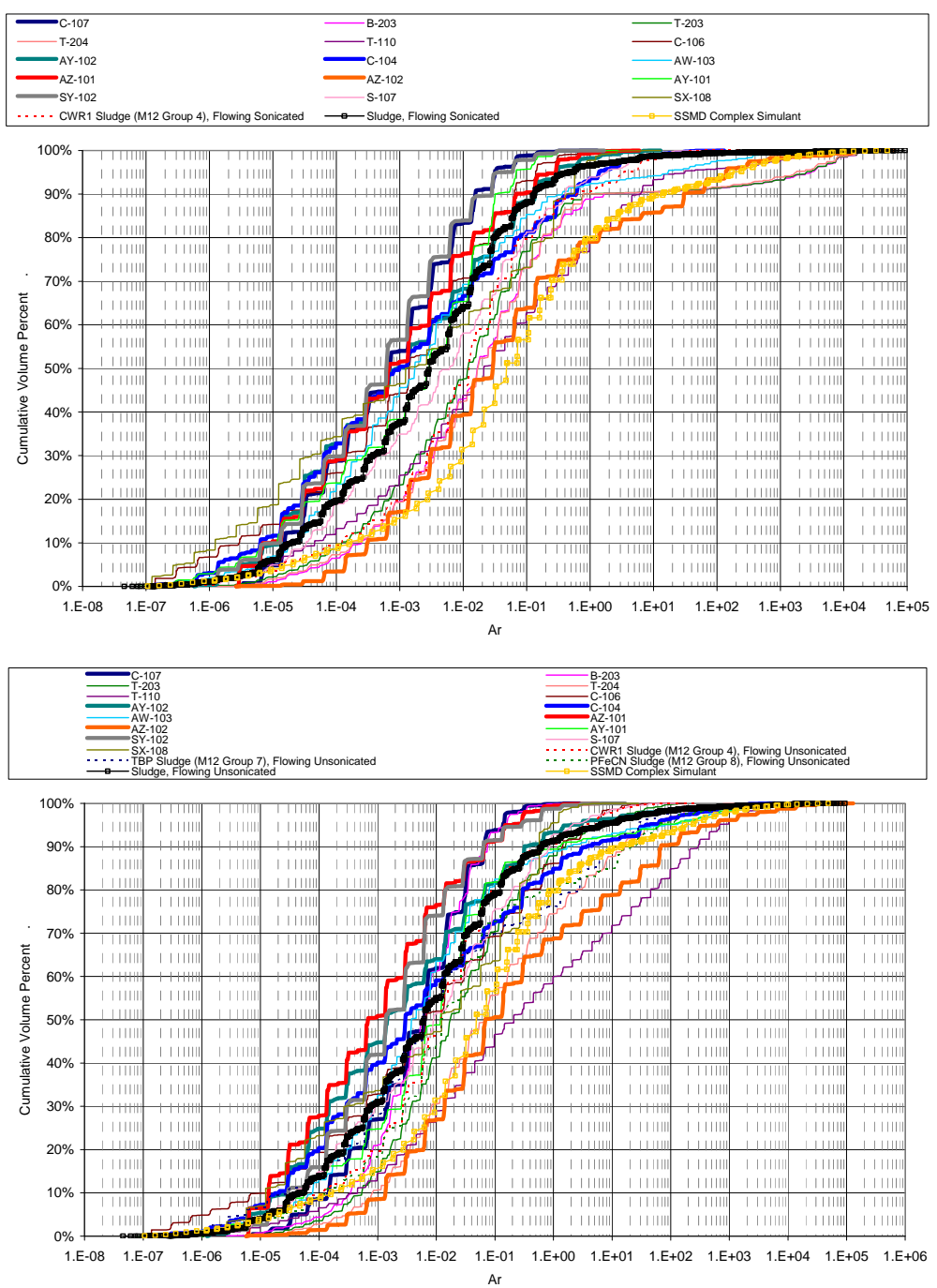

\begin{tabular}{|c|c|c|c|c|}
\hline - ${ }^{\mathrm{c}-107}$ & $-B X-107$ & $-\mathrm{T}-104$ & B-201 & $-_{B-111}$ \\
\hline$-\mathrm{T}-111$ & 一 $_{\mathrm{AY}-102}$ & 一 $\mathrm{c}-104$ & $-\mathrm{C}-103$ & 一 $_{A Z-101}$ \\
\hline 一 AZ-102 & —-110 & —sY-102 & $\rightarrow$-Sludge, & - SSMD Complex Simulant \\
\hline
\end{tabular}

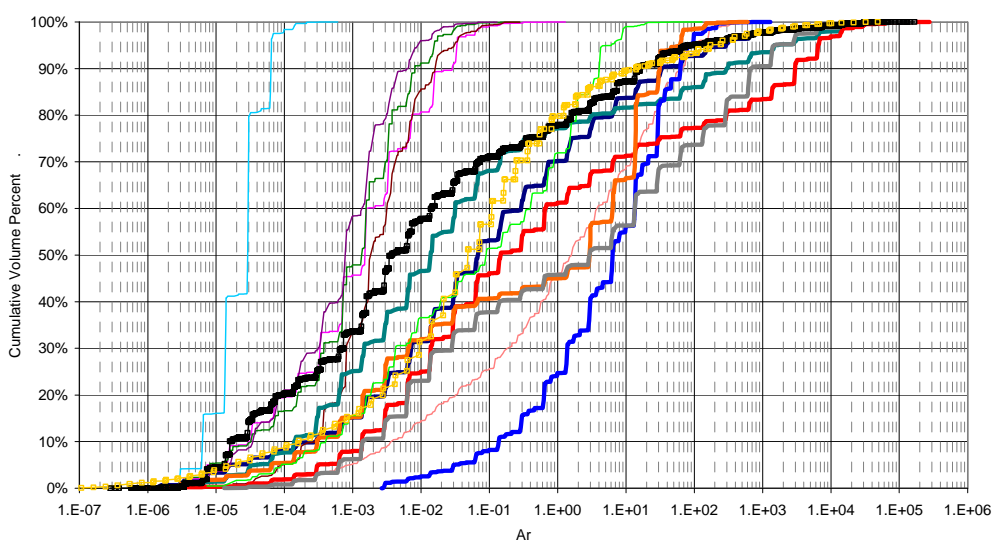

Figure 4.2. Archimedes Number Comparison. Top: Flowing Sonicated; Middle: Flowing Unsonicated; Bottom: No-flow Unsonicated. SSMD simulant, gold line and symbols; composite PSDD, black line and symbol; bold lines denote the tanks common to all three PSDD types. 

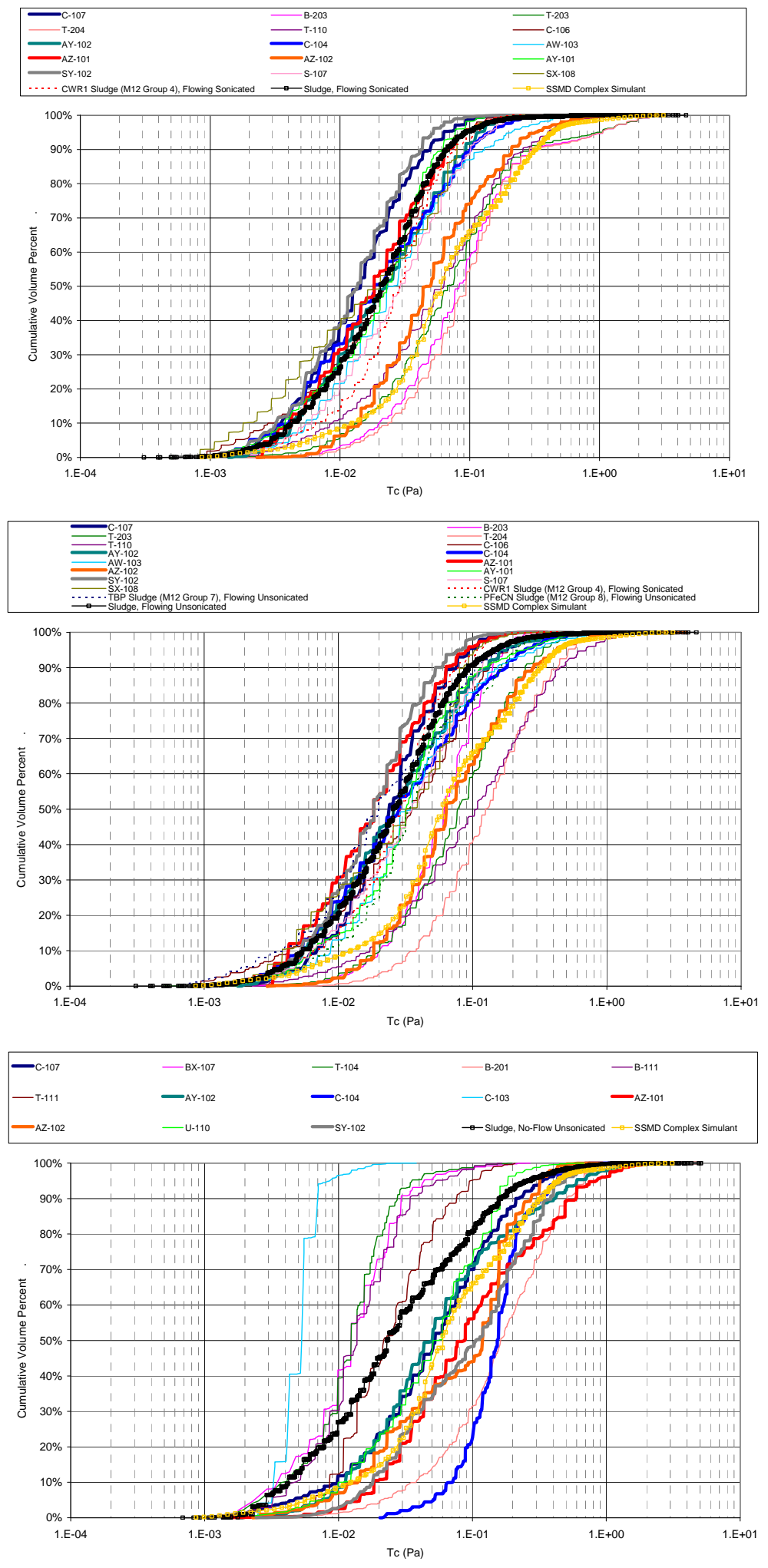

Figure 4.3. Critical Shear Stress for Erosion of Non-Cohesive Particles Comparison. Top: Flowing Sonicated; Middle: Flowing Unsonicated; Bottom: No-flow Unsonicated. SSMD simulant, gold line and symbols; composite PSDD, black line and symbol; bold lines denote the tanks common to all three PSDD types. 

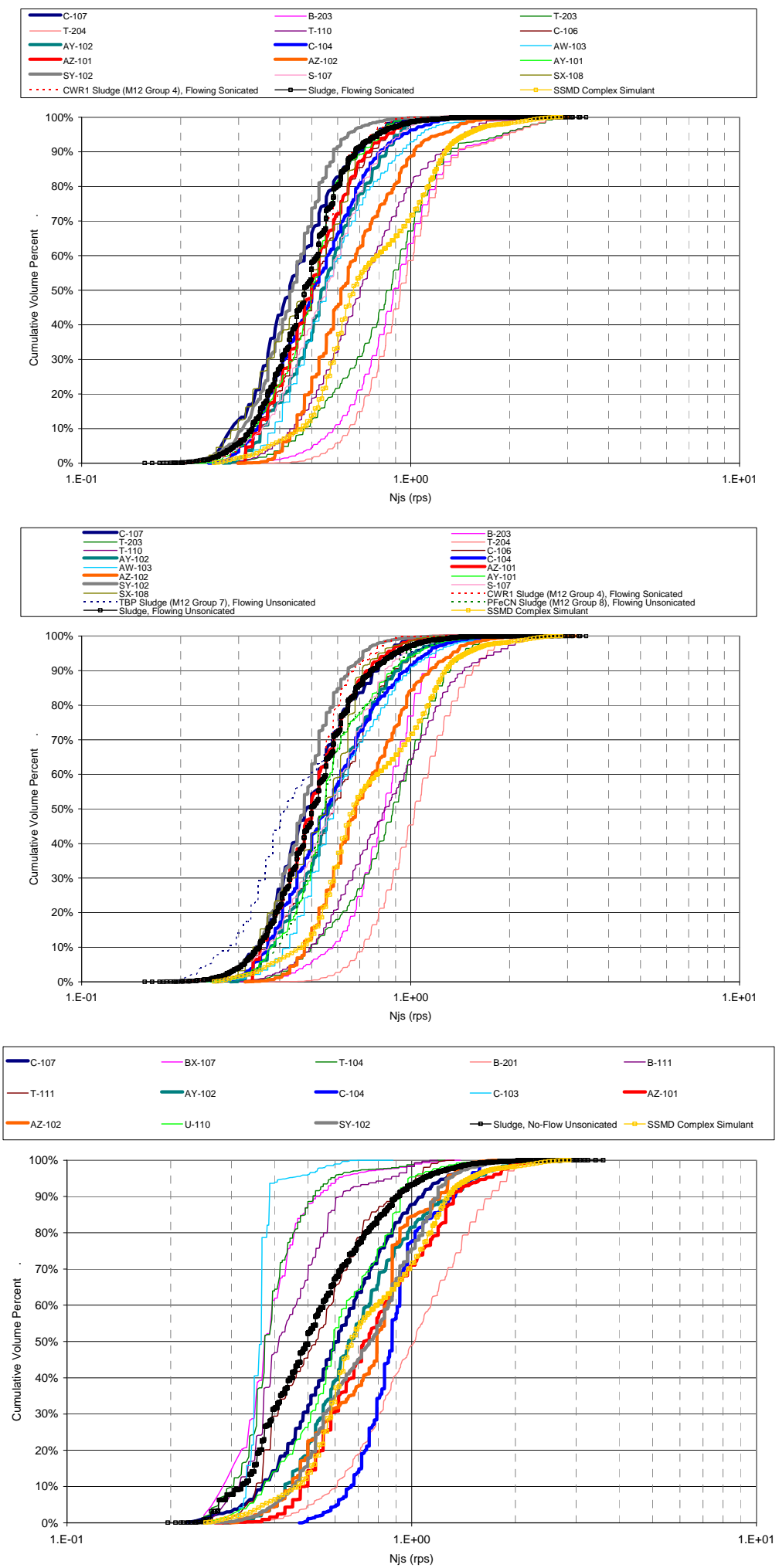

Figure 4.4. Just-Suspended Impeller Speed Comparison. Top: Flowing Sonicated: Middle: Flowing Unsonicated; Bottom No-flow Unsonicated. SSMD simulant, gold line and symbols; composite PSDD, black line and symbol; bold lines denote the tanks common to all three PSDD types. 

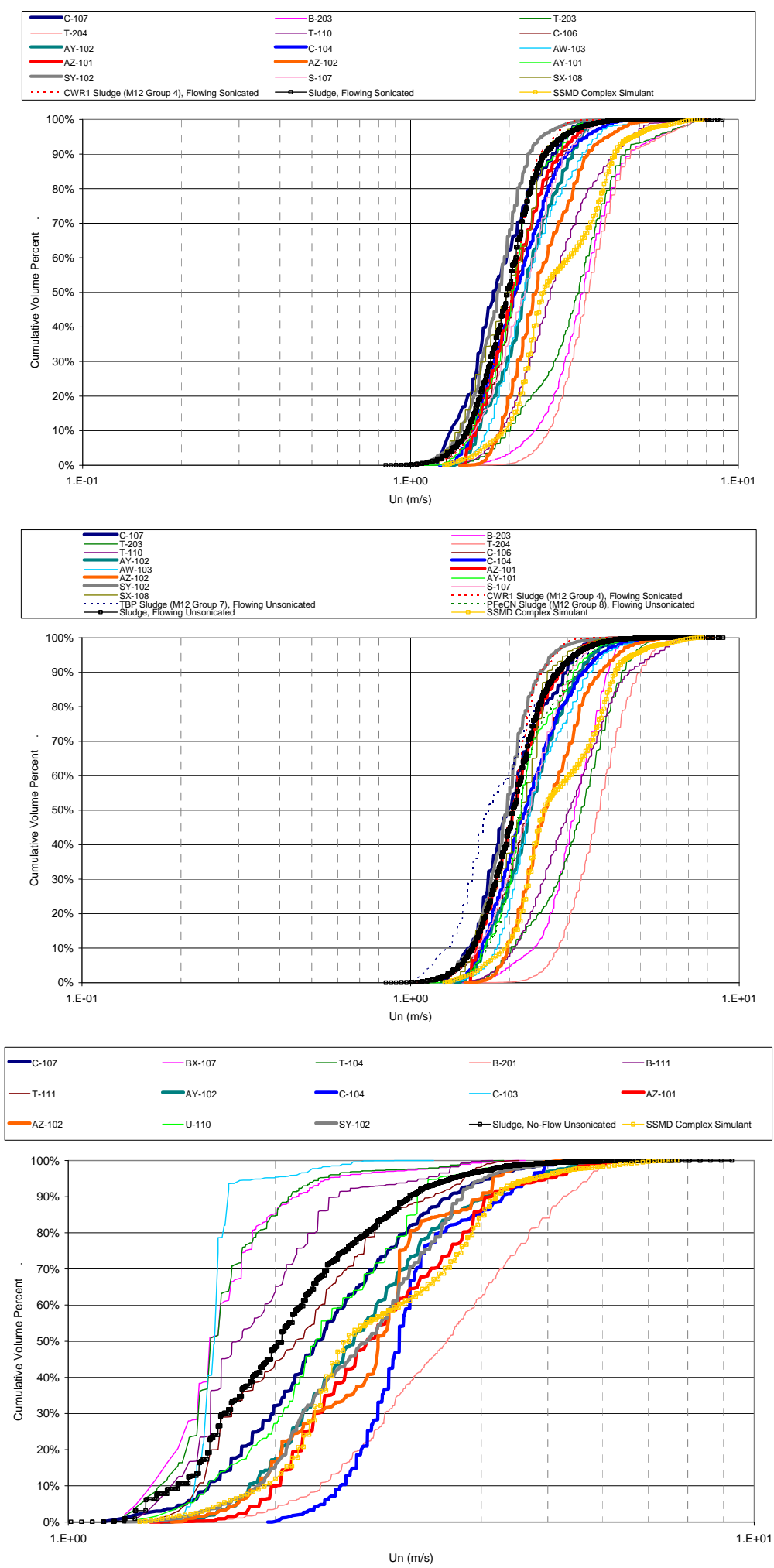

Figure 4.5. Jet Velocity Needed to Achieve a Certain Degree of Solid Suspension Comparison. Top: Flowing Sonicated; Middle: Flowing Unsonicated; Bottom: No-flow Unsonicated. SSMD simulant, gold line and symbols; composite PSDD, black line and symbol; bold lines denote the tanks common to all three PSDD types. 

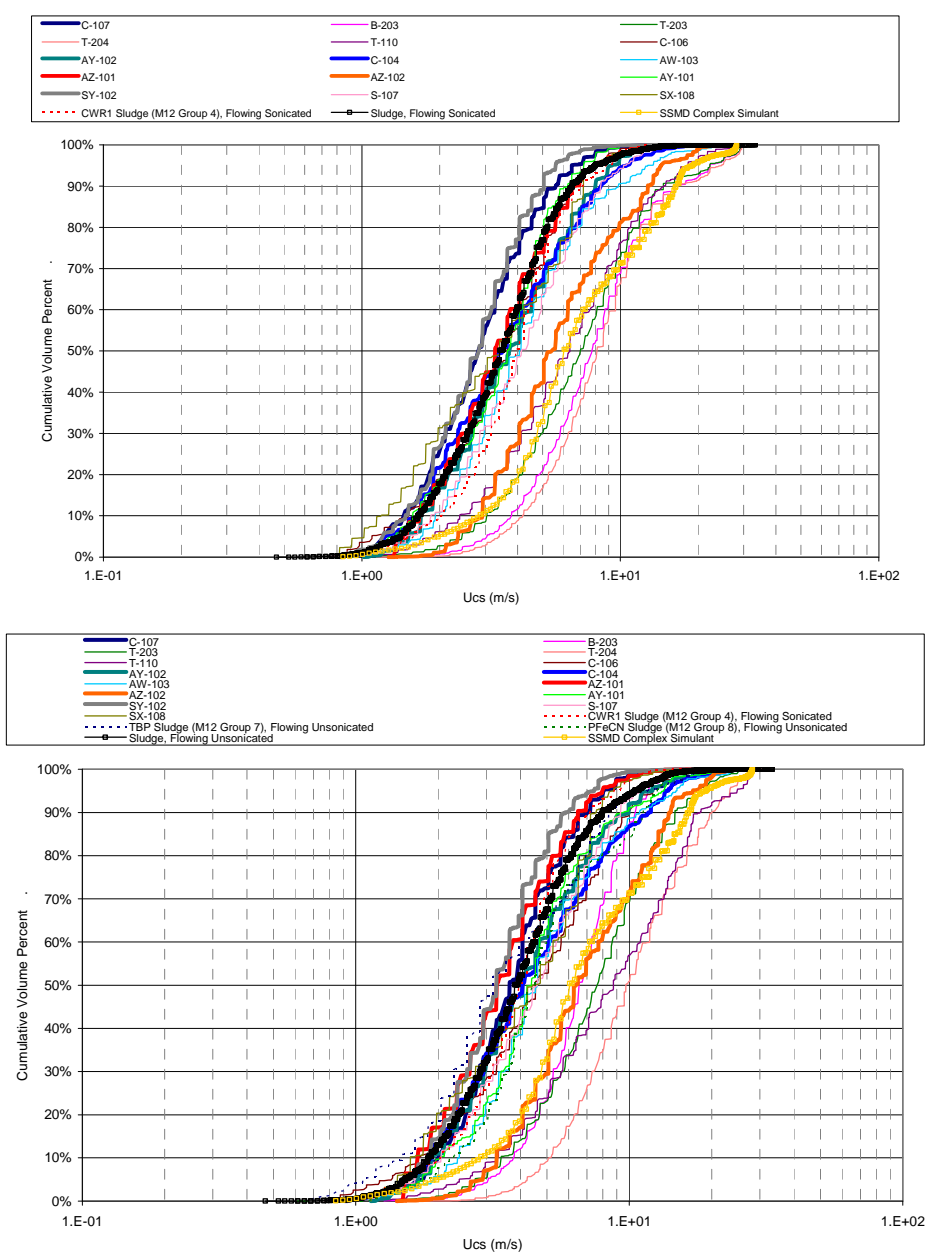

\begin{tabular}{|c|c|c|c|c|}
\hline - $\mathrm{c} \cdot 107$ & 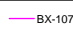 & $-\mathrm{T}-104$ & ${ }^{\mathrm{B}-201}$ & $-_{\mathrm{B}-111}$ \\
\hline - $\mathrm{T} \cdot 111$ & - $_{\mathrm{AY}-102}$ & 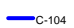 & C.103 & 一 $_{\mathrm{AZ} \cdot 101}$ \\
\hline - ${ }_{A Z-102}$ & $-\mathrm{U} \cdot 110$ & 一 SY-102 $_{\text {SY }}$ & $\rightarrow$ Sludge & $=$ SSMD Complex Simulant \\
\hline
\end{tabular}

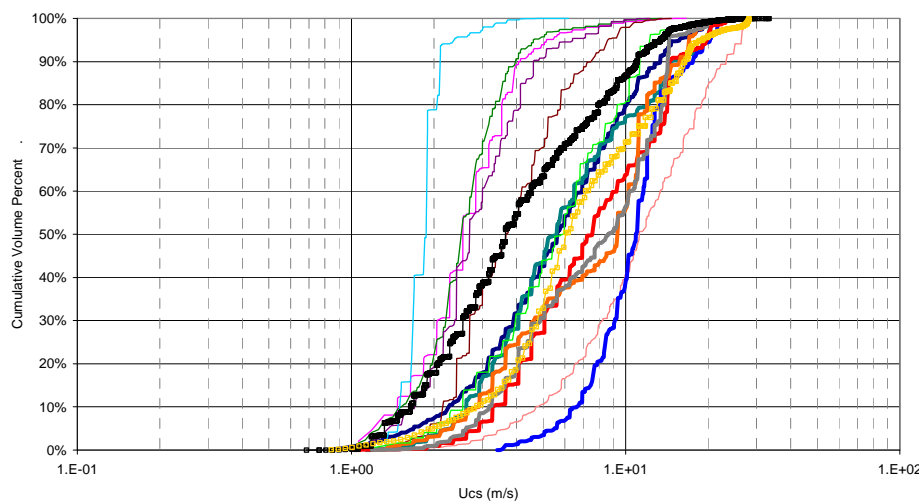

Figure 4.6. PJM Critical Suspension Velocity for Non-Cohesive Solids Comparison. Top: Flowing Sonicated; Middle: Flowing Unsonicated, Bottom: No-flow Unsonicated. SSMD simulant, gold line and symbols; composite PSDD, black line and symbol; bold lines denote the tanks common to all three PSDD types. 

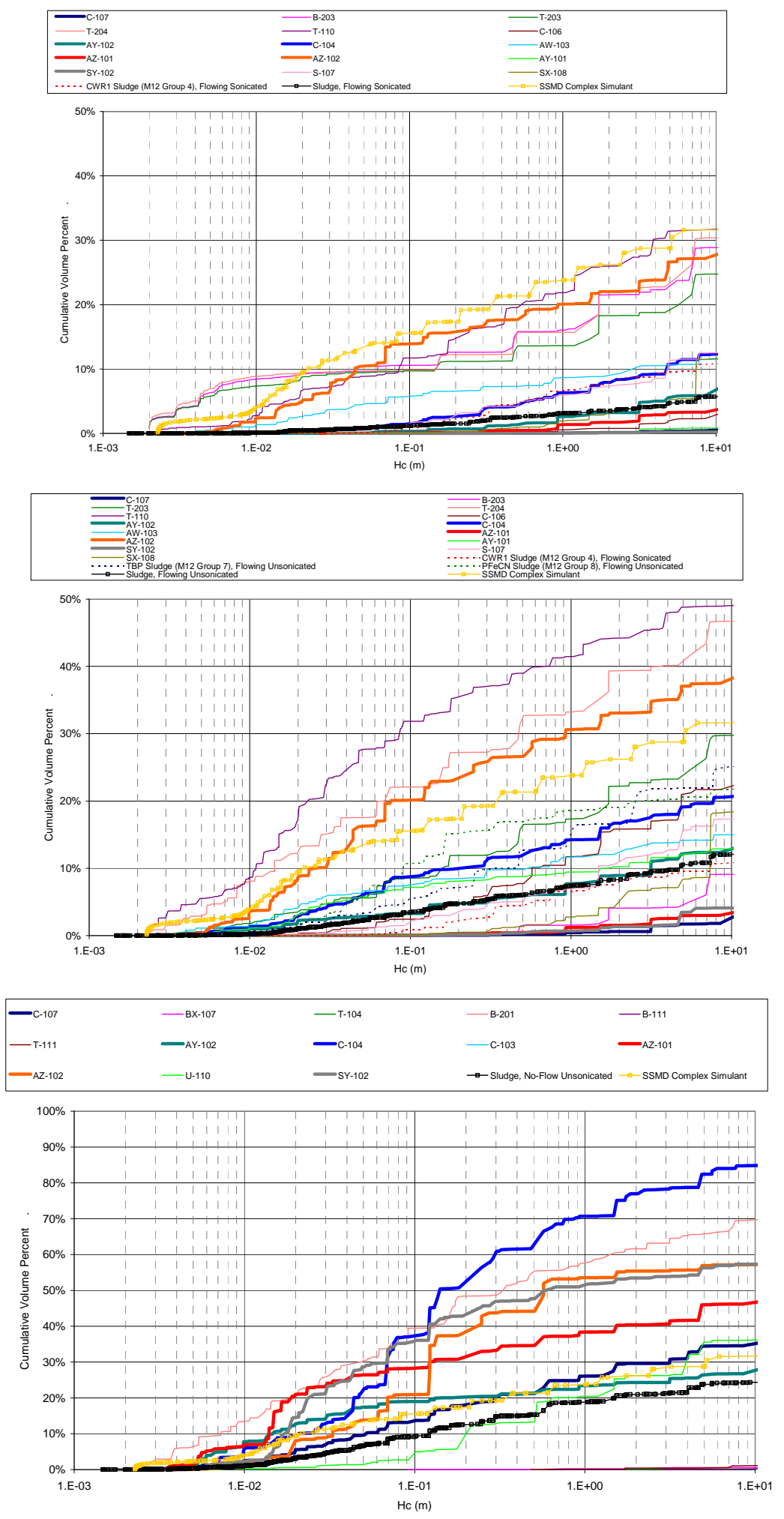

Figure 4.7. PJM Cloud Height for Non-Cohesive Solids Comparison. Top: Flowing Sonicated; Middle: Flowing Unsonicated; Bottom: No-flow Unsonicated. SSMD simulant, gold line and symbols; composite PSDD, black line and symbol; bold lines denote the tanks common to all three PSDD types. 

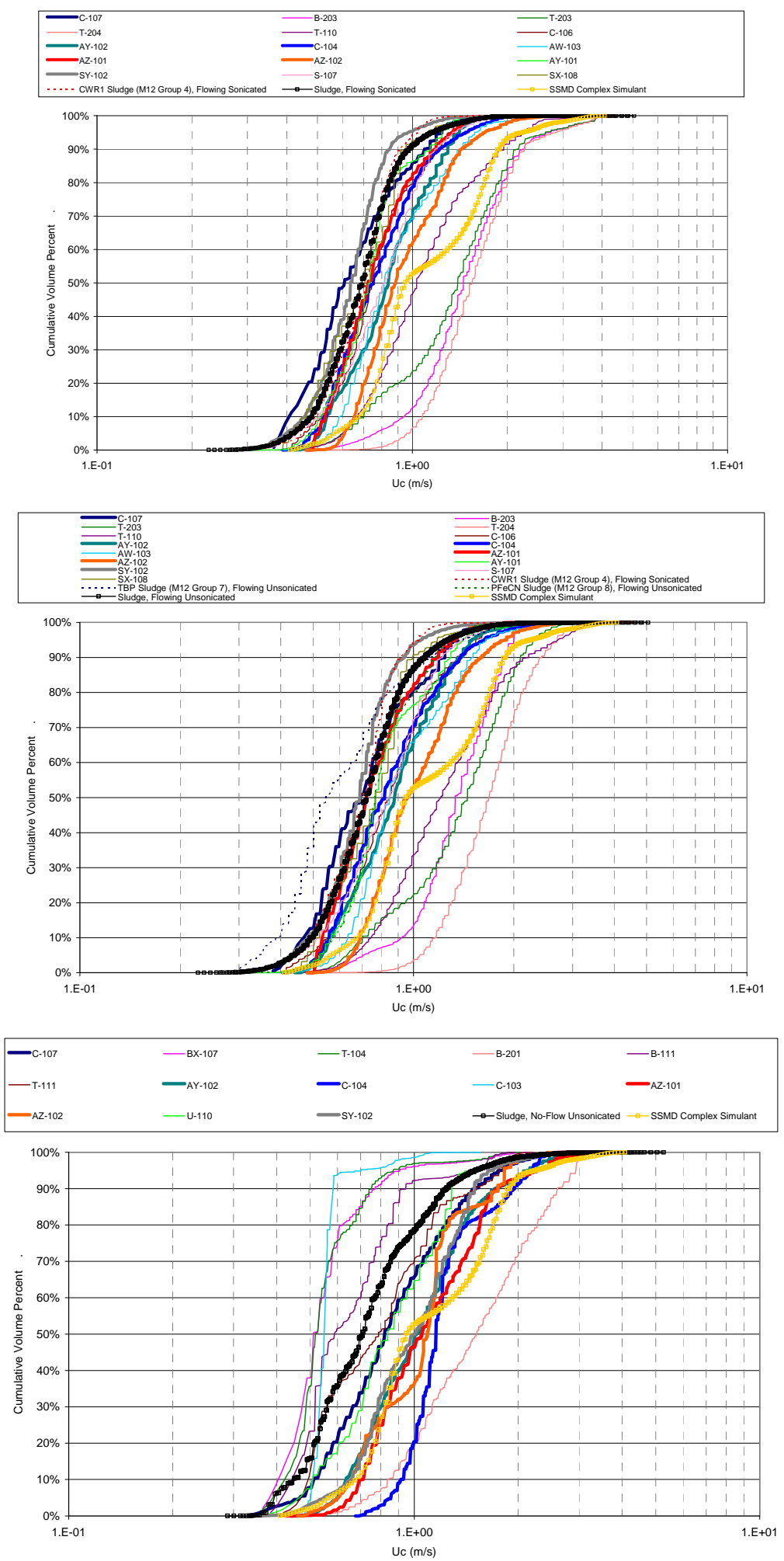

Figure 4.8. Pipeline Critical Transport Velocity Comparison. Top; Flowing Sonicated; Middle: Flowing Unsonicated; Bottom: No-flow Unsonicated. SSMD simulant, gold line and symbols; composite PSDD, black line and symbol; bold lines denote the tanks common to all three PSDD types. 
The result that the five-part SSMD simulant is near the "upper end" of the waste characterizations for the metrics considered suggests that the simulant is reasonably challenging compared to the waste strictly on terms of the number of tanks/waste types.. However, the limited fraction of the waste that has been characterized must be considered. In Table 4.1, the fractions of the total Hanford UDS inventory (including both sludge and saltcake) and of the Hanford sludge UDS inventory that have been characterized are listed by PSD type. ${ }^{(6)}$ Less than $5 \%$ and $20 \%$ of the total and sludge inventories are characterized by the PSDDs.

It may further be considered whether the characterized Hanford waste, even though limited, is representative of the potential variation in the waste. This concept is evaluated by considering the variation in tank PSDDs for a given waste type. If the waste of a given waste type can be well represented by a PSDD of that waste type, it may be possible that the potential variation in the waste is represented by the characterized material. Conversely, if there is PSDD variation within a given waste type, it is possible that the variation in the characterized waste under-represents the variation of the waste inventory. There is limited data for this evaluation, with all three of the PSDD types (Flowing Sonicated, Flowing Unsonicated, and No-Flow Unsonicated) including only two waste types that have characterizations for more than a single tank containing at least $70 \%$ by volume of that waste type. The metric of settling velocity is utilized in this comparison; see Figure 4.9 through Figure 4.11.

Figure 4.9 and Figure 4.10 show the calculated settling velocities for concurrent tanks and waste types for the Flowing Sonicated and Flowing Unsonicated PSDDs. The bold lines designate the $\mathrm{P} 3^{(7)}$ sludge waste type, and the fine lines designate the 224 Post- $1949^{(8)}$ sludge waste type. For the 224 Post1949 sludge waste type, $17 \%$ is represented by the waste in tanks B-203, T-203, and T-204, and 100\% of the P3 sludge waste type is represented by AZ-101 and AZ-102. For the No-Flow Unsonicated PSDD, Figure 4.11, bold lines again designate the P3 sludge waste type (100\%, AZ-101 and AZ-102), and the fine lines now indicate the $1 \mathrm{C}^{(9)}$ sludge waste type (29\%, BX-107 and T-104). In all figures, the composites and simulant are shown for reference. While there is some relative similarity in the PSDDs for the waste types of the No-Flow Unsonicated type, the variation in the PSDDs for a given waste type in the Flowing Sonicated and Flowing Unsonicated types is broad. Thus, it is possible that the variation in the limited characterization of the waste under-represents the variation of the entire waste inventory.

Table 4.1. Hanford UDS Volume Characterized by PSDDs

\begin{tabular}{cccc}
\hline & Flowing Sonicated & $\begin{array}{c}\text { PSD type } \\
\text { Flowing Unsonicated }\end{array}$ & No-flow Unsonicated \\
\hline $\begin{array}{c}\text { UDS volume characterized } \\
\text { by PSDDs/Total Hanford } \\
\text { UDS volume }\end{array}$ & $3.0 \%$ & $4.1 \%$ & $3.8 \%$ \\
$\begin{array}{c}\text { UDS volume characterized } \\
\text { by PSDDs/Total Hanford } \\
\text { sludge UDS volume }\end{array}$ & $13.8 \%$ & $18.8 \%$ & $17.4 \%$ \\
\hline
\end{tabular}

(6) Sludge and saltcake as designated by the waste type catagory.

(7) P3 sludge is high level waste from Plutonium Uranium Recovery and Extraction between 1983 and 1990.

(8) 224 Post 1949 waste is lanthanum fluoride process "224 Building" waste (1950-1956)

(9) 1C waste is BiPO4 first cycle decontamination waste (1944-1956) 


\begin{tabular}{|c|c|c|c|}
\hline$-B-203$ & $\begin{array}{c}224 \text { Post-19 } \\
\text { _ T-203 }\end{array}$ & $\longrightarrow$ T-204 & \\
\hline$-A Z-101$ & P3, 100\% $\longrightarrow A Z-102$ & $\rightarrow$ Sludge & Elowing Sonicated \\
\hline
\end{tabular}

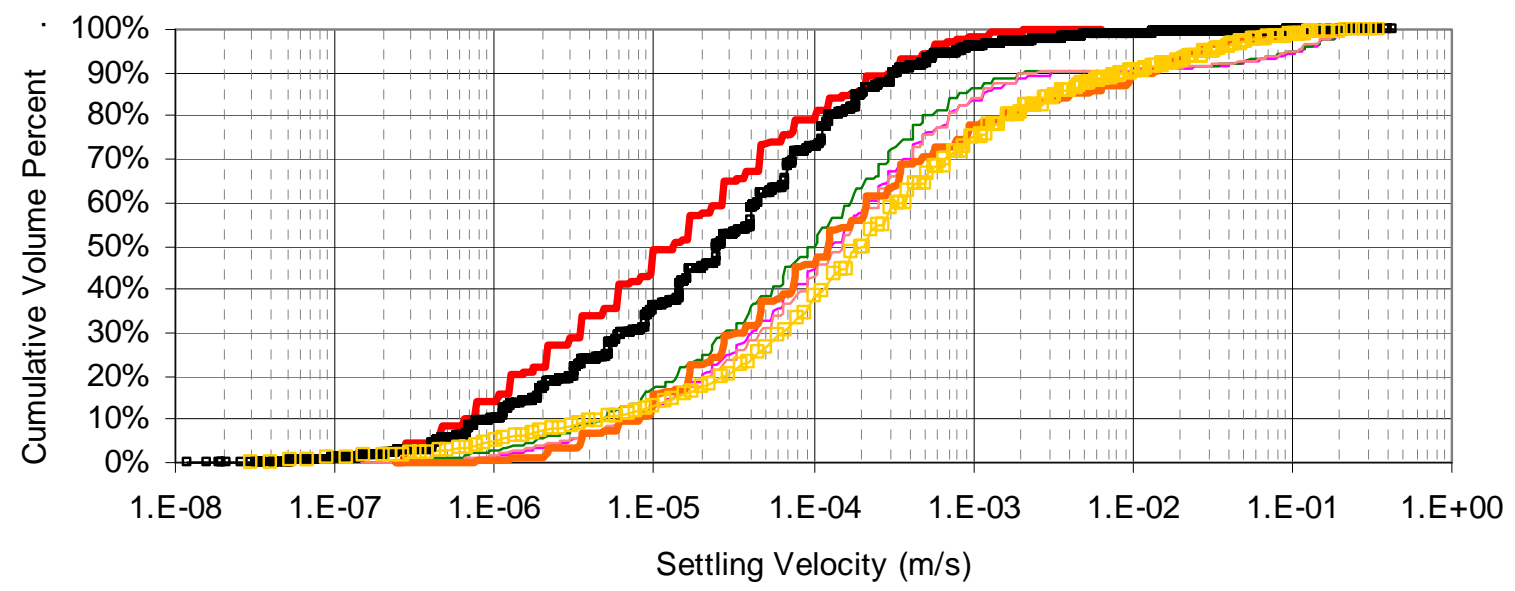

Figure 4.9. PSDD Variation, Flowing Sonicated

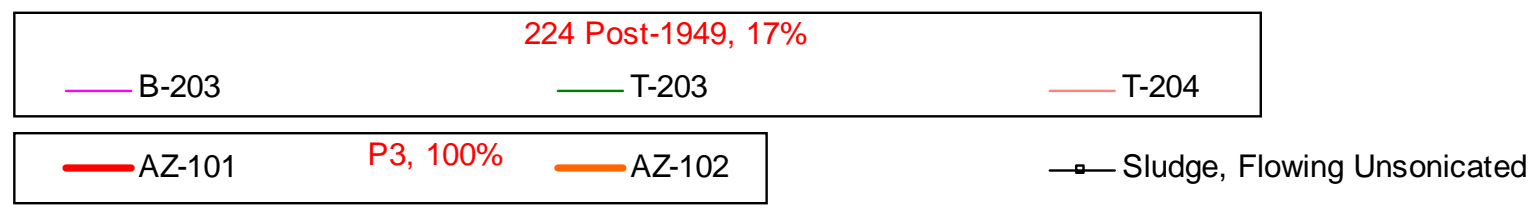

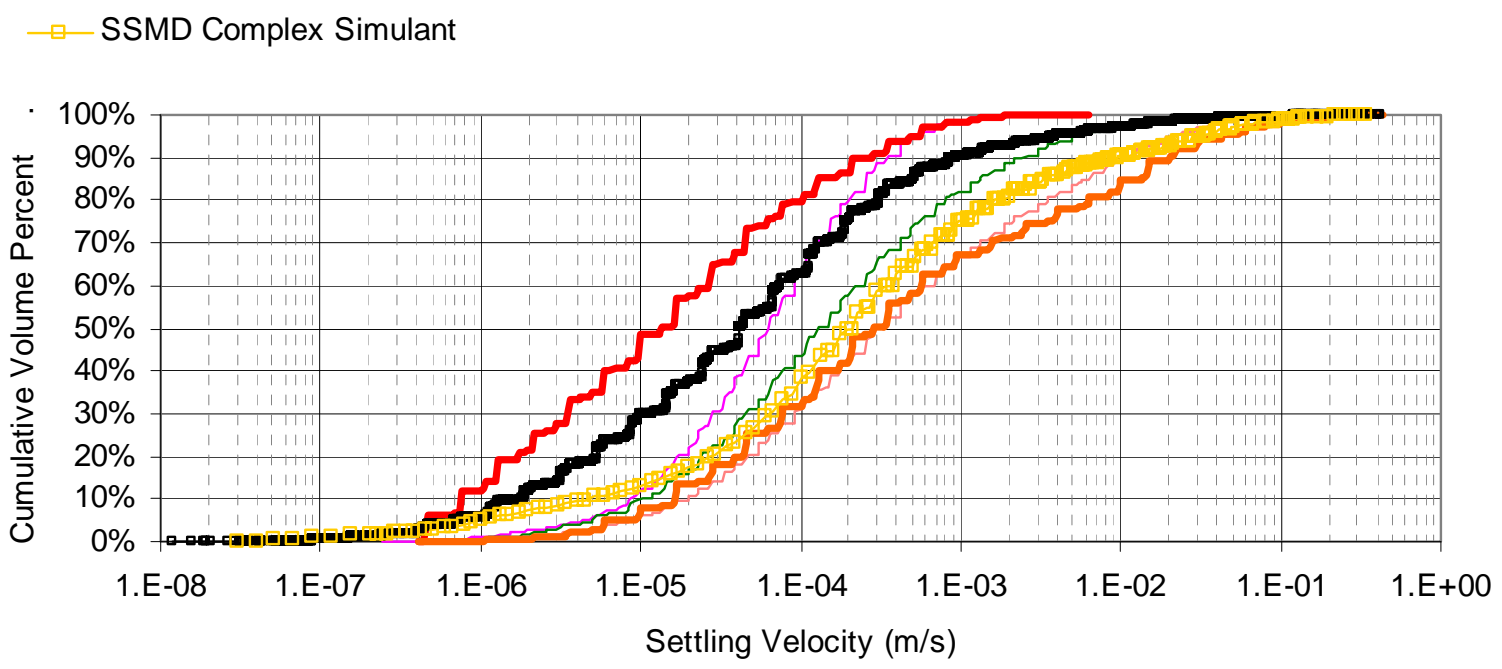

Figure 4.10. PSDD Variation, Flowing Unsonicated 


\begin{tabular}{|lcc|}
\hline BX-107 & 1C, 29\% & T-104 \\
\hline \hline AZ-101 & P3, 100\% \\
\hline & - AZ-102 \\
\hline — Sludge, No-Flow Unsonicated & - SSMD Complex Simulant
\end{tabular}

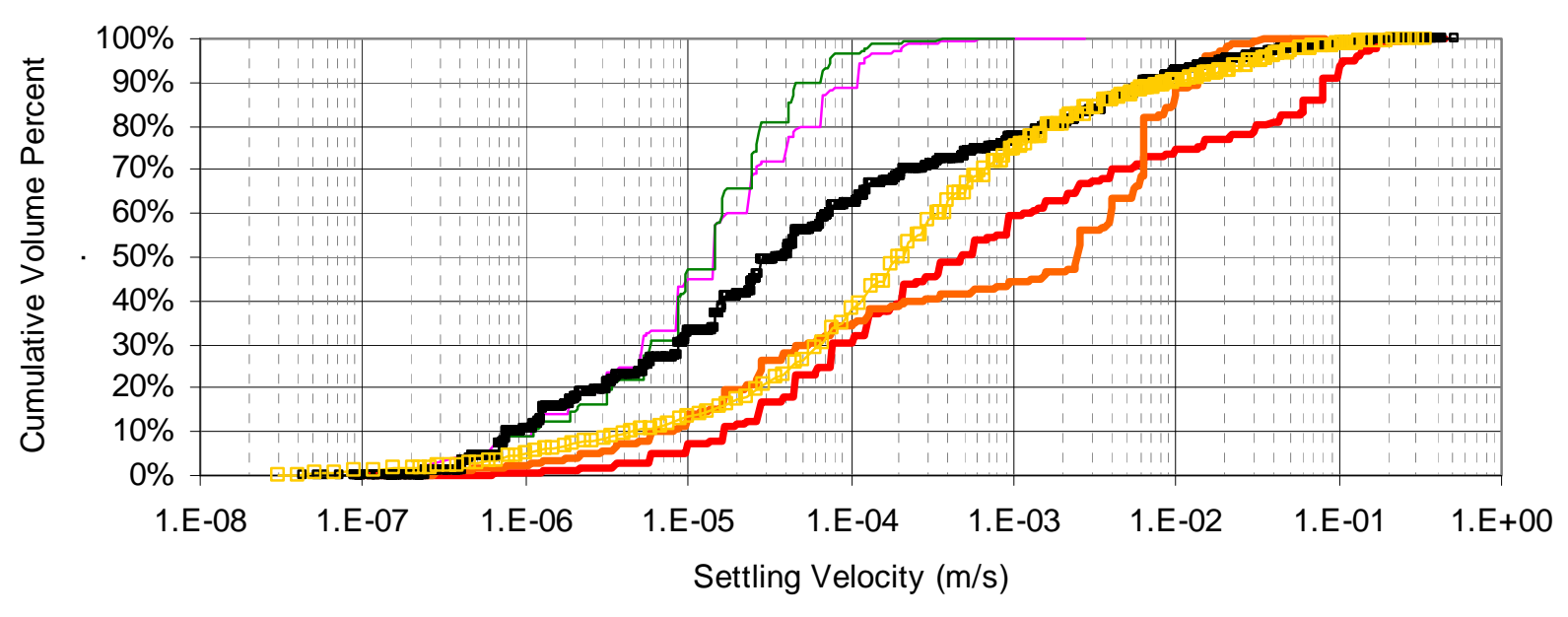

Figure 4.11. PSDD Variation, No-Flow Unsonicated

Summary of the results in Figure 4.1 through Figure 4.8 is made relative the Hanford waste inventory by volume and characterized fractions via two summary metrics:

1. Tanks and waste types for which at least $50 \%$ by volume of a given metric result are more challenging than the result of the five-part SSMD simulant. The $50 \%$ does not have to be contiguous.

2. Tanks and waste types for which a given metric result are more challenging than the $90^{\text {th }}$-percentileand-above results of the five-part SSMD simulant. Any exceedance above the $90^{\text {th }}$ percentile qualifies.

Examples of these two summary metrics are provided in Figure 4.12 and Figure 4.13. For Summary Metric 1, there are three tanks as designated in Figure 4.12 in which at least $50 \%$ by volume of particulate exceeds the simulant (T-204, AZ-102, and T-110). For Summary Metric 2, there are five tanks and one waste type as designated in Figure 4.13 that qualify (PFeCN Sludge (M12 Group 8), AZ-102, T-110, T204, AW-103, and AY-101). 

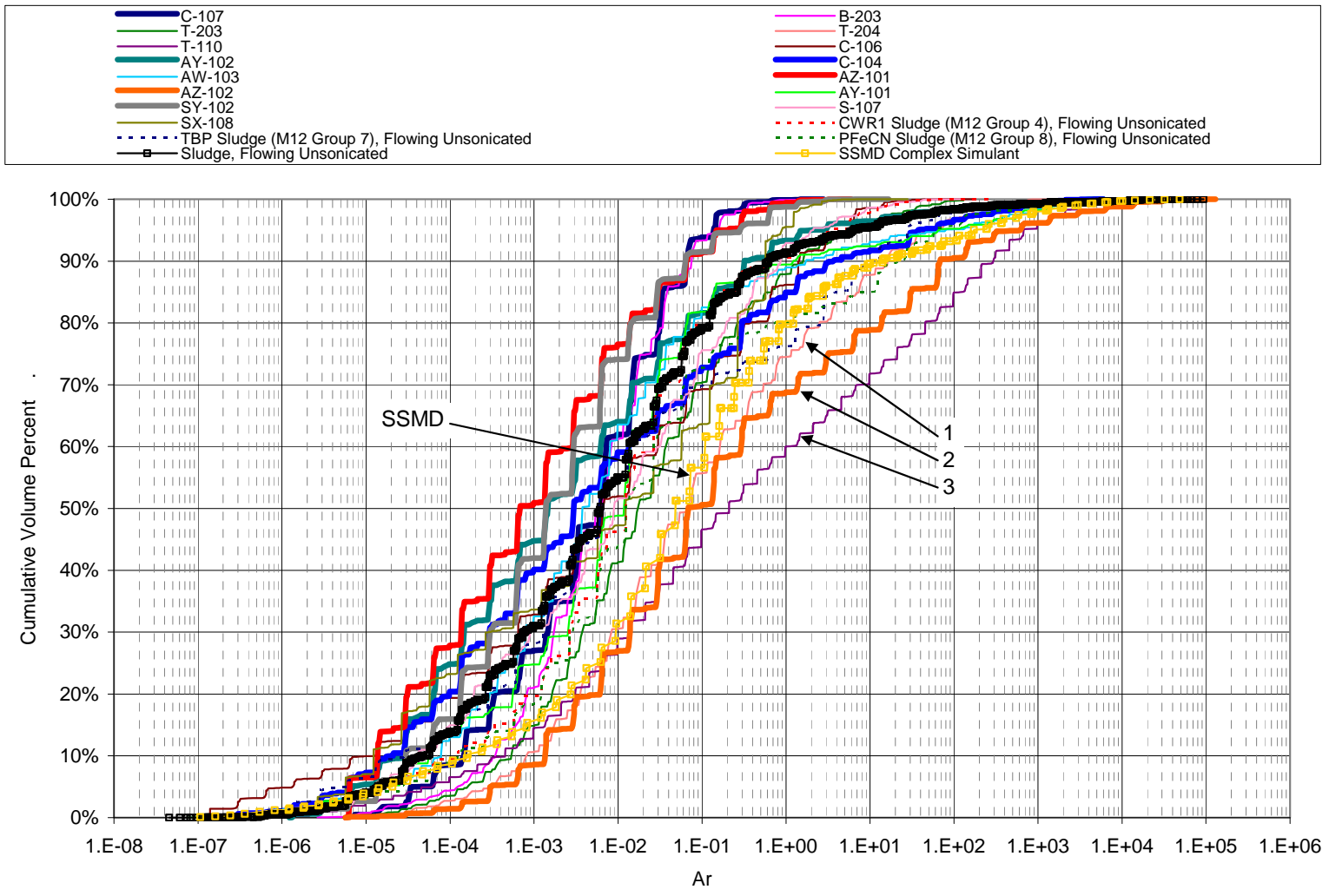

Figure 4.12. Summary Metric 1 Example, Archimedes number, Flowing Unsonicated 

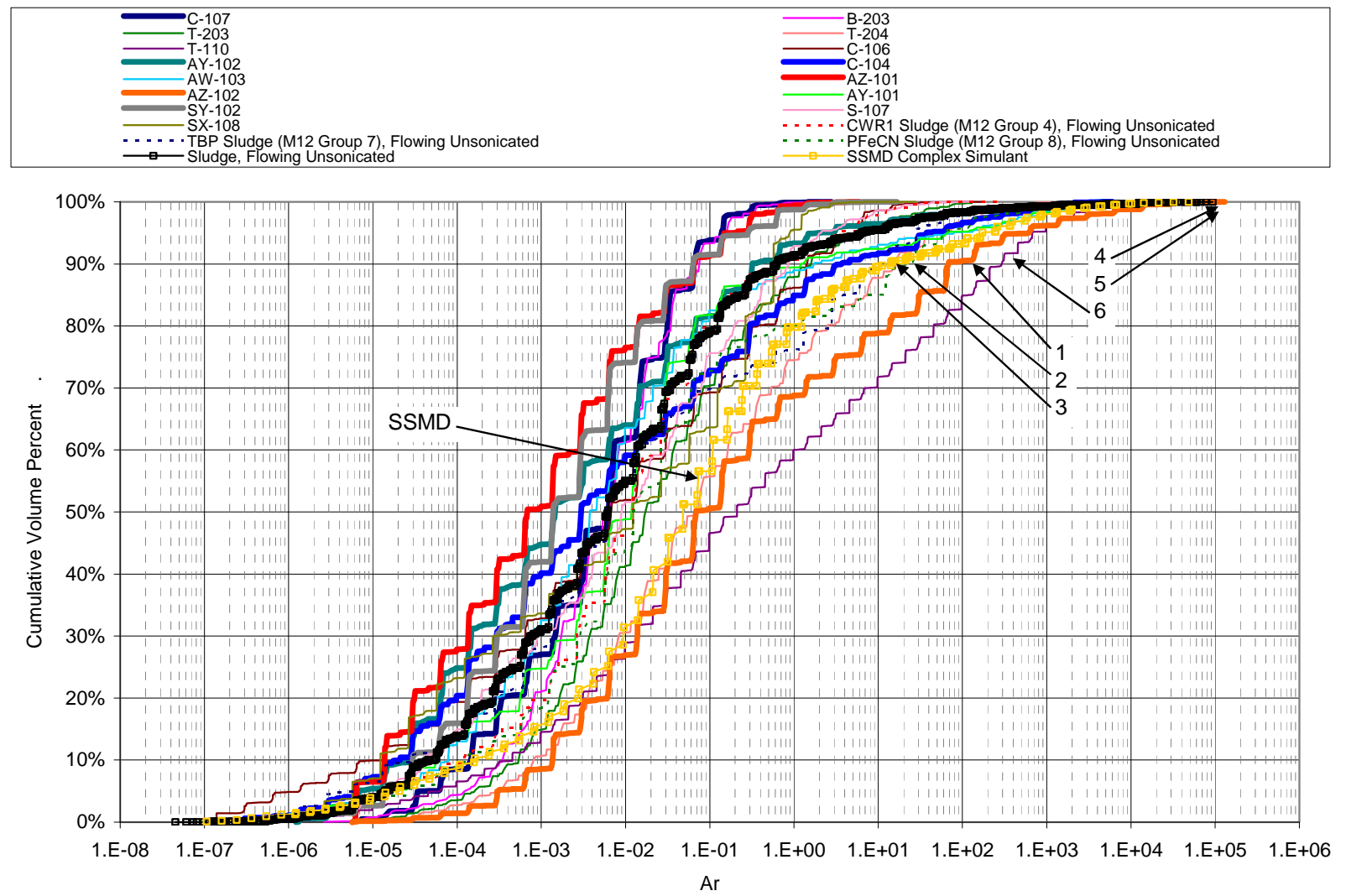

Figure 4.13. Summary Metric 2 Example, Archimedes number, Flowing Unsonicated

The summary metric results are provided in Table 4.2 and Table 4.3. For Summary Metric 1, (tanks and waste types for which at least $50 \%$ by volume of a given metric result are more challenging than the result of the five-part SSMD simulant):

- Similar tanks and waste types are more challenging than the five-part SSMD simulant independent of the waste operation metric

- Tanks and waste types exceeding the five-part SSMD simulant comprise less than $43 \%$ by volume of the characterized Hanford sludge UDS inventory (maximum of all PSDD types, less than $20 \%$ of the Hanford sludge inventory is characterized by the PSDDs).

- The most "restrictive" metric is the Archimedes number (similar to settling velocity).

For Summary Metric 2, (tanks and waste types for which a given metric result are more challenging than the $90^{\text {th }}$-percentile-and-above results of the five-part SSMD simulant):

- Similar tanks and waste types are more challenging than the five-part SSMD simulant independent of the waste operation metric

- Tanks and waste types exceeding the five-part SSMD simulant comprise less than $56 \%$ by volume of the characterized Hanford sludge UDS inventory (maximum of all PSDD types, less than $20 \%$ of the Hanford sludge inventory is characterized by the PSDDs).

- The most "restrictive" metric is cloud height, followed by the Archimedes number and the PJM critical suspension velocity. 
Table 4.2. Summary Metric 1 Results

\begin{tabular}{|c|c|c|c|}
\hline & \multicolumn{3}{|c|}{ PSD type } \\
\hline & Flowing Sonicated & Flowing Unsonicated & No-flow Unsonicated \\
\hline \multicolumn{4}{|c|}{ Number of Tanks and Percent by Volume of Hanford UDS that Exceeds > 50\% SSMD } \\
\hline \multirow{2}{*}{ Metric } & \multicolumn{3}{|c|}{ Number of Tanks } \\
\hline & \multicolumn{3}{|c|}{$\mathbf{V}_{50 \%>\text { SSMD }} / \mathbf{V}_{\text {Total PSDD UDS }}$} \\
\hline \multirow{2}{*}{$\mathrm{U}_{\mathrm{T}}(\mathrm{m} / \mathrm{s})$} & $\mathbf{0}$ & 3 & 7 \\
\hline & $0.0 \%$ & $3.8 \%$ & $42.4 \%$ \\
\hline \multirow{2}{*}{ Ar } & $\mathbf{0}$ & 3 & 7 \\
\hline & $0.00 \%$ & $3.8 \%$ & $42.36 \%$ \\
\hline \multirow[b]{2}{*}{$\tau_{\mathrm{c}}(\mathrm{Pa})$} & 2 & 5 & 5 \\
\hline & $0.51 \%$ & $4.2 \%$ & $24.25 \%$ \\
\hline \multirow{2}{*}{$\mathrm{N}_{\mathrm{js}}(\mathrm{rps})$} & 3 & 4 & 3 \\
\hline & $0.72 \%$ & $1.7 \%$ & $13.44 \%$ \\
\hline \multirow{2}{*}{$\mathrm{U}_{\mathrm{n}}(\mathrm{m} / \mathrm{s})$} & 3 & 4 & 3 \\
\hline & $0.72 \%$ & $1.7 \%$ & $13.4 \%$ \\
\hline \multirow{2}{*}{$\mathrm{U}_{\mathrm{CS}}(\mathrm{m} / \mathrm{s})$} & 3 & 5 & 5 \\
\hline & $0.72 \%$ & $4.2 \%$ & $24.25 \%$ \\
\hline \multirow{2}{*}{$\mathrm{H}_{\mathrm{C}}(\mathrm{m})$} & $\mathbf{0}$ & 3 & 5 \\
\hline & $0.00 \%$ & $3.8 \%$ & $24.25 \%$ \\
\hline \multirow{2}{*}{$\mathrm{U}_{\mathrm{C}}(\mathrm{m} / \mathrm{s})$} & 4 & 4 & 2 \\
\hline & $2.29 \%$ & $1.7 \%$ & $11.00 \%$ \\
\hline
\end{tabular}

Table 4.3. Summary Metric 2 Results

\begin{tabular}{|c|c|c|c|}
\hline & \multicolumn{3}{|c|}{ PSD type } \\
\hline & Flowing Sonicated & Flowing Unsonicated & No-flow Unsonicated \\
\hline \multicolumn{4}{|c|}{ Number of Tanks and \% by volume of Hanford UDS that exceeds $>90^{\text {th }}$ percentile SSMD } \\
\hline \multirow{2}{*}{ Metric } & \multicolumn{3}{|c|}{ Number of Tanks } \\
\hline & \multicolumn{3}{|c|}{$\mathbf{V}_{\mathbf{9 0 t h}>\text { SSMD }} / \mathbf{V}_{\text {Total PSDD UDS }}$} \\
\hline \multirow{2}{*}{$\mathrm{U}_{\mathrm{T}}(\mathrm{m} / \mathrm{s})$} & 5 & 4 & 7 \\
\hline & $5.7 \%$ & $21.4 \%$ & $40.6 \%$ \\
\hline \multirow{2}{*}{ Ar } & 5 & 6 & 7 \\
\hline & $5.69 \%$ & $38.1 \%$ & $40.59 \%$ \\
\hline \multirow{2}{*}{$\tau_{\mathrm{c}}(\mathrm{Pa})$} & 3 & 3 & 6 \\
\hline & $0.72 \%$ & $3.8 \%$ & $37.91 \%$ \\
\hline \multirow{2}{*}{$\mathrm{N}_{\mathrm{js}}(\mathrm{rps})$} & 4 & 4 & 6 \\
\hline & $2.29 \%$ & $4.0 \%$ & $37.91 \%$ \\
\hline \multirow{2}{*}{$\mathrm{U}_{\mathrm{n}}(\mathrm{m} / \mathrm{s})$} & 4 & 4 & 6 \\
\hline & $2.29 \%$ & $4.0 \%$ & $37.9 \%$ \\
\hline \multirow{2}{*}{$\mathrm{U}_{\mathrm{CS}}(\mathrm{m} / \mathrm{s})$} & 5 & 8 & 6 \\
\hline & $18.80 \%$ & $46.2 \%$ & $37.91 \%$ \\
\hline \multirow{2}{*}{$\mathrm{H}_{\mathrm{C}}(\mathrm{m})$} & 5 & 8 & 7 \\
\hline & $18.80 \%$ & $55.8 \%$ & $40.59 \%$ \\
\hline \multirow{2}{*}{$\mathrm{U}_{\mathrm{C}}(\mathrm{m} / \mathrm{s})$} & 4 & 4 & 6 \\
\hline & $2.29 \%$ & $1.7 \%$ & $37.91 \%$ \\
\hline
\end{tabular}




\subsection{SSMD Simulant Adjustment}

As discussed in Section 4.1, the five-part SSMD simulant is near the "upper-end" of the waste characterizations for the metrics considered, but there may be a significant fraction of the waste that is more challenging. The Archimedes number is a "restrictive" waste operation metric (i.e. the calculated Archimedes numbers for the PSDDs of certain tanks/waste types exceed some or all of those calculated for the five-part SSMD simulant) for both of the summary metrics (see Table 4.2 for Summary Metric 1 results, and Table 4.3 for Summary Metric 2). Adjustment of the five-part SSMD simulant component concentrations such that de minimis fractions of the calculated Ar numbers for tanks and waste types exceed those of the simulant is considered. Prior testing for the SSMD project has shown that the silicon carbide component has erosive properties that are problematic for the test equipment. The silicon carbide component is therefore excluded from this example simulant adjustment evaluation. ${ }^{(10)}$

A limited fraction of the waste is characterized, and it is possible that the variation in the limited characterization of the waste under-represents the variation of the waste inventory; see Section 4.1. Thus, the tanks with the maximum Archimedes number results at any given percentile from the most restrictive PSDD type, No-Flow Unsonicated, are used as the "target" for the simulant adjustment. From Figure 4.2 (see also Figure A.6, Appendix A), these tanks are C-104 up to nominally the $55^{\text {th }}$ percentile, SY-102 from nominally the $55^{\text {th }}$ to $80^{\text {th }}$ percentile, and AZ-101 for the remainder of the UDS volume. The Ar number results for these tanks, together with the composite and original 5-part SSMD simulant, are shown in Figure 4.14. The Archimedes number ranges for the simulant components, including the silicon carbide, are also shown in the figure, with their vertical position indicating their volume concentrations in the original simulant from Table 3.2. Note that the probabilities of the components over the given Archimedes number ranges are not constant as is illustrated by the PSDs of Figure 3.5 through Figure 3.9. The upper and lower Archimedes number ranges for the target tanks of Figure 4.14 are addressed by the stainless steel and gibbsite respectively.

Using four components of the original five-part SSMD simulant, stainless steel, gibbsite, zirconium oxide, and bismuth oxide, adjustments to the concentrations as provided in Table 4.4 yield a calculated Archimedes number distribution that approximates that of the previously-identified maximum tanks, Figure 4.15.

As the Archimedes number metric used for the example simulant adjustment is "restrictive", the adjusted SSMD simulant will be more challenging relative to other metrics. For example, from Table 4.2 and Table 4.3, a minimally restrictive metric is the just-suspended impeller speed, $\mathrm{N}_{\mathrm{js}}$ (Equation (2.8)). Comparison of the adjusted SSMD simulant to this metric is provided in Figure 4.16, and clearly the adjusted SSMD exceeds the characterized waste for $\mathrm{N}_{\mathrm{js}}$. The difference in the metric results is probably exacerbated by the difference in particle density affecting the different functionalities of $\mathrm{Ar}$ and $\mathrm{N}_{\mathrm{js}}$ with particle size and density $\left(\mathrm{Ar} \rightarrow(\mathrm{S}-1) \mathrm{d}^{3}, \mathrm{~N}_{\mathrm{js}} \rightarrow(\mathrm{S}-1)^{0.45} \mathrm{~d}^{0.2}\right)$. As given in Section 3.2, the concentration-weighted average particle density of the original SSMD simulant is $3.96 \mathrm{~g} / \mathrm{mL}$, while the adjusted SSMD simulant of Table 4.4 has a volume-weighted average density of $7.32 \mathrm{~g} / \mathrm{mL}$. Thus it is possible that an alternate simulant could be developed, with increased particle size and lower particle density components, that has Archimedes number results that approximate the maximum tanks as in Figure 4.15 but would be less restrictive in terms of $\mathrm{N}_{\mathrm{js}}$.

(10) Personal communication from MJ Thien, WRPS, to BE Wells and PA Gauglitz, PNNL, July 25, 2011. 
An alternate example adjusted simulant is made using the four components of Table 4.4 with an additional component of un-sieved sand modified by a 5-fold reduction in size from that of Meyer et al. (2010). The PSD used to represent the un-sieved sand component is provided in Figure 4.17, and the particle density is $2.65(\mathrm{~g} / \mathrm{mL})$. The alternate example adjusted simulant component concentrations as provided in Table 4.5 yield a calculated Archimedes number distribution that approximates that of the identified maximum tanks, Figure 4.18, and the alternate example adjusted simulant is shown to replicate the example adjusted simulant of Table 4.4 and Figure 4.15. However, as expected with a lower volume weighted average density of $4.47 \mathrm{~g} / \mathrm{mL}$ for the example adjusted simulant, the alternate example adjusted simulant is less challenging with respect to the just-suspended impeller speed, Figure 4.19, as compared to the example adjusted simulant of Table 4.4 and Figure 4.16.

Development of an SSMD simulant that addresses the restrictive waste for the metrics concurrently can be achieved by examining the PSDDs of those restrictive wastes to identify the magnitude of the large particle size and/or density that cause the metric values to exceed those of the SSMD simulant. Simulant components that exhibit these traits can then be selected and used to adjust the SSMD simulant composition to more concurrently match the restrictive wastes.

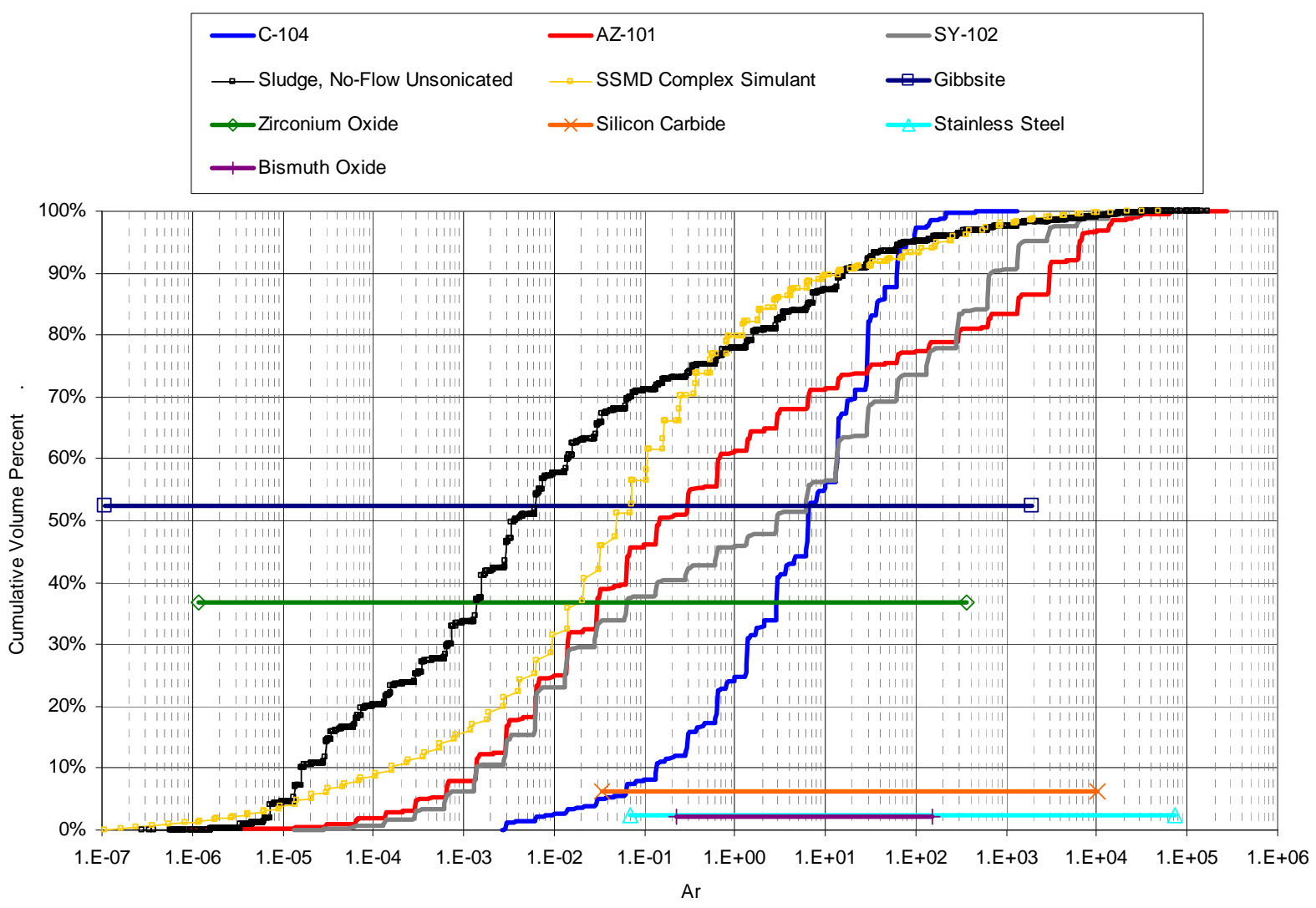

Figure 4.14. Archimedes Numbers for SSMD Simulant Adjustment: Original Simulant, Hanford Waste Composite and "Target" Tanks (No-Flow Unsonicated), and Simulant Components. 
Table 4.4. Example Adjusted SSMD Simulant Composition and Density

\begin{tabular}{|c|c|c|c|c|}
\hline Component & Density $(\mathbf{g} / \mathbf{m L})$ & $\begin{array}{c}\text { Median Particle } \\
\text { Size by Volume } \\
(\boldsymbol{\mu \mathbf { m } )}\end{array}$ & $\begin{array}{c}\text { UDS Mass } \\
\text { Fraction }\end{array}$ & $\begin{array}{c}\text { UDS Volume } \\
\text { Fraction }\end{array}$ \\
\hline Gibbsite & 2.42 & 10 & 0.053 & 0.16 \\
\hline Zirconium Oxide & 5.7 & 12 & 0.062 & 0.08 \\
\hline Stainless Steel & 8 & 128 & 0.350 & 0.32 \\
\hline Bismuth Oxide & 8.9 & 38 & 0.535 & 0.44 \\
\hline
\end{tabular}

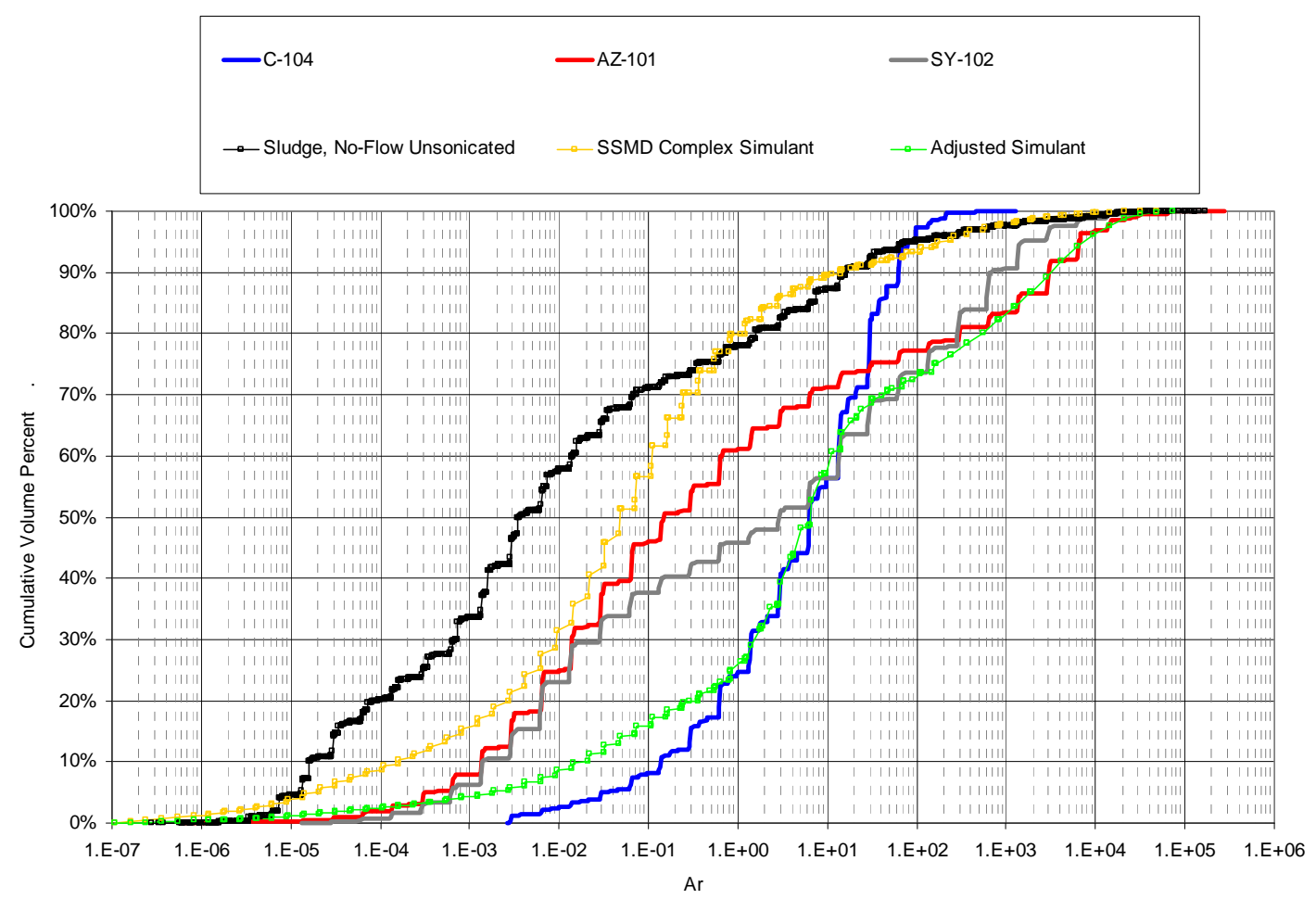

Figure 4.15. Archimedes Numbers for Example Adjusted SSMD Simulant, No-Flow Unsonicated 


\begin{tabular}{|c|c|c|c|}
\hline$\longrightarrow c-107$ & $-B X-107$ & $\longrightarrow \mathrm{T}-104$ & B-201 \\
\hline - B-111 & $\longrightarrow \mathrm{T}-111$ & AY-102 & $\longrightarrow \mathrm{C}-104$ \\
\hline$-\mathrm{C}-103$ & AZ-101 & AZ-102 & $-\mathrm{U}-110$ \\
\hline SY-102 & $\rightarrow$ Sludge, No-Flow Unsonicated & $\because$ SSMD Complex Simulant & $\because$ Adjusted SSMD Simulant \\
\hline
\end{tabular}

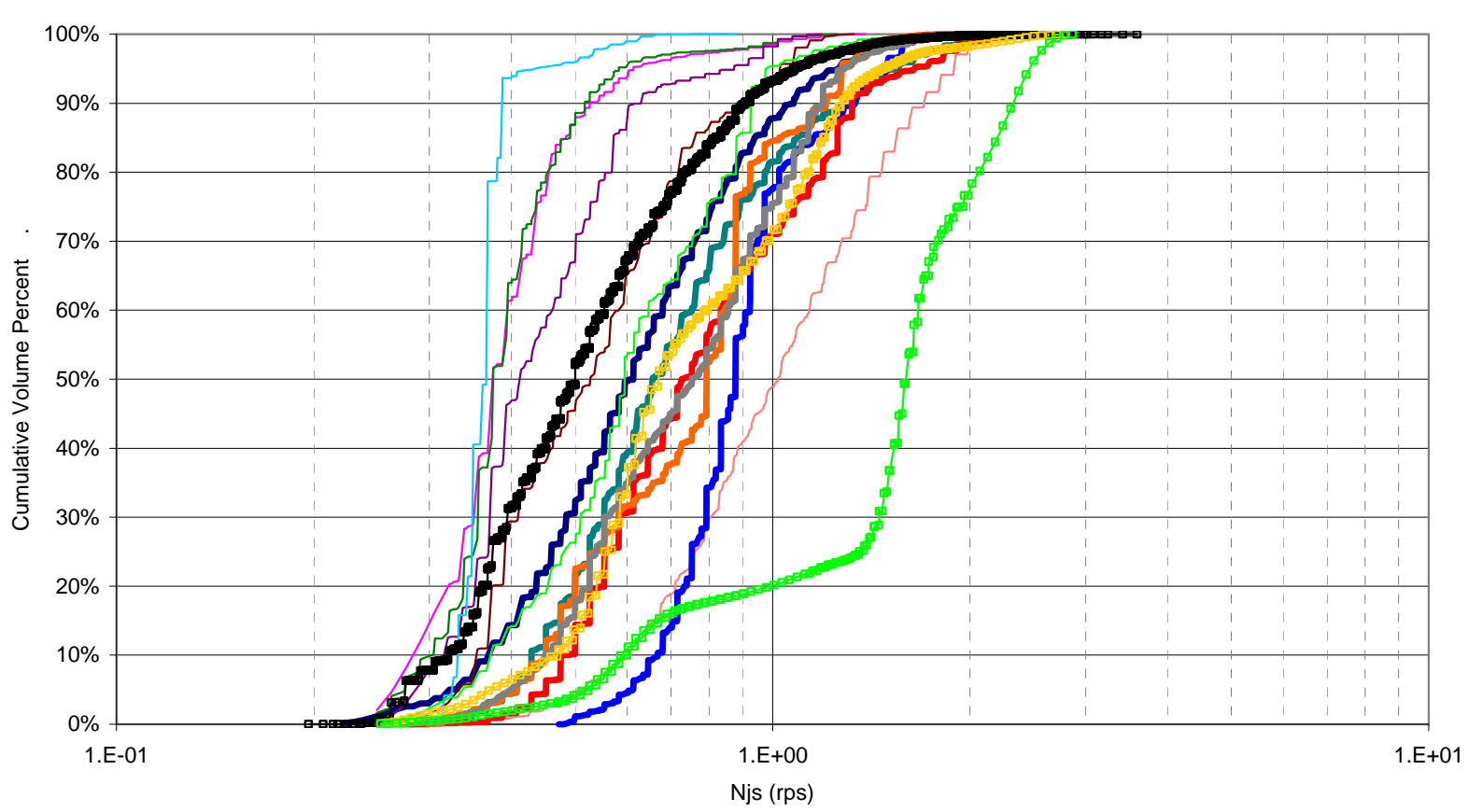

Figure 4.16. Just-Suspended Impeller Speed Comparison for Example Adjusted SSMD Simulant, NoFlow Unsonicated

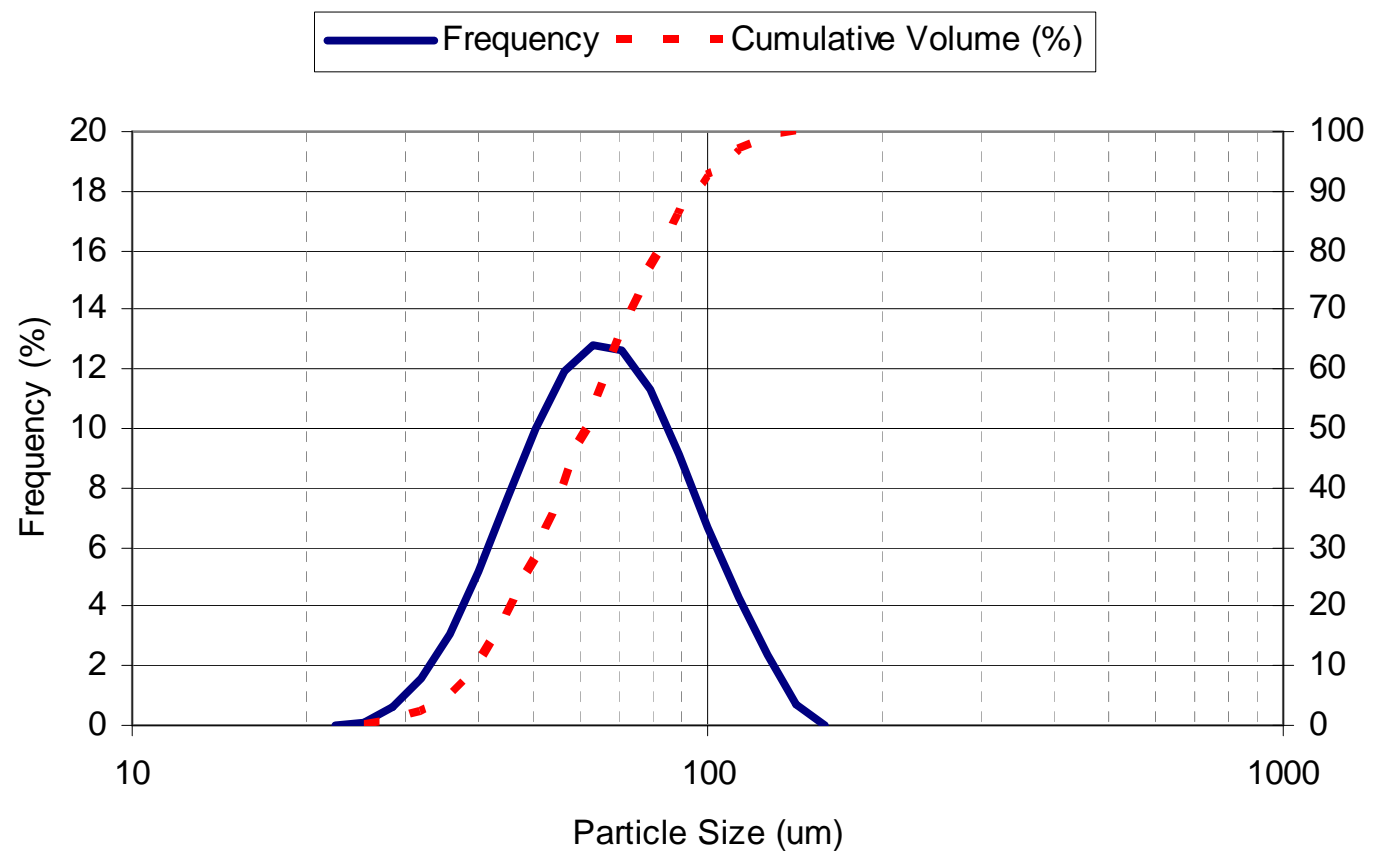

Figure 4.17. Un-sieved Sand Component PSD 
Table 4.5. Alternate Example Adjusted SSMD Simulant Composition and Density

\begin{tabular}{|c|c|c|c|c|}
\hline Component & Density $(\mathbf{g} / \mathbf{m L})$ & $\begin{array}{c}\text { Median Particle } \\
\text { Size by Volume } \\
(\boldsymbol{\mu} \mathbf{m})\end{array}$ & $\begin{array}{c}\text { UDS Mass } \\
\text { Fraction }\end{array}$ & $\begin{array}{c}\text { UDS Volume } \\
\text { Fraction }\end{array}$ \\
\hline Gibbsite & 2.42 & 10 & 0.097 & 0.18 \\
\hline Zirconium Oxide & 5.7 & 12 & 0.038 & 0.03 \\
\hline Stainless Steel & 8 & 128 & 0.572 & 0.32 \\
\hline Bismuth Oxide & 8.9 & 38 & 0.020 & 0.01 \\
\hline Un-sieved Sand & 2.65 & 62 & 0.272 & 0.46 \\
\hline
\end{tabular}

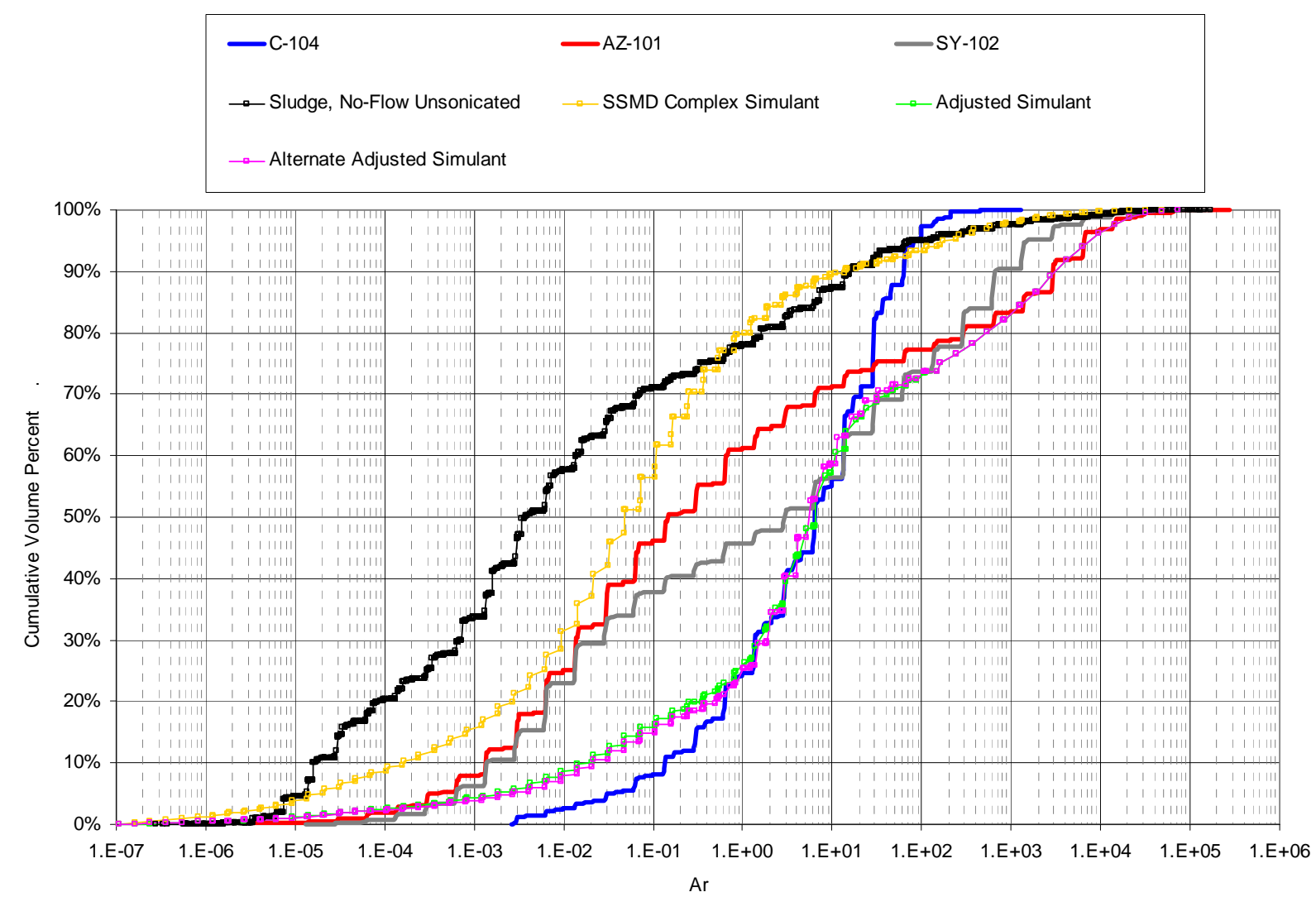

Figure 4.18. Archimedes Number for Alternate Example Adjusted SSMD Simulants, No-Flow Unsonicated 


\begin{tabular}{|c|c|c|c|}
\hline $\mathrm{C}-107$ & BX-107 & $-\mathrm{T}-104$ & B-201 \\
\hline B-111 & $-\mathrm{T}-111$ & ${ }_{A Y-102}$ & $\longrightarrow \mathrm{C}-104$ \\
\hline$-\mathrm{C}-103$ & AZ-101 & $\mathrm{AZ}-102$ & $-\mathrm{U}-110$ \\
\hline SY-102 & $\rightarrow$ Sludge, No-Flow Unsonicated & $\because-$ SSMD Complex Simulant & $\rightarrow-$ Adjusted SSMD Simulant \\
\hline
\end{tabular}

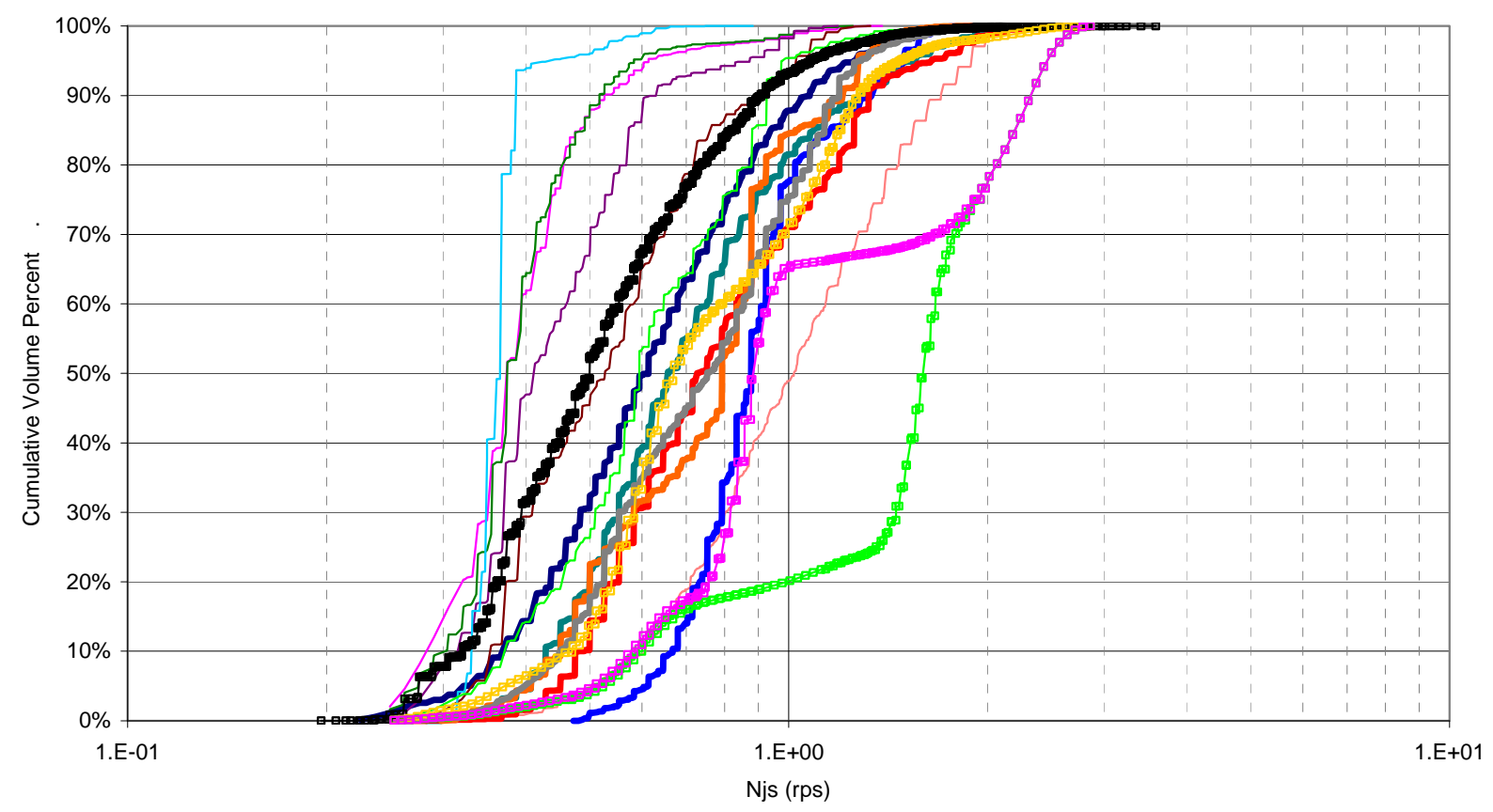

Figure 4.19. Just-Suspended Impeller Speed Comparison for Alternate Example Adjusted SSMD Simulants, No-Flow Unsonicated 


\subsection{Effect of Fluid Properties}

The primary focus of this report is to evaluate how the simulants used in SSMD testing compare with Hanford waste, in particular how the size and density of particles in SSMD testing compare with available data for Hanford waste. The test results show how simulant particles with different densities and sizes are mixed and transferred in batches from mixed tanks. The concentrations of specific particles in transferred waste depend on a number of interacting phenomena that occur during mixing, including the suspension of the particles off the bottom of the tank, the lifting of the particles by the jet, and the subsequent settling of the particles. The properties of the suspending fluid will also affect the mixing and batch transfer performance. Previously, Adamson and Gauglitz (2011) evaluated the role of cohesive particle interactions that result in non-Newtonian slurry rheology and concluded that testing of settling seed particles in water is conservative in terms of the quantity of seed particles transferred. None of the previous studies have specifically evaluated the effect of different fluid properties on mixing and batch transfer performance.

In this section, a simple model will be presented that shows how the effective cleaning radius (ECR) from turbulent jets depends on the fluid and particle properties and the jet velocity. This simple model will be used specifically to predict how the cleaning radius is affected by changes in fluid viscosity and density. This model does not specifically address mixing and batch transfer performance, but it does provide some useful insights.

\subsection{Liquid Density and Viscosity}

As discussed in Section 2.2, a well-established approach for predicting the onset of particle motion, or suspension, from a settled bed is provided by the Shields diagram and the dimensionless Shields parameter (e.g. Vanoni 1975, Julien 1998). The approach gives the wall shear stress in turbulent flow at the onset of particle erosion, which is the critical shear stress for erosion. In a DST with horizontal turbulent jets, the velocity decreases with distance away from the jet. Near the jet, the velocity is typically high enough to exceed the critical shear stress for erosion and there is a radial distance from the jet at which the velocity has decreased sufficiently that erosion no longer occurs. This radial distance is often called the effective cleaning radius (ECR).

There are numerous studies of the effective cleaning radius (see (Gauglitz et al. 2010) for a recent summary), and most of these studies focused on eroding layers of fine-particle (cohesive) materials where the yield stress of the layer was the dominant physical aspect of the layer resisting the erosion. The early result from Churnetski (1982) for turbulent jet erosion of a layer with a yield stress demonstrates the roles of the key parameters:

$$
\mathrm{ECR}=\mathrm{K}^{*} \mathrm{D}_{0} \mathrm{U}_{0}\left(\frac{\rho}{\tau_{\mathrm{y}}}\right)^{\frac{1}{2}}
$$

where $\mathrm{K}^{*}$ is a constant, $\mathrm{D}_{0}$ is the jet diameter, $\mathrm{U}_{0}$ is the jet velocity when fluid exits the jet, $\rho$ is the density of the slurry, and $\tau_{\mathrm{y}}$ is the yield stress of the layer. Note that the ECR is proportional to both the jet velocity and the jet diameter, and increases with the slurry density to the 0.5 power. An equivalent ECR relationship for particles with a critical shear stress for erosion, based on the Shields parameter, can be developed, but the dependence on fluid and particle properties becomes more complicated. 
To develop an expression for the ECR for particles using the Shields parameter, a relationship is first needed for the wall shear stress applied to the layer of particles as a function of the radial distance from the jet. A reasonable approximation for the wall shear stress from turbulent flow past a layer is (Bamberger et al. 2005):

$$
\tau_{\mathrm{w}}=\frac{\mathrm{C}_{\mathrm{f}} \rho \mathrm{U}^{2}}{2}
$$

where $U$ is the velocity of the slurry moving past the layer and $C_{f}$ is a friction coefficient. The friction coefficient depends weakly on velocity, and it will be assumed to be a constant here, which is consistent with previous studies (Bamberger et al. 2005). The following relationship from Rajaratnam (1976) describes how the velocity of a turbulent free jet decreases with distance from the jet

$$
\frac{\mathrm{U}(\mathrm{r})}{\mathrm{U}_{0}}=\frac{6.3}{\frac{\mathrm{r}}{\mathrm{D}_{0}}}
$$

where $U(r)$ is the centerline velocity of the jet at a distance $r$ from the nozzle. The ECR is determined when the wall shear stress is just equal to the critical shear stress for erosion, $\tau_{\mathrm{c}}$ :

$$
\tau_{\mathrm{c}}=\tau_{\mathrm{w}}
$$

Substituting Equations 5.2 and 5.3 into Equation 5.4, combining constants, and rearranging gives the following relationship for the ECR,

$$
\mathrm{ECR}=\mathrm{KD}_{0} \mathrm{U}_{0}\left(\frac{\rho}{\tau_{\mathrm{c}}}\right)^{\frac{1}{2}}
$$

Note that this expression is equivalent to Equation 5.1, where the critical shear stress for erosion has replaced the yield stress and the constant $\mathrm{K}$ is also different.

The Shields diagram summarizes experimental results for the critical shear stress for erosion in terms of the dimensionless Shields parameter $\tau_{*}$ (see Section 2.2). The Shields parameter (see Equation 2.4) is the ratio of critical shear stress for erosion to the buoyant force on the particle and gives a useful relationship for $\tau_{\mathrm{c}}$ with the slurry density $\rho$ replacing the liquid density $\rho_{\mathrm{L}}$

$$
\tau_{\mathrm{C}}=\tau_{*}\left(\rho_{\mathrm{S}}-\rho\right) \mathrm{gd}
$$

The Shields parameter is not a constant, and has a complex dependence on particle diameter and density as shown in Figure 2.3 in terms of $\mathrm{Ar}^{1 / 3}$, or equivalently $\mathrm{D}_{*}$. One comparison that will be discussed below is how different suspending fluids erode and mix $100 \mu \mathrm{m}$ stainless steel particles in water that settle into a layer. As discussed in Section 2.2, for $100 \mu \mathrm{m}$ stainless steel particles in water $\mathrm{D}_{*}=\operatorname{Ar}^{1 / 3} \sim 4$. In this region of the Shields diagram, the relatively simple relationship for $\tau_{*}$ given by Equation (2.7) can be used, giving the following: 


$$
\tau_{\mathrm{C}}=0.131 \mathrm{D}_{*}^{-0.55}\left(\rho_{\mathrm{S}}-\rho\right) \mathrm{gd}
$$

where $\mathrm{D}_{*}=\mathrm{Ar}^{1 / 3}$ with a -0.55 power provides additional effects of particle and fluid properties. In this region of the Shields diagram, the negative power relationship for D* gives a non-intuitive result where this contribution is actually decreasing $\tau_{\mathrm{c}}$ with increased particle diameter. Substituting the definition of Ar given by Equation (2.3) (the liquid density $\rho_{\mathrm{L}}$ is replaced with the slurry density $\rho$ and the liquid kinematic viscosity $v$ is replaced with the slurry kinematic viscosity written as $\mu / \rho$, where $\mu$ is the slurry dynamic viscosity) into Equation (5.7) in combination with Equation (5.5) and collecting like terms gives the following relationship

$$
\mathrm{ECR}=\mathrm{KU}_{0} \mathrm{D}_{0} \rho^{\left(\frac{1}{2}+\frac{0.55}{6}\right)}\left(\rho_{\mathrm{S}}-\rho\right)^{\left(-\frac{1}{2}+\frac{0.55}{6}\right)} \mathrm{d}^{\left(-\frac{1}{2}+\frac{0.55}{2}\right)} \mu^{\left(-\frac{0.55}{3}\right)} \mathrm{g}\left(-\frac{1}{2}+\frac{0.55}{6}\right)
$$

where constants have been combined and the exponents for each of the terms have not been combined to help recognize the origin of the different contributions to the effects of fluid and particle properties on the ECR and to compare this result to Equations (5.1) and (5.5).

For this particular region of the Shields diagram that is appropriate for $100 \mu \mathrm{m}$ stainless steel (SS) particles, Equation (5.8) shows that the ECR increases with slurry density but slightly more strongly than $1 / 2$ power. The ECR decreases with increasing density difference and increasing particle diameter, but again less strongly than $-1 / 2$ power. Finally, the ECR decreases with increasing viscosity. This relationship can help explain some of the recent observations reported by Adamson et al. (2010) and Adamson and Gauglitz (2011) on ECRs and batch transfer results in small-scale experiments that all used $100 \mu \mathrm{m}$ SS particles in different suspending fluids.

Adamson et al. (2010) conducted small-scale mixing and transfer studies of $100 \mu \mathrm{m}$ SS particles in a suspending fluid composed of $30 \mu \mathrm{m}$ gibbsite particles in a salt solution. The salt solution had a density of $1289 \mathrm{~kg} / \mathrm{m}^{3}$ and a viscosity of $2.55 \mathrm{mPa} \cdot \mathrm{s}$. These studies were conducted at a jet velocity of $22.4 \mathrm{ft} / \mathrm{s}$. This study did not specifically measure the ECR, but did report information on the quantity of the SS particles transferred in individual batches to six receipt tanks, which is a related metric and generally should increase with increasing ECR.. These tests can be compared with the studies by Adamson and Gauglitz (2011) where identical $100 \mu \mathrm{m}$ SS particles were studied with a range of different suspending fluids. The results for the Newtonian fluids, water and a glycerol water solution will be discussed here. The results for the non-Newtonian slurries of kaolin in water will be discussed in Section 5.2. In Adamson et al. (2010), the simulant had a total of $10.52 \mathrm{~kg}$ of SS particles while the studies reported by Adamson and Gauglitz (2011) had a higher amount, $17.29 \mathrm{~kg}$, of SS particles.

Table 5.1 gives experimental conditions, predicted ECR values from Equation 5.8, and selected testing results for these studies. The suspending fluid bulk density is shown without including the SS particles, because each of the tests suspended the SS particles to different degrees. For the ECR results, the predicted values are shown as a ratio in comparison to water. The first entry is for water at a jet velocity of $28 \mathrm{ft} / \mathrm{s}$. The second entry is for a $6.2 \mathrm{mPa} \cdot \mathrm{s}$ solution of glycerol and water. For this suspending fluid, the ECR is predicted to decrease to $78 \%$ of the value for water. In Equation 5.8, the higher viscosity decreases the ECR to a greater degree than the increase in ECR due to the slightly higher density. The actual observation in Adamson and Gauglitz (2011) is that the ECR with the $6.2 \mathrm{mPa} \cdot \mathrm{s}$ glycerol/water solution was always lower than water for a range of jet velocities, and was about $95 \%$ of 
the ECR for water at $28 \mathrm{ft} / \mathrm{s}$. This result suggests that the ECR viscosity dependence given by Equation 5.8 is too strong. The batch transfer results for the glycerol/water solution showed a significant increased amount of SS particles transferred to the individual receipt tanks, even though the ECR decreased. For the glycerol/water solution, the increased viscosity slowed the settling of particles that were suspended and this improved the overall transfer of the SS particles even though the ECR decreased.

The slurry of $30 \mu \mathrm{m}$ gibbsite in salt solution tested by Adamson et al. (2010) had both an increased viscosity and an increased density in comparison with water. This slurry can also be compared with the $6.2 \mathrm{mPa} \cdot \mathrm{s}$ glycerol/water solution which had a higher viscosity and lower density. Based in Equation 5.8, the ECR for the gibbsite/salt solution slurry is 3\% larger than the value for water. Only batch transfer results, and no ECR data, were reported for this slurry and only at a jet velocity of $22.4 \mathrm{ft} / \mathrm{s}$. The average height of SS particles in receipt vessels 1-5 for the batch transfers was 9.5 inches and essentially all of the SS particles were transferred during the test. In contrast, the batch transfer of SS particles with water gave only 7 inches of SS at a higher velocity of $28 \mathrm{ft} / \mathrm{s}$; note that this water test had a larger amount of SS particles, so the transfer with water was even less effective when considering this. In comparison with the glycerol/water solution, the gibbsite slurry had a higher density but a lower viscosity and test results for both were available at $22.4 \mathrm{ft} / \mathrm{s}$ jet velocity. As listed in Table 5.1, the amount of SS particles transferred with the gibbsite/salt solution slurry was higher (9.5 inches average height in receipt tanks 1-5) in comparison with the glycerol/water result of 6.5 inches in the receipt tanks. The overall observation is that the gibbsite/salt solution slurry was more effective at transferring the SS particles. The higher density of the gibbsite/salt solution slurry may be the reason for the improved batch transfer and the predicted ECR is higher for this gibbsite slurry in comparison the glycerol/water solution. It is also possible that the presence of the gibbsite particles in the suspending fluid is somehow assisting in the erosion and batch transfer of the SS particles by some mechanism other than just increasing the density of the suspending fluid. One possibility is that the gibbsite particles are colliding with the SS particles and assisting in the erosion and suspension. The final entry in Table 5.1 shows the fluid properties and predicted ECR for the SS particles in just the salt solution. There are no test data available for just the salt solution, but removing the gibbsite from the salt solution reduces the density and ECR by only a small amount. A batch transfer test with salt solution and SS particles would be useful to help understand the role of the gibbsite particles in the slurry on the suspension and transfer of SS particles..

\subsection{Slurry Rheology}

Batch transfer and ECR tests with non-Newtonian slurry simulants were reported by Adamson and Gauglitz (2011) to determine the role of slurry rheology on batch transfer and ECR results. In these tests, kaolin clay slurries with Bingham yield stresses ranging from $0.3 \mathrm{~Pa}$ to $7 \mathrm{~Pa}$ were investigated with $100 \mu \mathrm{m}$ stainless steel particles, and these results were compared to the results with Newtonian liquids of water and a glycerol/water solution. Increasing the slurry yield stress decreased the ECR, but the total transfer of SS particles always increased with increasing yield stress. What appears to happen with jet mixing of yield-stress slurries is that while is more difficult to suspend particles from the tank bottom with increasing yield stress, the particles stay suspended to a greater degree once lifted from the tank bottom. The combined effect of increasing the yield stress is an increase in the transfer of seed particles.

A comparison of testing results with slurries having Bingham yield stresses of $1.6 \mathrm{~Pa}$ to $7 \mathrm{~Pa}$ with a Newtonian glycerol/water mixture having a viscosity approximately equal to the Bingham consistency (viscosity) of the slurry shows very similar ECR results, but the slurries had significantly increased batch 
transfer of SS particles. This finding shows that when the suspending fluid has a non-Newtonian rheology with a yield stress there is an overall increase in SS particle suspension and transfer, which is an improvement in mixing performance by this metric. Overall, for the batch transfer of fast-settling particles, the test results show that testing with water is conservative, since using a simulant with a yield stress and/or elevated viscosity always resulted in a better total transfer of solid.

Table 5.1. Effective Cleaning Radius with Different Suspending Fluids in Comparison to Water, and Experimental Observations of ECRs and the Related Metric of Batch Transfer Quantities

\begin{tabular}{|c|c|c|c|c|}
\hline $\begin{array}{l}\text { Suspending } \\
\text { Fluid }\end{array}$ & $\begin{array}{l}\text { Suspending } \\
\text { Fluid } \\
\text { Density } \\
\left(\mathrm{kg} / \mathrm{m}^{3}\right)\end{array}$ & $\begin{array}{l}\text { Suspending } \\
\text { Fluid } \\
\text { Viscosity } \\
(\mathrm{mPa} \cdot \mathrm{s})\end{array}$ & $\begin{array}{l}\text { Predicted } \\
\mathrm{ECR} / \mathrm{ECR}_{\text {water }}\end{array}$ & Experimental Observations \\
\hline Water $^{(a)}$ & $998^{(\mathrm{c})}$ & $1.00^{(\mathrm{c})}$ & 1 & $\begin{array}{l}\text { At } 28 \mathrm{ft} / \mathrm{s} \text { jet velocity, batch transfer } \\
\text { gave an average of } 7 \text { inches of SS in } \\
\text { receipt tanks } 1-5 \text {. }\end{array}$ \\
\hline $\begin{array}{l}52 \mathrm{wt} \% \\
\text { Glycerol in } \\
\text { Water }^{(\mathrm{a})}\end{array}$ & $1130^{(\mathrm{c})}$ & 6.2 & 0.78 & $\begin{array}{l}\text { At } 28 \mathrm{ft} / \mathrm{s} \text { jet velocity, ratio of ECR to } \\
\text { water ECR was } 0.95 \text {. Batch transfer } \\
\text { gave an average of } 9 \text { inches in receipt } \\
\text { tanks } 1-5 \text {, which is higher than water } \\
\text { results of } 7 \text { inches. At } 22.4 \mathrm{ft} / \mathrm{s} \text {, batch } \\
\text { transfer gave } 6.5 \text { inches of } \mathrm{SS} \text { in } \\
\text { receipt tanks } 1-5 \text {. }\end{array}$ \\
\hline $\begin{array}{l}30 \mu \mathrm{m} \\
\text { Gibbsite in } \\
\text { Salt Solution }^{(\mathrm{b})}\end{array}$ & $1343^{(\mathrm{d})}$ & 2.55 & 1.03 & $\begin{array}{l}\text { At } 22.4 \mathrm{ft} / \mathrm{s} \text { jet velocity, batch } \\
\text { transfer of } 4 \text { separate tests gave } \\
\text { average of } 9.5 \text { inches of SS in receipt } \\
\text { tanks } 1-5 . \text { No ECR data. }\end{array}$ \\
\hline Salt Solution ${ }^{(b)}$ & 1289 & 2.55 & 1.00 & No experiments \\
\hline \multicolumn{5}{|c|}{$\begin{array}{l}\text { (a) Adamson and Gauglitz (2011), } 17.29 \mathrm{~kg} \text { of SS particles, } 1.6 \mathrm{rpm} \text { jet rotation rate } \\
\text { (b) Adamson et al. (2010), } 10.52 \mathrm{~kg} \text { of SS particles, } 1.6 \mathrm{rpm} \text { jet rotation rate for Tests 9,10,12,13 } \\
\text { (c) Dean }(1979) \text { at } 20^{\circ} \mathrm{C} \text {, excluding SS particles } \\
\text { (d) Bulk density, excluding SS particles }\end{array}$} \\
\hline
\end{tabular}





\subsection{Computational Fluid Dynamics Tool to Quantify Uncertainty from Simulant Selections}

The differences of particle size and density distribution and liquid properties between SSMD simulant and actual tank waste may result in different tank mixing behavior. An alternate method can be used to quantify the uncertainty associated with the simulant selection. One approach is to use computational fluid dynamics to predict the suspended solids and sediment concentrations for both the simulant and tank waste properties and particle distributions and compare results. This method may be used to assess whether the selected simulant represents more challenging waste or identify adjustments that would make it so. This section describes one candidate computational fluid dynamics tool, ParaFlow, and provides examples of how this tool could be used to evaluate simulants.

\subsection{ParaFlow Capabilities}

The ParaFlow computer program, developed at PNNL, has been designed to simulate solid-liquid multiphase resuspension and mixing in chemical processing systems. The solution procedure is based on a new lattice kinetics algorithm, also developed at PNNL, which scales efficiently on massively parallel computers (Rector and Stewart 2010a). The ParaFlow program has been applied to a variety of multiphase processing systems, including slurry pipelines, ultrafiltration, pulse jet mixing and jet pump tank mixing (Rector et al. 2009, Rector and Stewart 2010b).

Solid-liquid waste processing applications are modeled using multiple continuum phase fields, one for the liquid phase and one for each type of suspended particle with a corresponding size, material type and density. In addition, a separate continuum field is used to represent the settled solids, or sediment, on the tank bottom. The surface topology of the sediment changes as a function of time and the particle composition of the sediment can vary as a function of location. Material is exchanged between the suspended and settled solids due to sedimentation and jet erosion.

A series of Waste Feed Delivery scaled tank simulations are being conducted under the U.S. Department of Energy Office of Environmental Management Waste Processing (EM-31) program. The rotating fluid jets in the Hanford storage tanks are modeled using rotating cylindrical regions centered on each jet support column, with a boundary interface between each rotating region and the rest of the tank, which is stationary. This allows the lattice grid surrounding the nozzle to remain fixed, resulting in greater accuracy and stability. Figure 6.1 shows concentration and sediment isosurfaces during the initial stages of Waste Feed Delivery tank sediment resuspension in a 120" tank. The cylinders represent the air lift circulators, the transfer line and the rotating jet support. The initial supernate is clear. The light green concentration isosurface is for resuspended solids and the dark green indicates the sediment layer. Sediment erosion occurs when the turbulent wall shear stress exceeds a critical shear stress that is a function of particle type. 


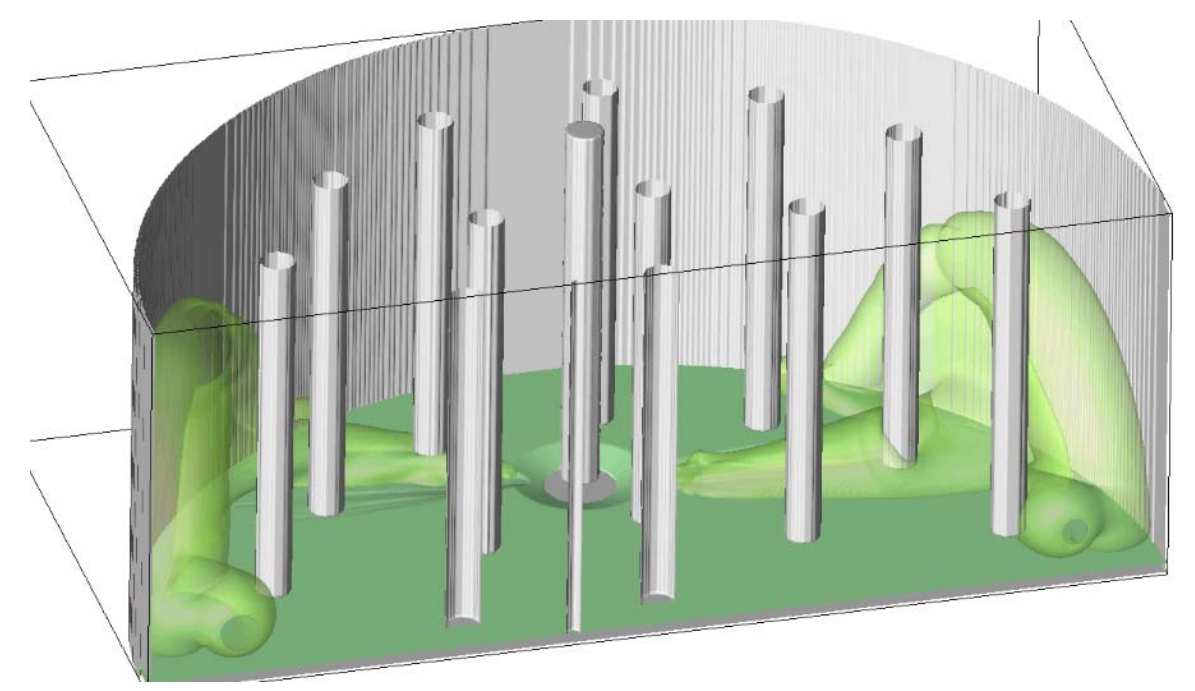

Figure 6.1. Concentration and Sediment Isosurfaces during Waste Feed Delivery Tank Sediment ReSuspension

Single-particle simulations have been performed for both the 120" and 43.2" diameter scaled tanks that correspond to scaled tank experiments conducted under the Small Scale Mixing Demonstration (RPP48358). The simulant was a suspension of $6 \mathrm{wt} \% \mathrm{ZrO}_{2}$ particles with a 5.7 specific gravity. Simulations were performed for the 43.2" tank for nozzle flow rates/velocities of $6.5 \mathrm{gpm}(17 \mathrm{ft} / \mathrm{s}), 7.5 \mathrm{gpm}(19 \mathrm{ft} / \mathrm{s})$ and $8.5 \mathrm{gpm}(22 \mathrm{ft} / \mathrm{s})$. The nozzle flow rates/velocities for simulations of the 120 " tank were $70 \mathrm{gpm}(22$ $\mathrm{ft} / \mathrm{s}), 80 \mathrm{gpm}(25 \mathrm{ft} / \mathrm{s})$ and $90 \mathrm{gpm}(28 \mathrm{ft} / \mathrm{s})$.

Preliminary simulation results show different suspended-solids behavior for the two different tank scales. The suspended-solids concentration profile for the tank cross-section midway between the jet pumps in terms of mixture density is shown in Figure 6.2 for the 43.2" tank at 7.5 gpm and in Figure 6.3 for the 120" tank at $80 \mathrm{gpm}$. The dark blue in the figure represents the tank walls, air lift circulators and transfer line. The jet pump nozzles are in the same orientation for both figures. Note that the solids in the smaller tank are distributed throughout the tank with only a small region of settling separation at the top of the tank. In contrast, the larger tank shows a distinct cloud height. Final tank simulation results will be compared with concentration profile data by the end of this fiscal year under the EM-31 program.

When there is no convection, the suspended solids descend at a hindered-settling rate that is a function of the suspension concentration. The rotating fluid jets erode the sediment layer and propel a high solids-concentration mixture up along the sides of the tank and above the cloud height elevation. The higher density of the mixture results in transverse flows across the cloud surface to redistribute the newly resuspended solids. The cloud height reaches equilibrium when the rate of upward convection of suspended solids near the tank wall equals the hindered settling across the cloud surface. 


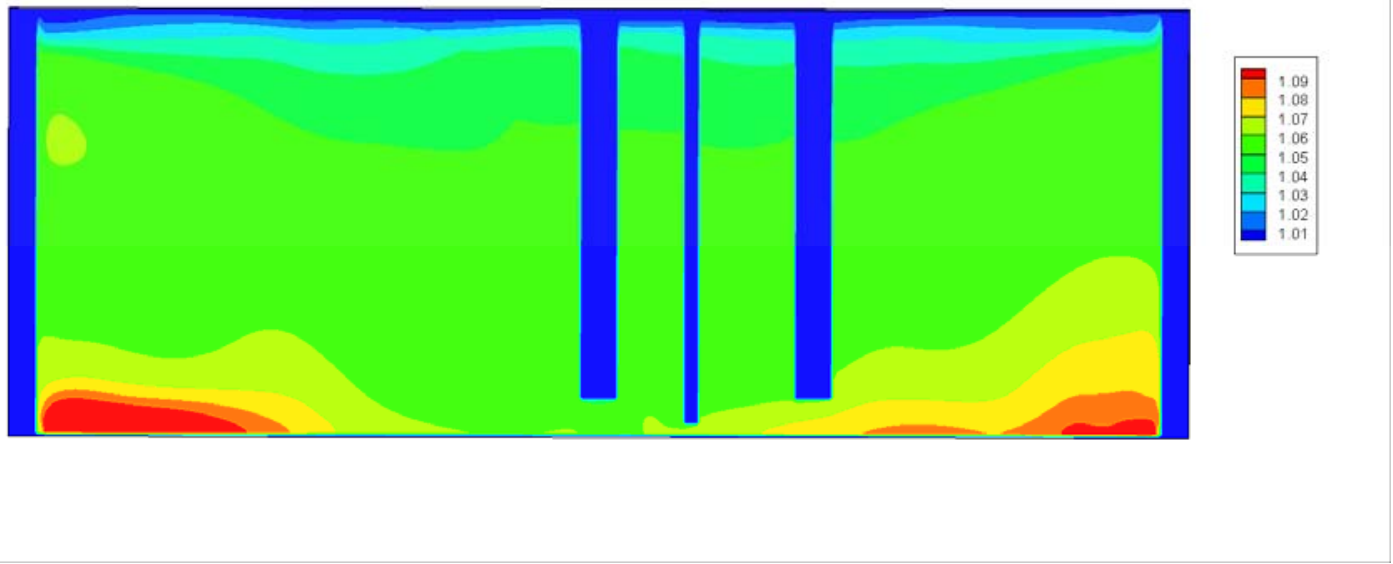

Figure 6.2. Suspended Solids Concentration Profile in Terms of Bulk Density for 43.2" Tank at 7.5 GPM

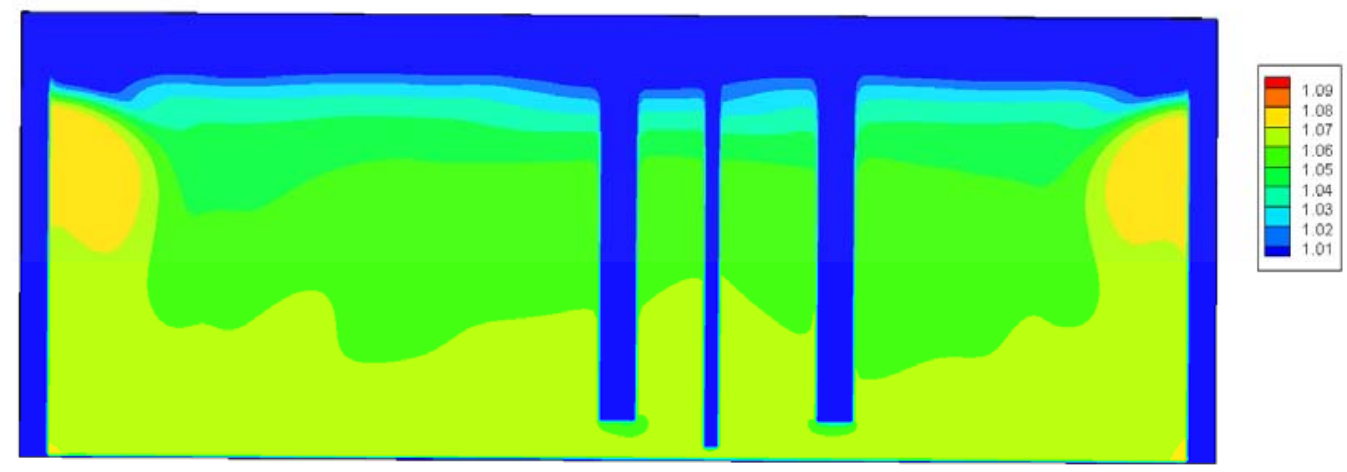

Figure 6.3. Suspended Solids Concentration Profile in Terms of Bulk Density for 120" Tank at 80 GPM

The higher concentrations along the tank bottom and sides of both figures show the resuspension of solids from the sediment layer. There was no noticeable sediment accumulation beyond the sedimentation that occurs during each pump rotation half-cycle, indicating that the jets clear the bottom out to the edge of the tank as they pass by. The simulation of more-complex simulants, with heavier particles such as stainless steel, are underway and are expected to be completed by the end of Fiscal Year 2011 under the EM-31 program.

\subsection{Procedure for Evaluating Simulation Selections}

The selection of a simulant to represent tank waste required a series of assumptions and simplifications. For example, a complex particle size and composition distribution is reduced to a limited number of specific particle types, or a chemically complex supernate is replaced with water. A method is required to quantify the uncertainty associated with the simulant selection. One approach is to use computational fluid dynamics to predict the suspended solids and sediment concentrations for both the 
simulant and tank waste properties and particle distributions and compare results. This method may be used to assess whether the selected simulant represents more challenging waste or to identify adjustments that would make it so.

The basis for comparing two simulations may be quantities such as suspended solids concentrations within the tank, similar to those shown in Figure 6.2 and Figure 6.3. However, simulation results are most useful when they correspond to the desired product from the system, in this case the composition of the batches delivered to the WTP. For this reason, a ParaFlow simulation was performed for the 120" scale tank to demonstrate how this information may be obtained.

The ParaFlow simulation for the 80 gpm case with $\mathrm{ZrO}_{2}$ particles described in Section 6.1 was modified to withdraw material near Riser 30, near the center of the tank, at an elevation above the jet nozzles. The slip surface at the top of the liquid, where the boundary velocity matches the fluid, moved down at a rate equivalent to the volumetric withdrawal rate. The transfer ceased when one-sixth of the tank contents had been removed. The resulting solids concentration profile is shown in Figure 6.4.

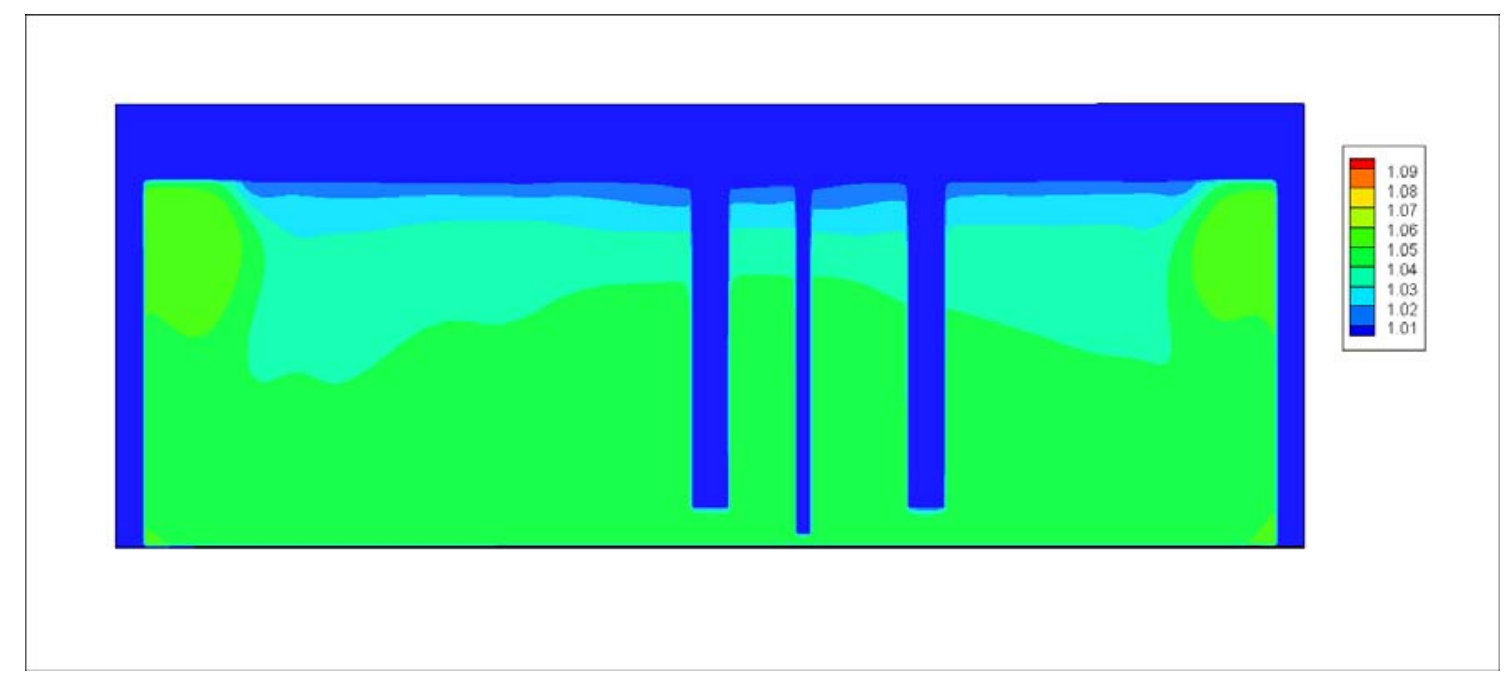

Figure 6.4. Suspended Solids Concentration Profile in Terms of Bulk Density for 120" Tank at 80 GPM after First Pumpout

The tank average specific gravity at the beginning of the simulation is approximately 1.052 . Figure 6.3 shows a lower cloud height, which implies a higher average solids concentration in the mixed region of the tank. The average mixture density at the withdrawal point showed this in the simulation, with a value of just over 1.06 at the beginning of the transfer. As the suspension is removed, the cloud height does not change appreciably throughout the simulation. The cloud height appears to be more a function of the jet speed and simulant type than of slight changes in solids concentration resulting from the transfer. The reduction in solids is uniformly distributed throughout the cloud region, reducing the mixture density until a final averaged withdrawal-point density of approximately 1.048 is reached. These results compare well with the measured densities from the TK-301 batch transfer testing (RPP-47557).

This simulation approach may be used to examine the variations in batch transfer properties due to effects of simulant variation on both cloud height formation and accumulation due to sedimentation. Examples of proposed studies that could benefit from the use of this type of analysis are described below. 


\subsubsection{Comparisons of SSMD Simulant in Water and Alternate Liquid}

Some tank simulants use a suspending liquid with physical properties that differ from water. For example, Savannah River Site scaled tank tests have been conducted as part of the SSMD project with a salt liquor with a density of $1,289 \mathrm{~kg} / \mathrm{m}^{3}$ and a viscosity of 2.55 centipoise (Adamson et al. 2010). This difference can result in a variety of competing effects in tank suspension behavior. The increased liquid density and viscosity reduce the rate of hindered settling. The increased liquid density reduces the critical yield stress, increasing the rate of erosion for the same flow conditions. However, the change in properties will also affect the fluid jet inertia and interaction with the tank floor and side. Simulations using the ParaFlow program could be used to determine the net result of all these effects and how the use of water affects the test results.

\subsubsection{Comparisons of SSMD Simulant and Adjusted Simulant in Water}

Simulation results for both SSMD simulants and a more detailed representation of the actual tank waste could be compared to evaluate the uncertainty associated with the simulant selection. If, as a result, the simulant needs to be adjusted, further simulations may be used to guide the process of modifying the simulant to meet the project objectives. 



\subsection{Conclusions}

The Hanford DST system provides the staging location for waste feed delivery to the WTP. The objectives of Washington River Protection Solutions' SSMD project are to understand and demonstrate

the DST sampling and batch transfer performance, and to do so the project utilizes geometrically scaled DST feed tanks and waste simulants to generate mixing, sampling, and transfer test data. In Phase 2 of the testing (RPP-49740 Rev A), the five-part simulant defined in (RPP-48358) was used as the waste slurry simulant. The Phase 2 test data are being used to estimate the expected performance of the prototypic systems in the full-scale DSTs. Thus it is critical to understand how the simulant relates to the actual waste.

A comparison of the sizes and densities of the particulates comprising the five-part SSMD simulant to those of the characterized Hanford sludge waste particulate was made in this report. The comparison was made by computing metrics for particle mobilization, suspension, settling, transfer-line intake, and pipeline transfer where dependence on particle size and density may be different, including:

1. Settling velocity

2. Archimedes number

3. Critical shear stress for erosion of noncohesive particles

4. Just-suspended impeller speed

5. Jet velocity needed to achieve a certain degree of solid suspension

6. PJM critical suspension velocity for noncohesive solids

7. PJM cloud height for noncohesive solids

8. Pipeline critical transport velocity

The five-part SSMD simulant and Hanford sludge waste particulate are represented by particle size and density distributions (PSDDs), Wells et al. (2011). The PSDDs from Wells et al. (2011) are used to describe the Hanford sludge. The particle size distribution of Hanford waste is characterized using PSD instrumentation. As described in Wells et al. (2011), certain particle-size analyzers suspend and circulate solid samples with adjustable suspension and circulation rates within the instrument during PSD measurements, and sonication may also be employed. Depending on how the PSD instrument is configured during a measurement, there is different potential to break-up agglomerates. The particle density of the PSDDs is determined by the UDS composition and assumptions about that composition and the density of the particulate as it exists as primary particles, hard agglomerates, and soft agglomerates or flocs.

Based on comparison of calculated and measured settling velocities, it is suggested that:

- There is no conclusive evidence that characterization of the Hanford waste particle size via any of the presented PSD types over-represents the settling characteristics of particles suspended by jet mixer pump operation.

- Agglomerated particles are present in Hanford waste, and as such, these particles likely have a density less than that of a UDS compound crystal density. However, there is no conclusive evidence that representing the particle density of Hanford waste particles by assuming that all particles have a 
density equal to the UDS compound crystal density regardless of the measured particle size overrepresents the settling characteristics of particles suspended by jet mixer pump operation.

Thus, the comparison of the SSMD simulant and Hanford sludge waste is made for all PSD techniques and with the particle density equal to the UDS compound crystal density independent of particle size. As designed (see RPP-49740 Rev A), the five-part SSMD simulant is typically more challenging than the AY-102 waste except for the larger and more dense particulate of the most challenging PSDD type. The five-part SSMD simulant is also typically more challenging than the waste composites with the exception of the most challenging particulate. The SSMD simulant was not as challenging compared to other sludge wastes. Summary metrics of the comparison results are made as:

Summary Metric 1. Tanks and waste types for which at least $50 \%$ by volume of a given metric result are more challenging than the result of the five-part SSMD simulant. The 50\% does not have to be contiguous.

Summary Metric 2. Tanks and waste types for which a given metric result are more challenging than the $90^{\text {th }}$-percentile-and-above results of the five-part SSMD simulant. Any exceedance above the $90^{\text {th }}$ percentile qualifies.

For Summary Metric 1, it was determined that:

- Similar tanks and waste types are more challenging than the five-part SSMD simulant independent of the waste operation metric.

- Tanks and waste types exceeding the five-part SSMD simulant comprise less than $43 \%$ by volume of the characterized Hanford sludge UDS inventory (maximum of all PSDD types, less than $20 \%$ of the Hanford sludge inventory is characterized by the PSDDs).

- The most "restrictive" metric is the Archimedes number (similar to settling velocity).

For Summary Metric 2, it was determined that:

- Similar tanks and waste types are more challenging than the five-part SSMD simulant independent of the waste operation metric.

- Tanks and waste types exceeding the five-part SSMD simulant comprise less than $56 \%$ by volume of the characterized Hanford sludge UDS inventory (maximum of all PSDD types, less than $20 \%$ of the Hanford sludge inventory is characterized by the PSDDs).

- The most "restrictive" metric is cloud height, followed by the Archimedes number and the PJM critical suspension velocity.

As indicated in the summary metric results by the increase in percentage from total Hanford UDS inventory, to Hanford sludge UDS inventory, then to the characterized Hanford sludge UDS inventory, a limited fraction of the waste has been characterized. Less than $5 \%$ and $20 \%$ of the total and sludge inventories, respectively, are characterized by the PSDDs. It is also possible that the PSDD variation in the limited characterization of the waste under-represents the variation of the entire waste inventory. Thus, although the five-part SSMD simulant is near the "upper-end" of the waste characterizations with respect to particle mobilization, suspension, settling, transfer-line intake, and pipeline transfer, it is possible that at least $50 \%$ by volume of the Hanford sludge UDS particulate may be more challenging than that represented by the five-part SSMD simulant. 
Two different example adjustments of the concentrations of components of the SSMD simulant are provided to match the most challenging of the characterized sludge waste. One of the simulants is based on components of the five-part SSMD simulant, while the other includes an additional component. The differences in these example adjusted simulants illustrate the significance of the different dependencies on particle size and density depending on the metric considered.

Previous testing has shown that the batch transfer of settling SS particles in a slurry of dense salt solution and fine gibbsite particles was more effective than batch transfers of identical SS particles when the suspending fluid was water or glycerol/water solutions. A simple model showing the roles of suspending-fluid density and viscosity on the ECR of the jet mixers was developed. The analysis gives the correct qualitative effect of the ECR increasing with increasing suspending-fluid density and decreasing with increasing viscosity, but the analysis does not give good quantitative predictions based on the limited data. A summary of available data shows that a change in fluid properties that decreases the ECR may still increase the amount of settling particles transferred; for example, increased viscosity. The batch transfer data clearly show that transferring settling SS particles in water is more challenging than in the gibbsite/salt solution slurry or the glycerol/water solution. In both cases the predicted ECR is higher in water, but the increased density and/or viscosity of the other fluids improves the overall suspension and transfer of particles. The simple ECR model only accounts for particle erosion, and does not include coupled behavior of particle settling and suspension, which is needed to explain the batch transfer results.

The coupled behavior of particle erosion, suspension, and settling, and the roles of particle and fluid properties, can be investigated with appropriate computational tools. The ability of the ParaFlow code to address this physical behavior was presented. ParaFlow may be used to quantify simulant selections as discussed, not only for the particulate selection, but also in consideration of the effects of the characteristics of the suspending fluid on test results. 



\subsection{References}

Adamson DJ and PA Gauglitz. 2011. Demonstration of Mixing and Transferring Settling Cohesive Slurry Simulants in the AY-102 Tank. SRNL-STI-2011-00278, Rev. 0. Savannah River National Laboratory, Aiken, SC.

Adamson DJ, ML Restivo, TJ Steeper, and DA Greer. 2010. Demonstration of Mixer Jet Pump Rotational Sensitivity on Mixing and Transfers of the AY-102 Tank, SRNL-STI-2010-00521, Savannah River National Laboratory, Aiken, South Carolina.

Arakali AV, DL Banning, PA Benson, and DA Greer. 2011. Initial Data Quality Objectives for WTP Feed Acceptance Criteria. WTP Project Doc. No. 24590-WTP-RPT-MGT-11-014, Rev 0. BNI.

Bamberger JA, PA Meyer, JR Bontha, CW Enderlin, DA Wilson, AP Poloski, JA Fort, ST Yokuda, HD Smith, F Nigl, MA Friedrich, DE Kurath, GL Smith, JM Bates, and MA Gerber. 2005. Technical Basis for Testing Scaled Pulse Jet Mixing Systems for Non-Newtonian Slurries. PNWD-3551 (WTP-RPT-113 Rev. 0), Battelle-Pacific Northwest Division, Richland, Washington.

Bechtold DB, WS Callaway GA Cooke, JB Duncan, DL Herting, JR Jewett, JC Person, and JM Tingey. 2002. Particle Property Analyses of High-Level Waste Tank Sludges. HNF-8862 Rev. 0, Fluor Hanford, Inc., Richland, Washington.

Beeman GH. 2010. Letter from GH Beeman (PNNL) to HR Hauzen (Bechtel National Inc.), March 12, 2010. "Subcontract No. 24590-QL-HC49-00001 - Project 55753 (WA \#028) Recipes for Simulant Strengths.” WTP/RPP-MOA-PNNL-00494.

Beheshti AA, and B Ataie-Ashatiani. 2008. "Analysis of Threshold and Incipient Conditions for Sediment Movement.” Coastal Engineering 55(5):423-430.

Brownlie WR. 1981. Prediction of Flow Depth and Sediment Discharge in Open Channels. Rep. KH-R43A, California Institute of Technology, Pasadena, California.

Camenen B. 2007. "Simple and General Formula for the Settling Velocity of Particles." Journal of Hydraulic Engineering 133(2):229-233.

Carlson AB, PJ Certa, TM Hohl, JR Bellomy III, TW Crawford, DC Hedengren, AM Templeton, HS Fisher, SJ Greenwood, DG Douglas, and WJ Ulbright Jr. 2001. Test Report, 241-AZ-101 Mixer Pump Test. RPP-6548, Rev. 1, Numatec Hanford Corporation, Richland, WA.

Churnetski BV. 1982. "Prediction of Centrifugal Pump Cleaning Ability in Waste Sludge." Nuclear and Chemical Waste Management, 3(4):199-203.

CCN 132846. 2006. Comprehensive Review of the Hanford Waste Treatment Plant Flowsheet and Throughput - Assessment Conducted by an Independent Team of External Experts. Chartered by the Hanford Waste Treatment and Immobilization Plant Project at the Direction of the U.S. Department of Energy, Office of Environmental Management, Washington DC. 
Chien N, and ZH Wan. 1983. Mechanics of Sediment Movement. Science Publications, Beijing. (in Chinese)

Dean JA. 1979. Lange's Handbook of Chemistry. $12^{\text {th }}$ Edition, McGraw-Hill, New York.

Etchells 2007. Letter correspondence from AW Etchells, Dupont Technology Consulting to SA Saunders, WTP-Bechtel. January 29, 2007. Comments on the Input Particle Size Report. WTP Project Memorandum CCN 186332.

Fort JA, PA Meyer, JA Bamberger, CW Enderlin, PA Scott, MJ Minette, and PA Gauglitz. 2010. Scaled Testing to Evaluate Pulse Jet Mixer Performance in Waste Treatment Plant Mixing Vessels. 10487, WM2010 Conference, March 7-10, 2010, Phoenix, AZ.

Hall MN. 2006. Design Guide: Minimum Flow Velocity for Slurry Lines. WTP Project Doc. No. 24590WTP-GPG-M-0058, Rev 0. BNI.

Julien, PY. 1998. Erosion and Sedimentation. Cambridge University Press, Cambridge, United Kingdom.

Kale RN, and AW Patwardhan. 2005. "Solid Suspension in Jet Mixers." The Canadian Journal of Chemical Engineering 83(5):816-828.

Mantz PA. 1977. "Incipient Transport of Fine Grains and Flakes by Fluids - Extended Shields Diagram." Journal of the Hydraulics Division, Proceedings of the American Society of Civil Engineers 103(6):601615.

Meyer PA, JA Bamberger, CW Enderlin, JA Fort, BE Wells, SK Sundaram, PA Scott, MJ Minette, GL Smith, CA Burns, MS Greenwood, GP Morgen, EBK Baer, SF Snyder, M White, GF Piepel, BG Amidan, and A Heredia-Langner. 2009. Pulse Jet Mixing Tests with Noncohesive Solids. PNNL-18098 (WTPRPT-182, Rev. 0), Pacific Northwest National Laboratory, Richland Washington.

Meyer PA, EBK Baer, JA Bamberger, JA Fort, and MJ Minette. 2010. Assessment of Differences in Phase 1 and Phase 2 Test Observations for Waste Treatment Plant Pulse Jet Mixer Tests with NonCohesive Solids. PNNL-19085 (WTP-RPT-208, Rev. 0), Pacific Northwest National Laboratory, Richland Washington.

Olson JW. 2011. ICD 19 - Interface Control Document for Waste Feed. 24590-WTP-ICD-MG-01-019, Rev 5. River Protection Project, Waste Treatment Plant, Richland, WA.

Oroskar AR and RM Turian. 1980. "The Critical Velocity in Pipeline Flow of Slurries." AIChE Journal 26(4): 550-558.

Paphitis D. 2001. Sediment Movement Under Unidirectional Flows: An Assessment of Empirical Threshold Curves. Coastal Engineering, 43, 227-245.

Parker SP. 1984. McGraw-Hill Dictionary of Scientific and Technical Terms, 3rd Edition, McGraw-Hill, New York. 
Paul EL, VA Atiemo-Obeng, and SM Kresta. 2004. Handbook of Industrial Mixing Science and Practice. John Wiley \& Sons, Inc., Hoboken, New Jersey.

Poloski AP, AW Etchells, J Chun, HE Adkins, AM Casella, MJ Minette, and ST Yokuda. 2010. “A Pipeline Transport Correlation for Slurries With Small But Dense Particles.” Canadian Journal of Chemical Engineering 88(2):182-189.

Rector DR, ML Stewart, and AP Poloski. 2009. Modeling of Sediment Bed Behavior for Critical Velocity in Horizontal Piping. Presented at the 2009 Waste Management Conference, Phoenix.

Rector DR, and ML Stewart. 2010a. "A semi-implicit lattice method for simulating flow.” J. Comput. Phys. 229(19):6732-6743.

Rector DR, and ML Stewart. 2010b. Modeling of Leaching Filter Pressure Drop and Fouling Behavior. Presented at the 2010 Waste Management Conference, Phoenix, AZ.

RPP-47557. 2010. Small Scale Mixing Demonstration Initial Results Report. RPT-SSMD-EG-0003, Rev A. ENERGY SOLUTIONS, Richland, WA.

RPP-48358. 2011. Waste Feed Delivery Small Scale Mixing Demonstration Simulant Selection Report for Phase 2 Testing. PL-SSMD-PR-0003, Rev 1. ENERGY SOLUTIONS, Richland, WA.

RPP-49740. 2011. Small Scale Mixing Demonstration Sampling and Batch Transfers Initial Results Report. RPT-SSMD-EG-0005, Rev A. ENERGY SOLUTIONS, Richland, WA.

Townson P. 2009. Tank Farm Mixing Demonstration Planning Workshop. RPT-1741-0001, Rev. 0. ENERGY SOLUTIONS, Richland, WA.

Vanoni AA, Editor. 1975. Sedimentation Engineering, the ASCE Task Committee for the Preparation of the Manual on Sedimentation of the Sedimentation Committee of the Hydraulic Division. The American Society of Civil Engineers, New York.

Weber RA. 2009. Methodology and Calculations for the Assignment of Waste Groups for the Large Underground Waste Storage Tanks at the Hanford Site. RPP-10006, Rev. 8, Washington River Protection Solutions LLC, Richland, Washington.

Wells BE and JJ Ressler. 2009. Estimate of the Distribution of Solids Within Mixed Hanford DoubleShell Tank AZ-101: Implications for AY-102. PNNL-18327, Pacific Northwest National Laboratory, Richland, Washington.

Wells BE, MA Knight, EC Buck, SK Cooley, RC Daniel, LA Mahoney, PA Meyer, AP Poloski, JM Tingey, WS Callaway III, GA Cooke, ME Johnson, MG Thien, DJ Washenfelder, JJ Davis, MN Hall, GL Smith, SL Thomson, and Y Onishi. 2007. Estimate of Hanford Waste Insoluble Solid Particle Size and Density Distribution. PNWD-3824 (WTP-RPT-153, Rev. 0), Battelle-Pacific Northwest Division, Richland, Washington. 
Wells BE, CW Enderlin, PA Gauglitz, and RA Peterson. 2009. Assessment of Jet Erosion for Potential Post-Retrieval K-Basin Settled Sludge. PNNL-18831, Pacific Northwest National Laboratory, Richland, Washington.

Wells BE, DE Kurath, LA Mahoney, Y Onishi, JL Huckaby, SK Cooley, CA Burns, EC Buck, JM Tingey, RC Daniel, and KK Anderson. 2011. Hanford Waste Physical and Rheological Properties: Data and Gaps. PNNL-20646. Pacific Northwest National Laboratory, Richland Washington. 
Appendix A

\section{PSDD Comparison Plots}





\section{Appendix A - PSDD Comparison Plots}

The PSSD comparison plots of Section 4.1 are provided here in larger size. 


\begin{tabular}{|c|c|c|}
\hline$C-107$ & B-203 & $-\mathrm{T}-203$ \\
\hline$-\mathrm{T}-204$ & $\longrightarrow \mathrm{T}-110$ & $\longrightarrow \mathrm{C}-106$ \\
\hline$A Y-102$ & $\longrightarrow \mathrm{C}-104$ & $-\mathrm{AW}-103$ \\
\hline$A Z-101$ & AZ-102 & $-\mathrm{AY}-101$ \\
\hline SY-102 & S-107 & SX-108 \\
\hline - - - - CWR1 Sludge (M12 Group 4), Flowing Sonicated & $\longrightarrow$ Sludge, Flowing Sonicated & $\square$ SSMD Complex Simulant \\
\hline
\end{tabular}

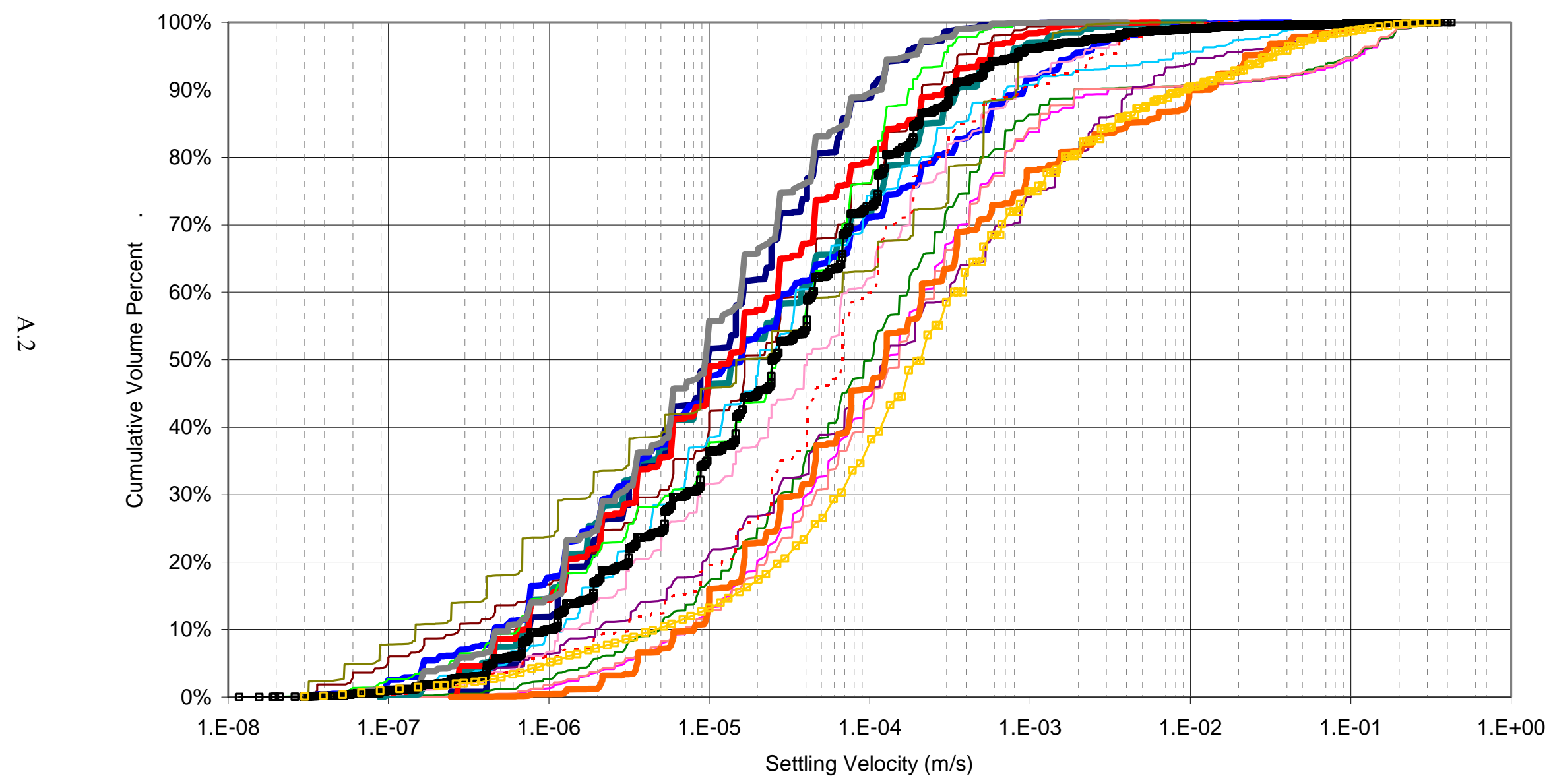

Figure A.1. Settling Velocity Comparison. Flowing, Sonicated. (Same as Figure 4.1, Top). 


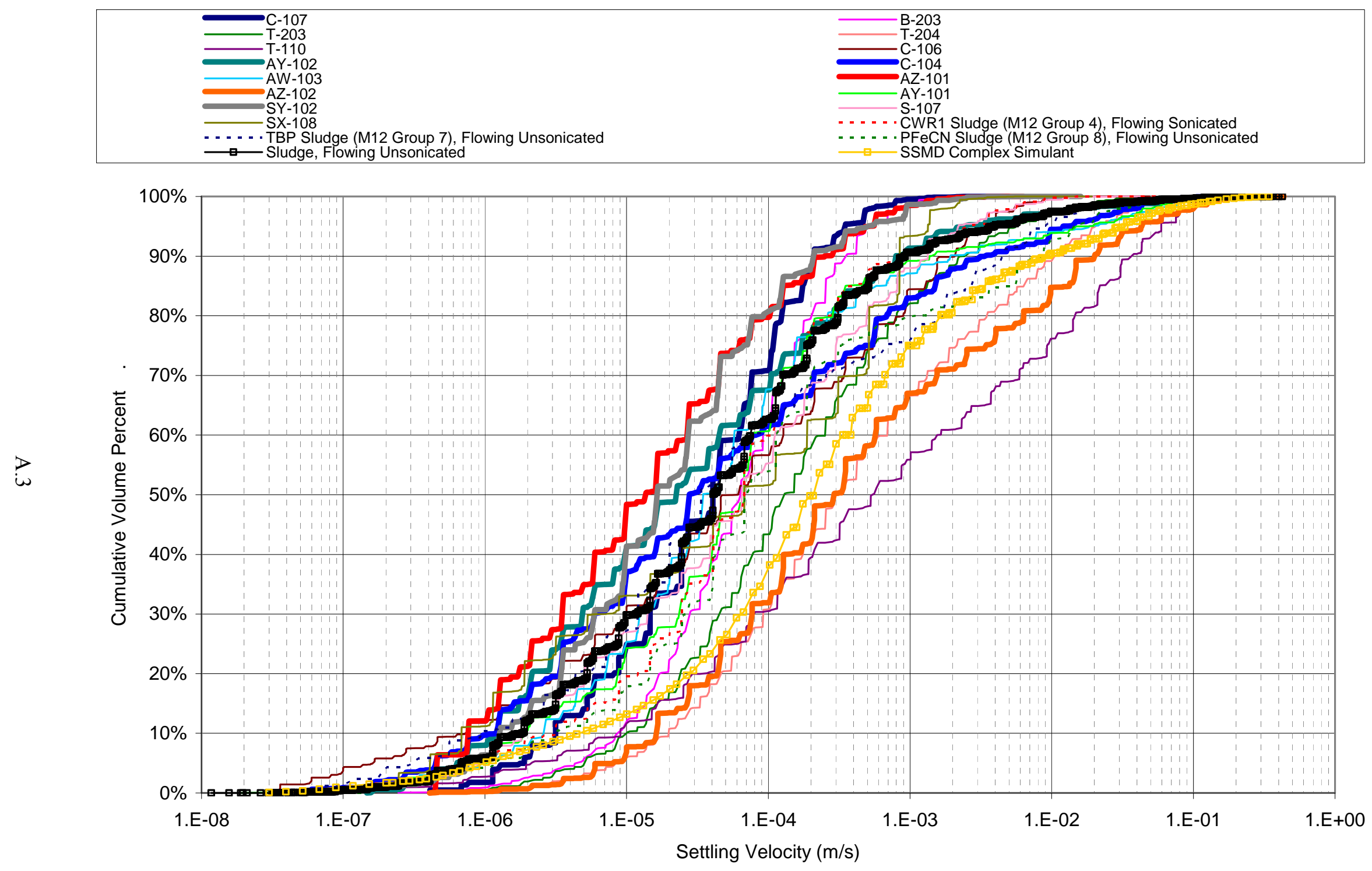

Figure A.2. Settling Velocity Comparison. Flowing, Unsonicated. (Same as Figure 4.1, Middle). 


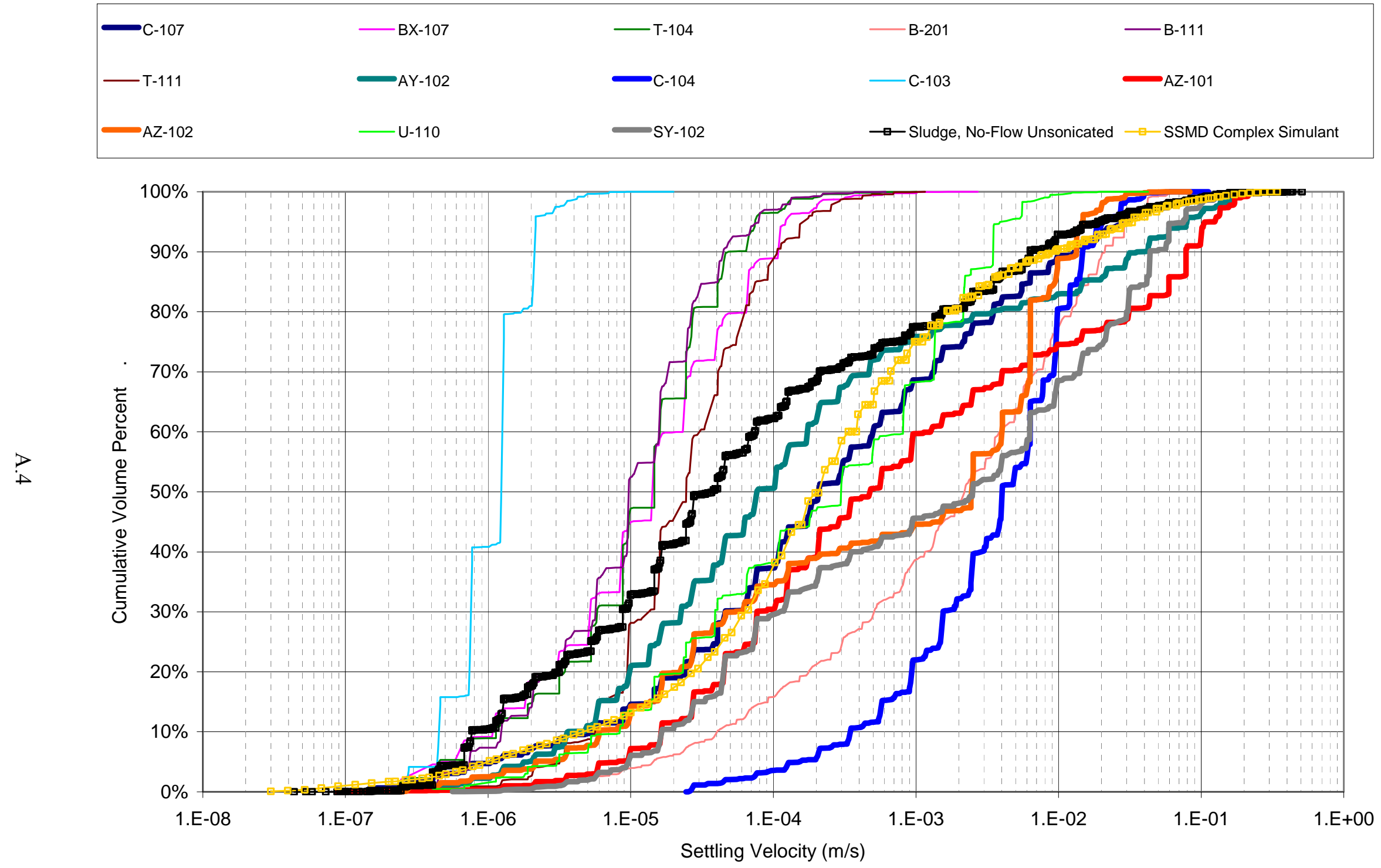

Figure A.3. Settling Velocity Comparison. No-Flow, Unsonicated. (Same as Figure 4.1, Bottom). 


\begin{tabular}{|c|c|c|}
\hline$C-107$ & B-203 & $-\mathrm{T}-203$ \\
\hline$-\mathrm{T}-204$ & $\longrightarrow \mathrm{T}-110$ & $\longrightarrow \mathrm{C}-106$ \\
\hline$A Y-102$ & $\longrightarrow \mathrm{C}-104$ & $-\mathrm{AW}-103$ \\
\hline$A Z-101$ & AZ-102 & $-\mathrm{AY}-101$ \\
\hline SY-102 & S-107 & SX-108 \\
\hline - - - - CWR1 Sludge (M12 Group 4), Flowing Sonicated & $\longrightarrow$ Sludge, Flowing Sonicated & $\square$ SSMD Complex Simulant \\
\hline
\end{tabular}

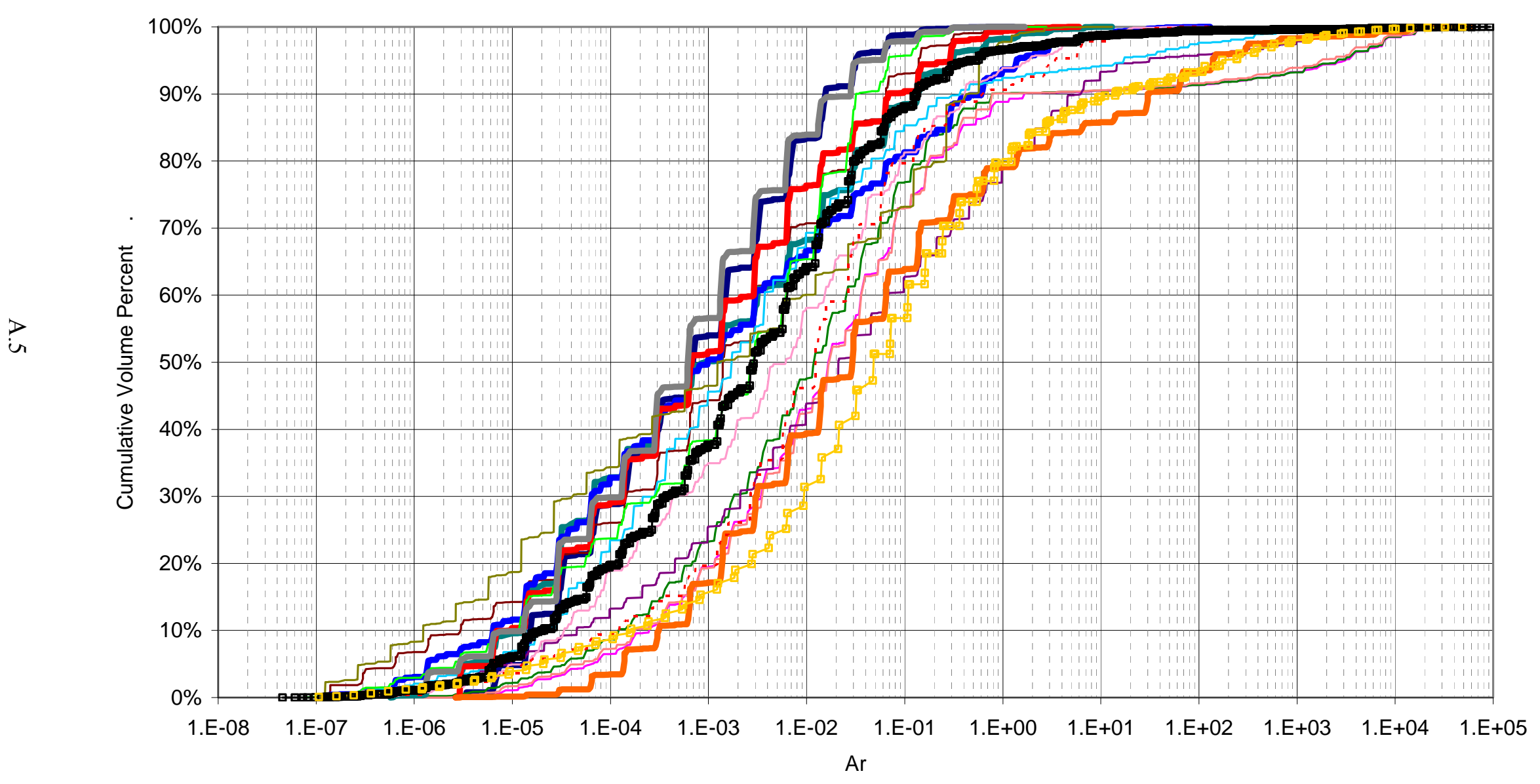

Figure A.4. Archimedes Number Comparison. Flowing, Sonicated. (Same as Figure 4.2, Top). 


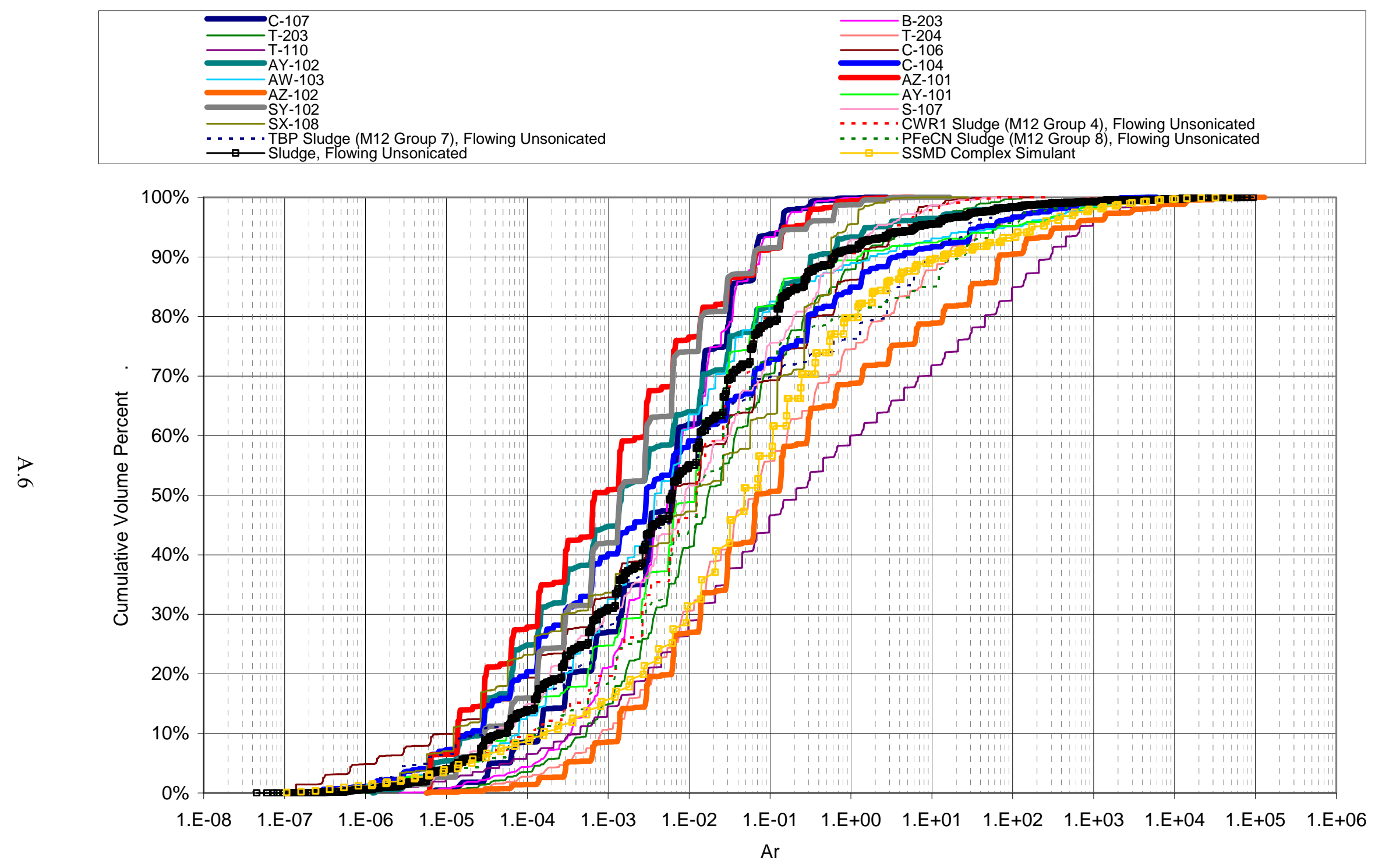

Figure A.5. Archimedes Number Comparison. Flowing, Unsonicated. (Same as Figure 4.2, Middle). 


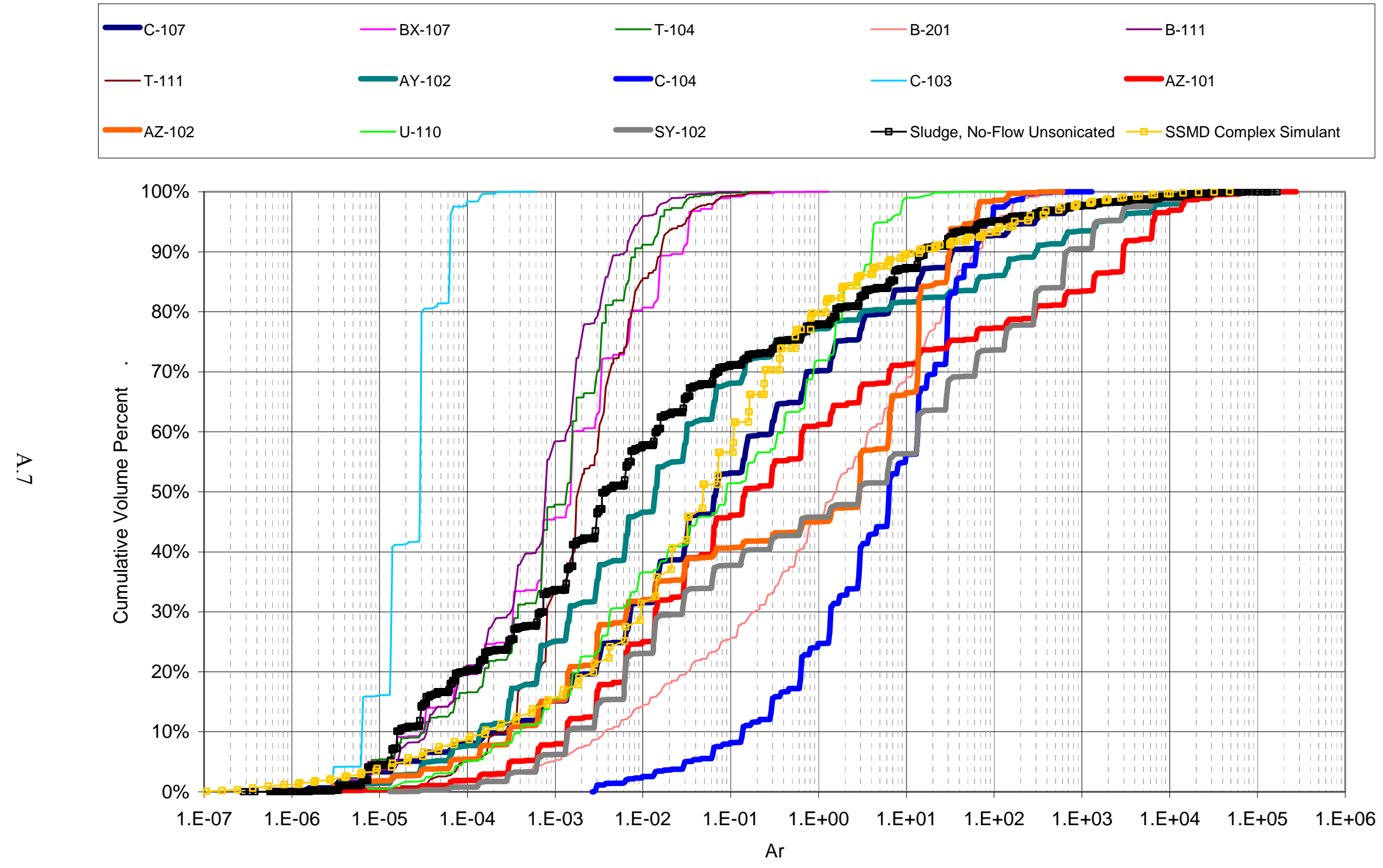

Figure A.6. Archimedes Number Comparison. No-Flow, Unsonicated. (Same as Figure 4.2, Bottom). 


\begin{tabular}{|c|c|c|}
\hline$C-107$ & B-203 & $-\mathrm{T}-203$ \\
\hline$-\mathrm{T}-204$ & $\longrightarrow \mathrm{T}-110$ & $\longrightarrow \mathrm{C}-106$ \\
\hline$A Y-102$ & $\longrightarrow \mathrm{C}-104$ & $-\mathrm{AW}-103$ \\
\hline$A Z-101$ & AZ-102 & $-\mathrm{AY}-101$ \\
\hline SY-102 & S-107 & SX-108 \\
\hline - - - - CWR1 Sludge (M12 Group 4), Flowing Sonicated & $\longrightarrow$ Sludge, Flowing Sonicated & $\square$ SSMD Complex Simulant \\
\hline
\end{tabular}

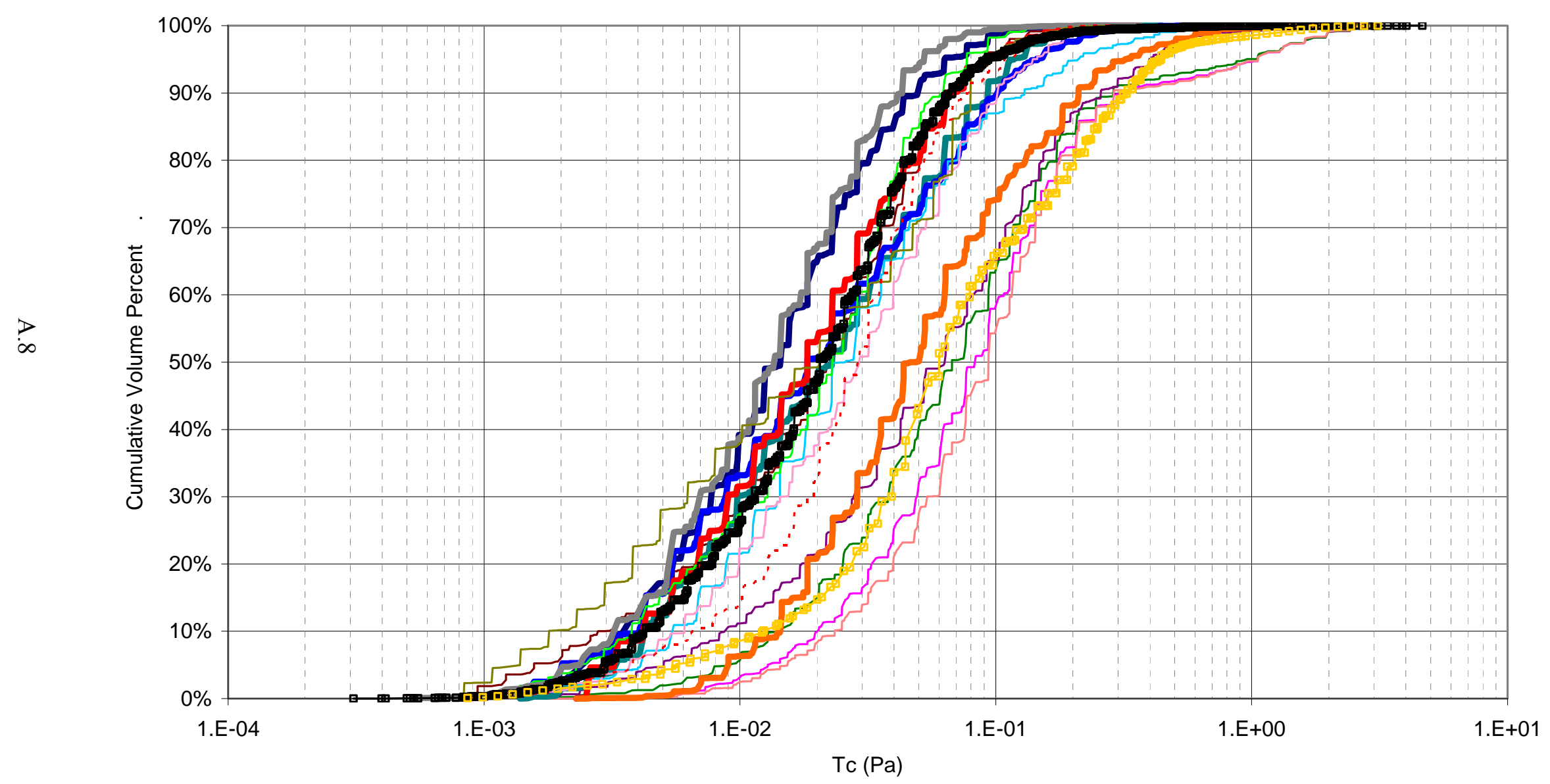

Figure A.7. Critical Shear Stress for Erosion of Non-Cohesive Particles Comparison. Flowing, Sonicated. (Same as Figure 4.3, Top). 


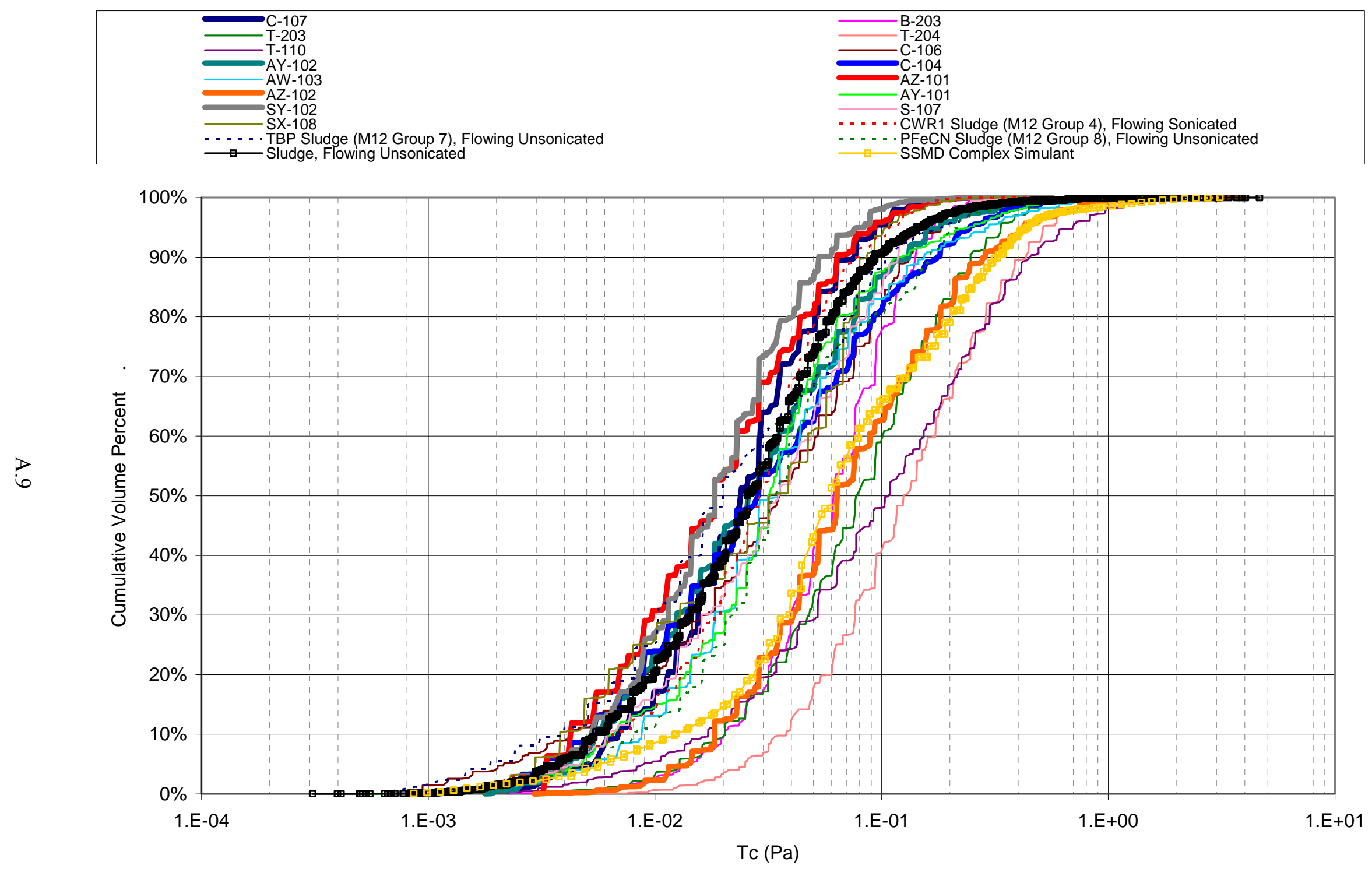

Figure A.8. Critical Shear Stress for Erosion of Non-Cohesive Particles Comparison. Flowing, Unsonicated.

(Same as Figure 4.3, Middle). 


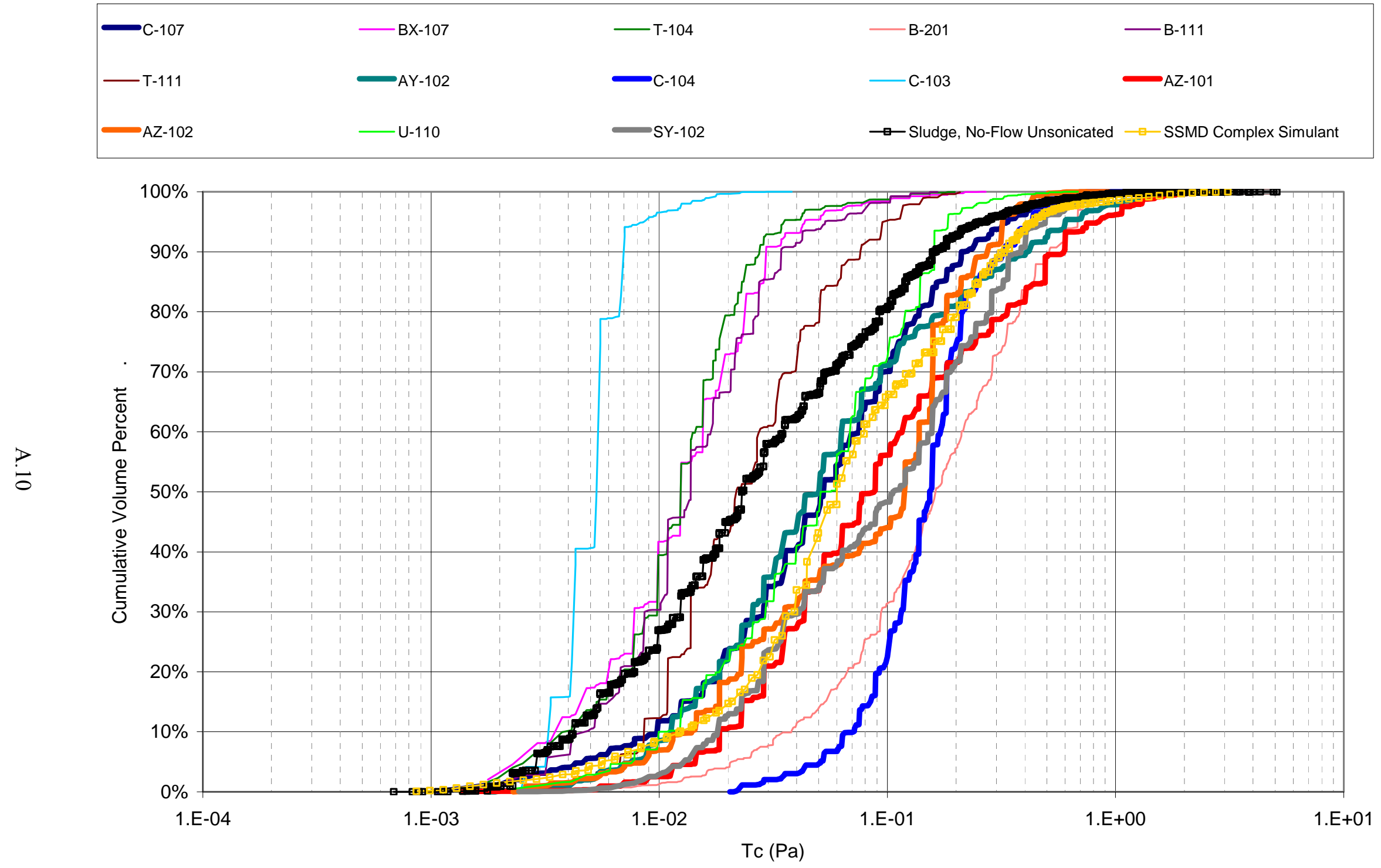

Figure A.9. Critical Shear Stress for Erosion of Non-Cohesive Particles Comparison. No-Flow, Unsonicated.

(Same as Figure 4.3, Bottom). 


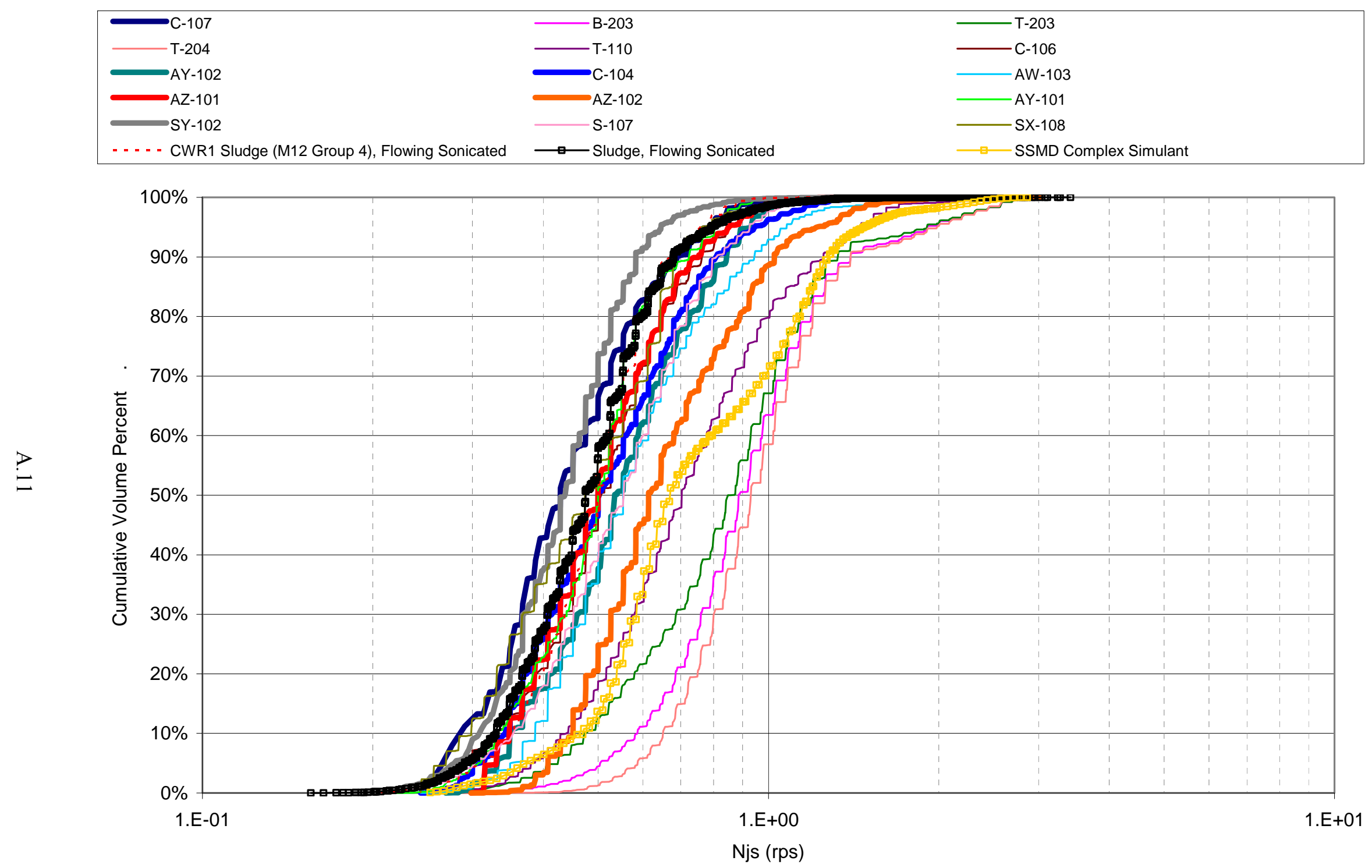

Figure A.10. Just-Suspended Impeller Speed Comparison. Flowing, Sonicated. (Same as Figure 4.4, Top) 


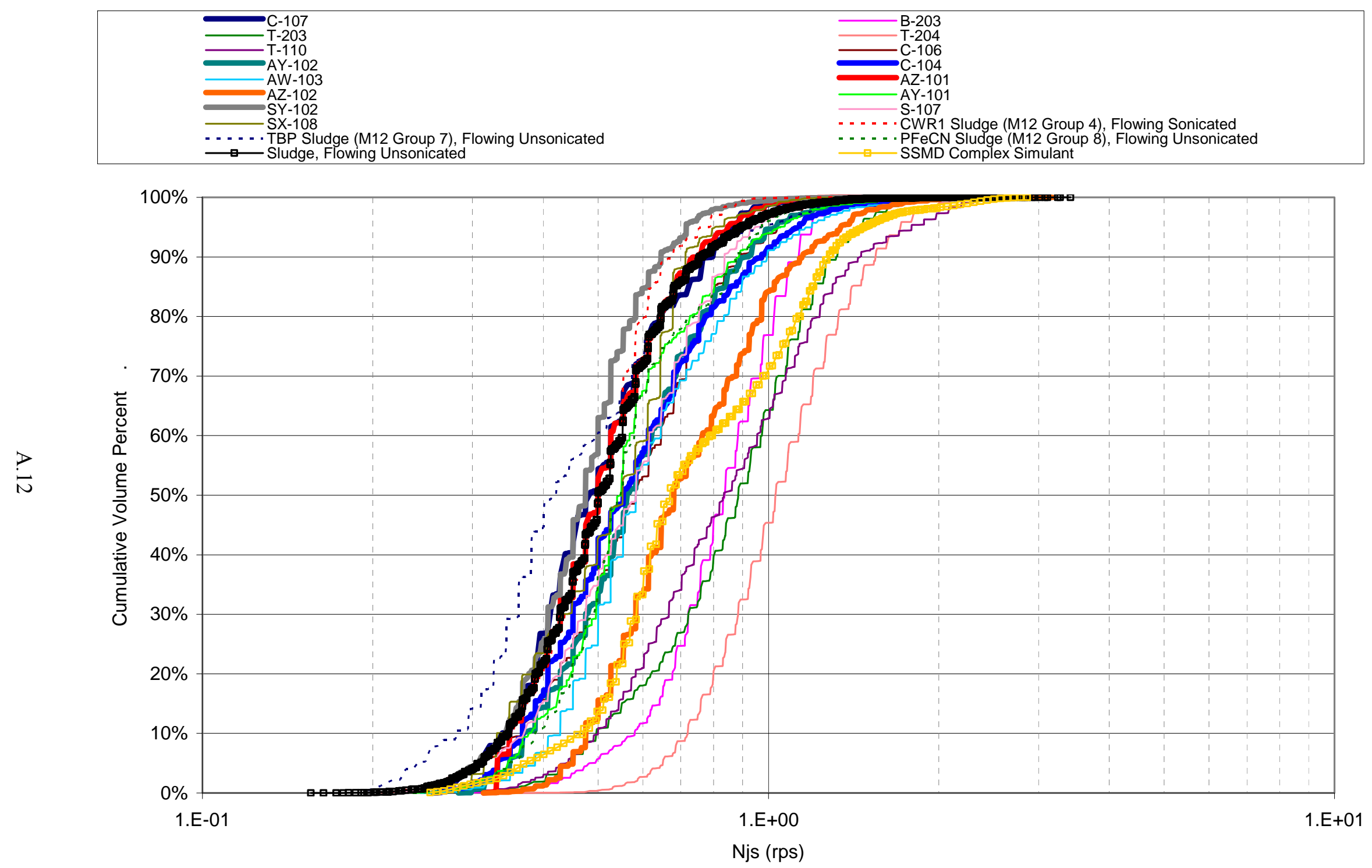

Figure A.11. Just-Suspended Impeller Speed Comparison. Flowing, Unsonicated. (Same as Figure 4.4, Middle). 


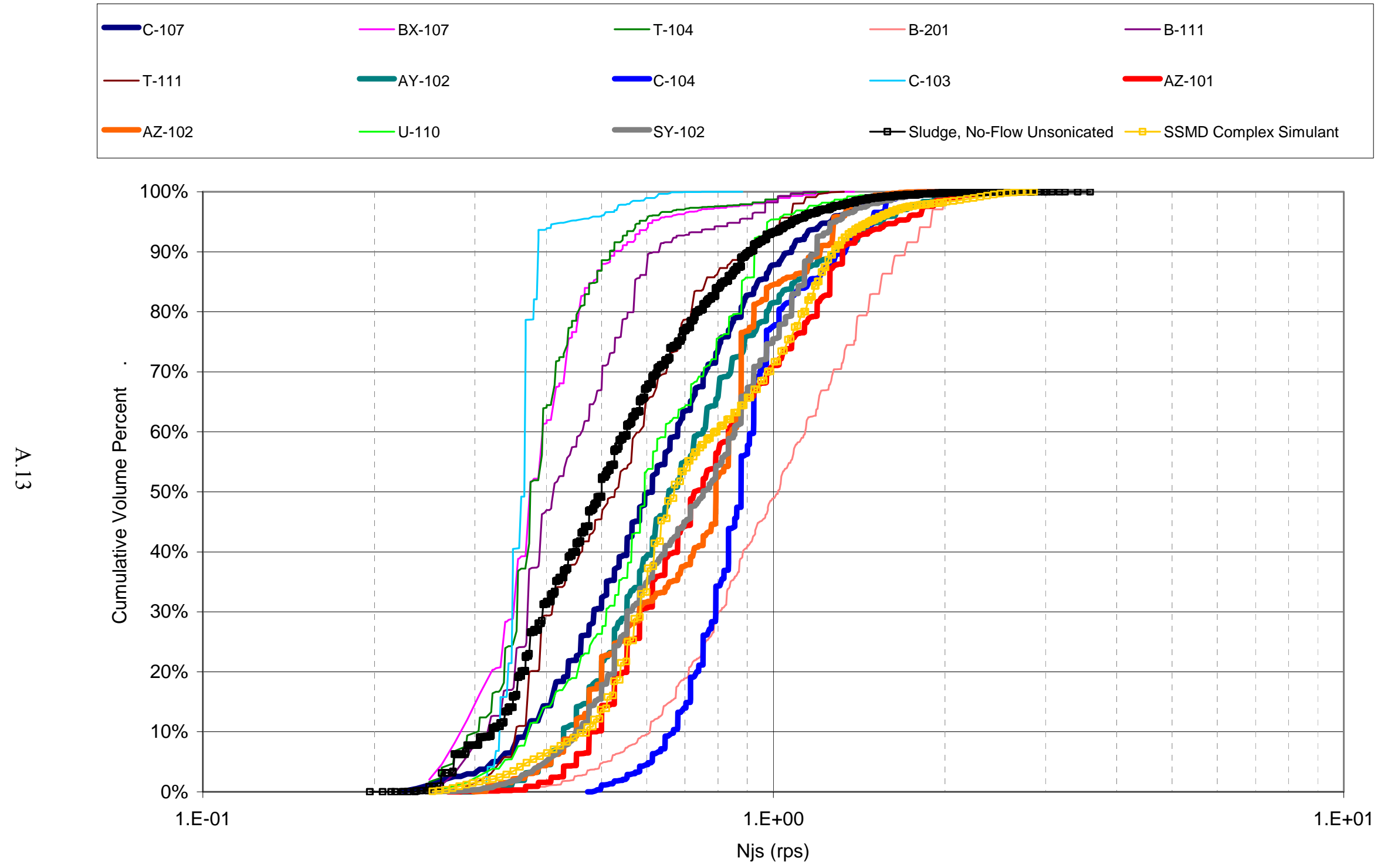

Figure A.12. Just-Suspended Impeller Speed Comparison. No-Flow, Unsonicated. (Same as Figure 4.4, Bottom). 


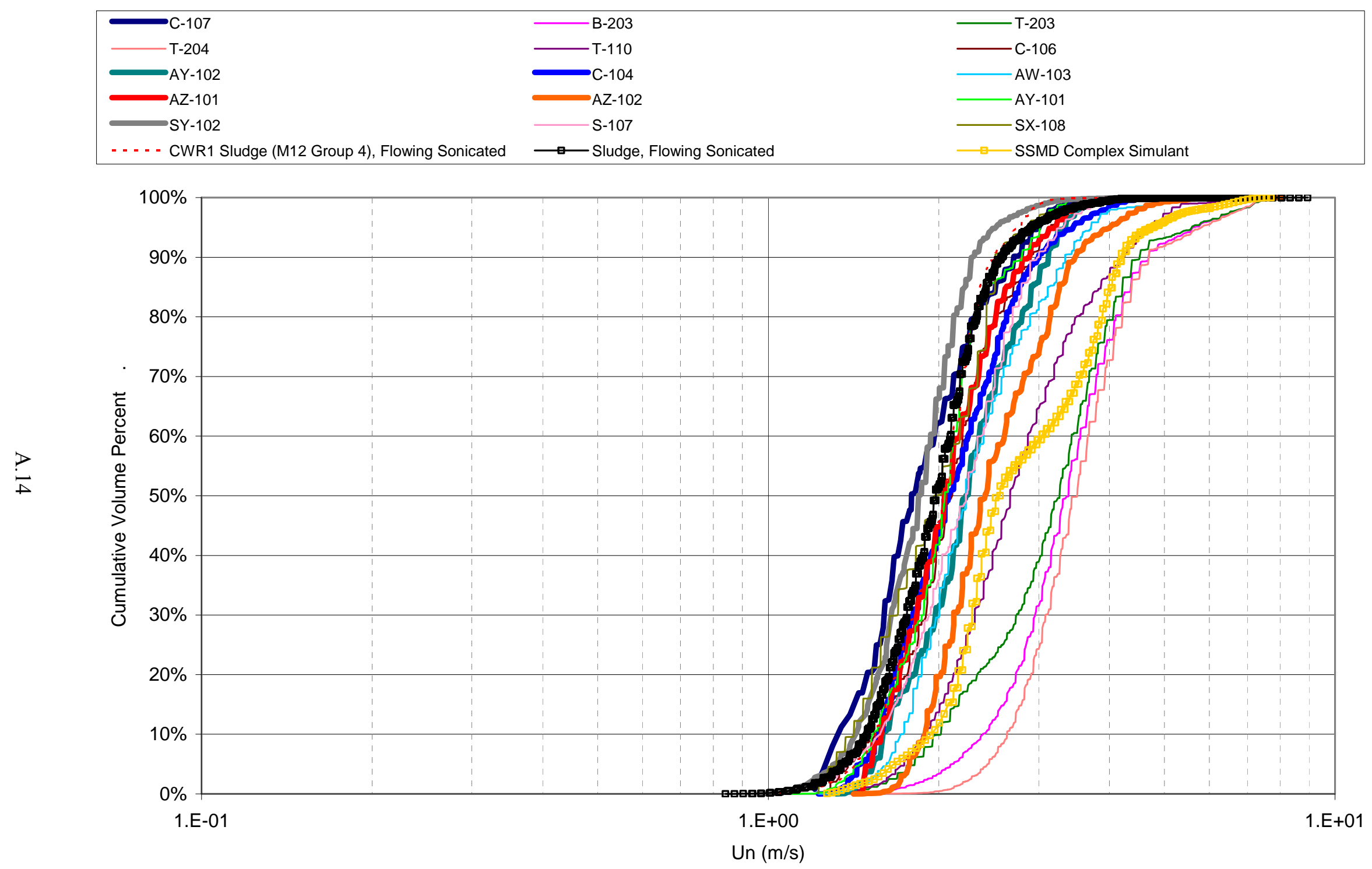

Figure A.13. Jet Velocity Needed to Achieve a Certain Degree of Solid Suspension Comparison. Flowing, Sonicated. (Same as Figure 4.5, Top). 

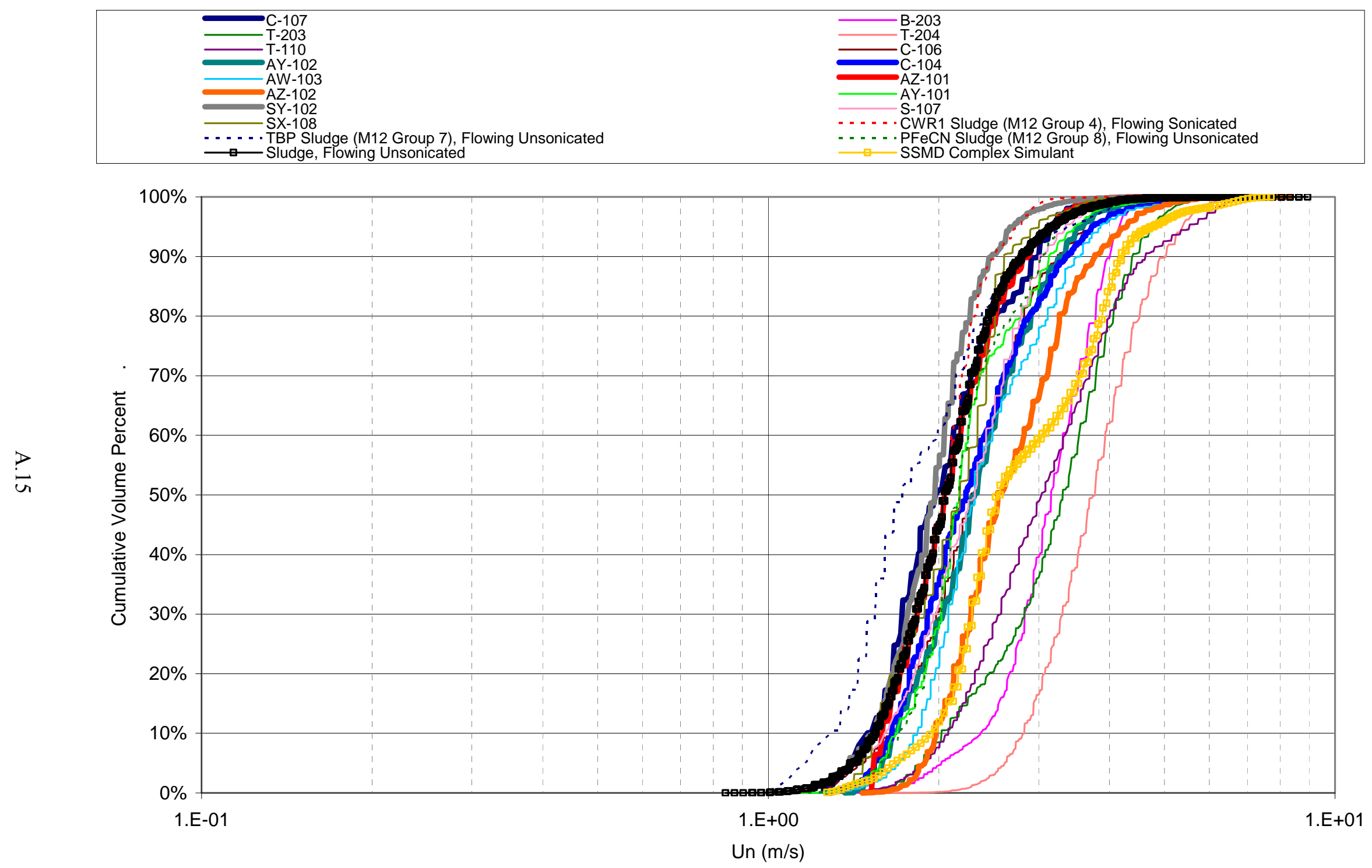

Figure A.14. Jet Velocity Needed to Achieve a Certain Degree of Solid Suspension Comparison. Flowing, Unsonicated. (Same as Figure 4.5, Middle). 


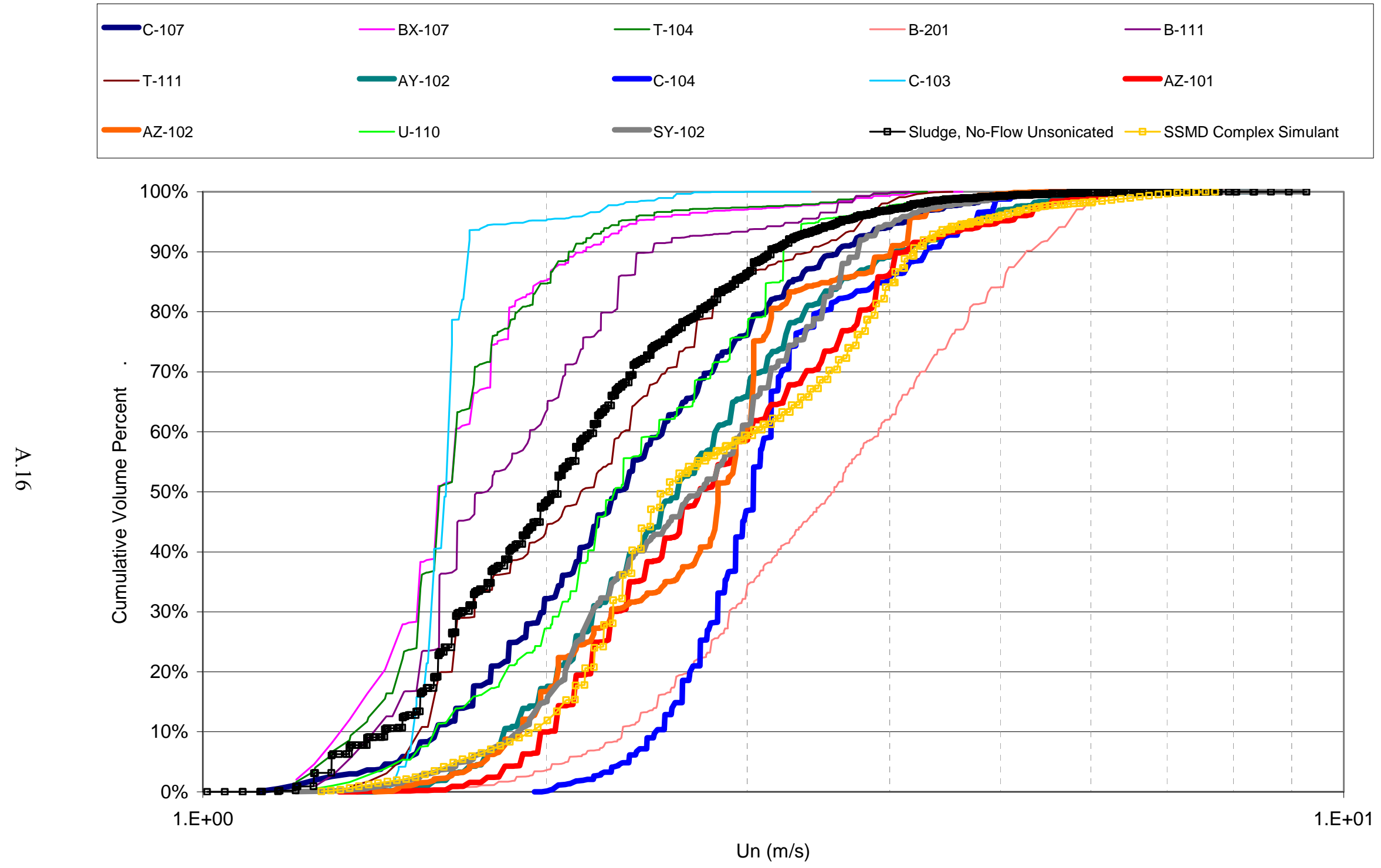

Figure A.15. Jet Velocity Needed to Achieve a Certain Degree of Solid Suspension Comparison. No-Flow, Unsonicated. (Same as Figure 4.5, Bottom). 


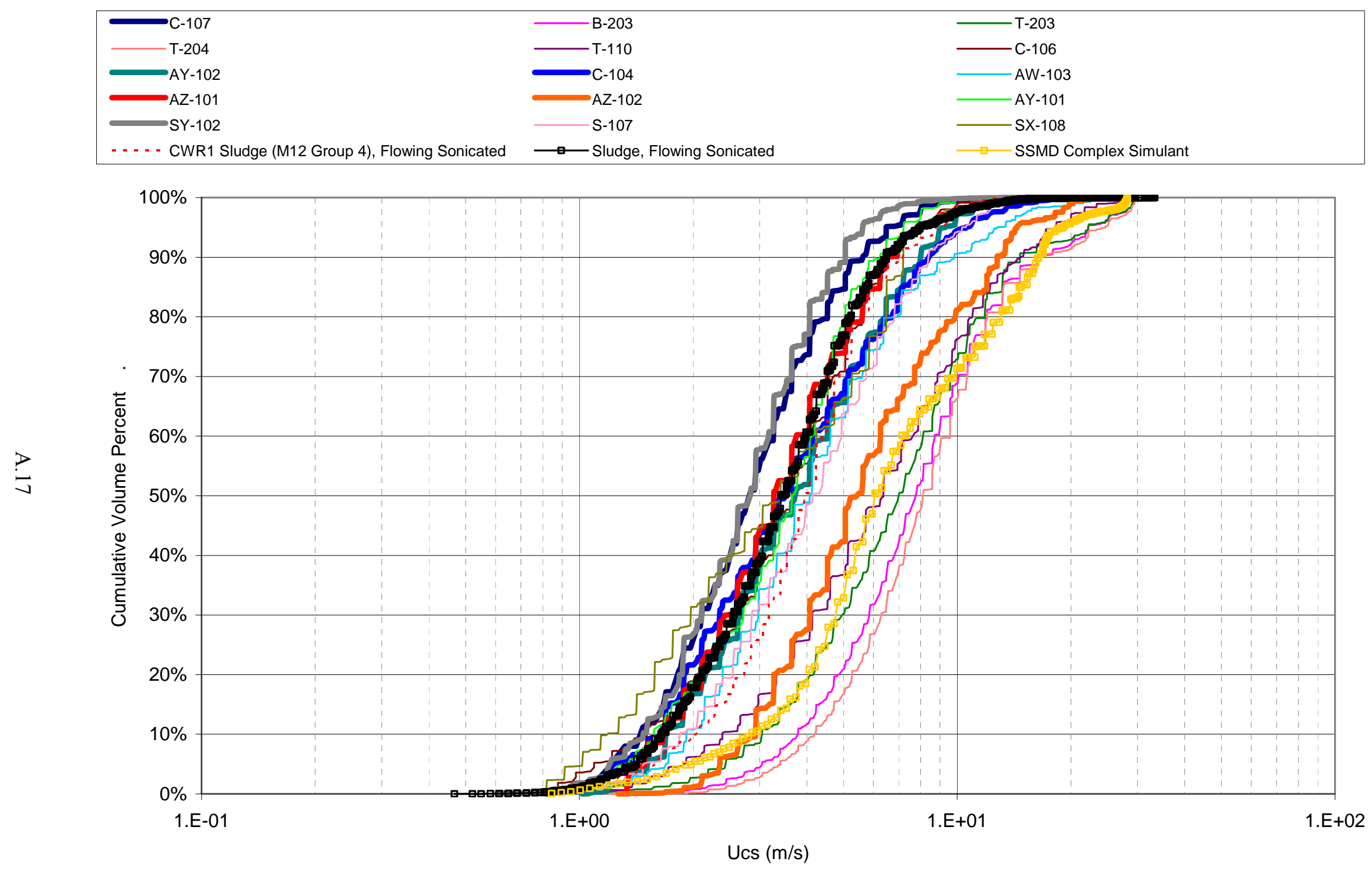

Figure A.16. PJM Critical Suspension Velocity for Non-Cohesive Solids Comparison. Flowing, Sonicated. (Same as Figure 4.6, Top). 


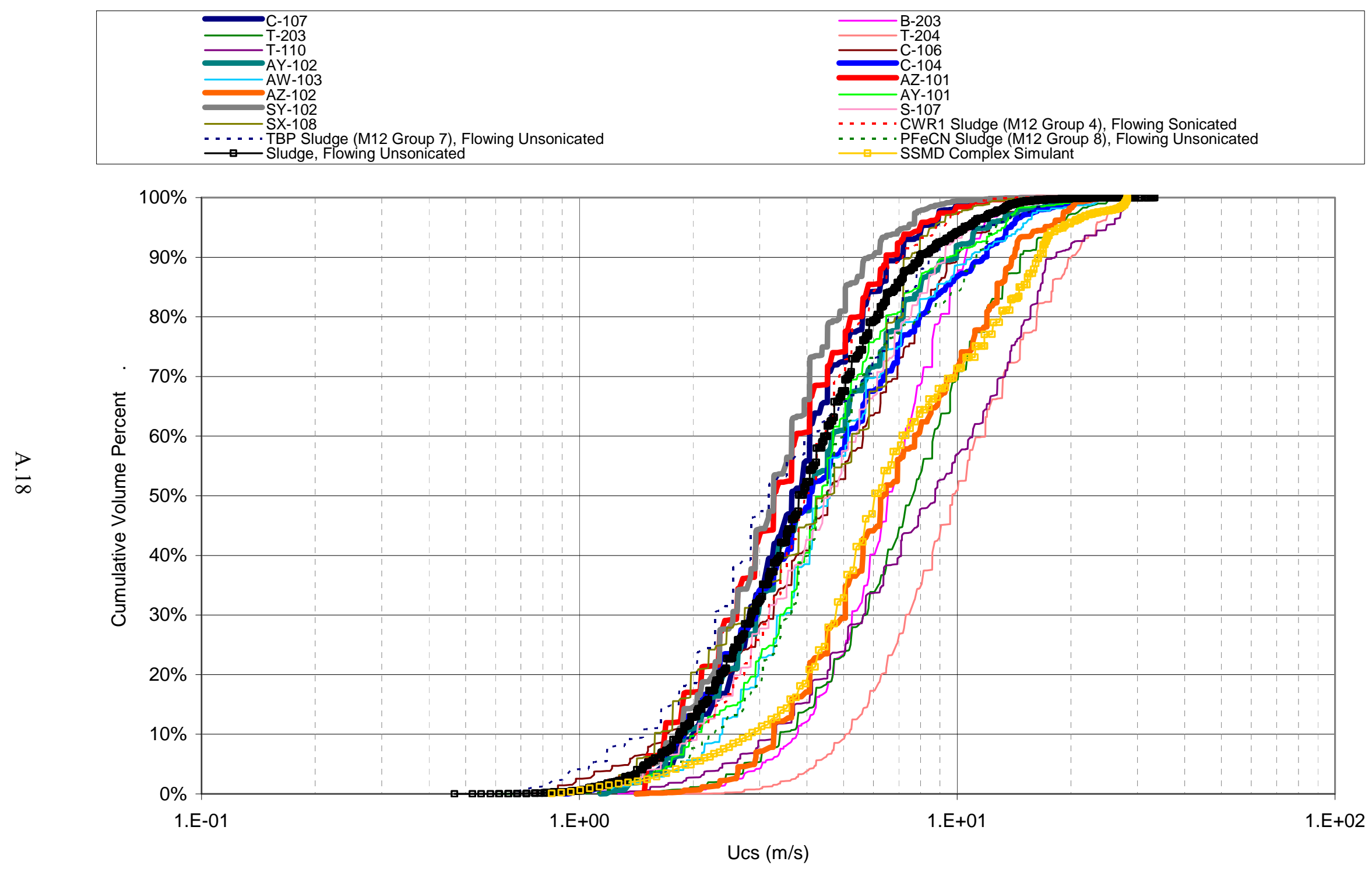

Figure A.17. PJM Critical Suspension Velocity for Non-Cohesive Solids Comparison. Flowing, Unsonicated. (Same as Figure 4.6, Middle). 


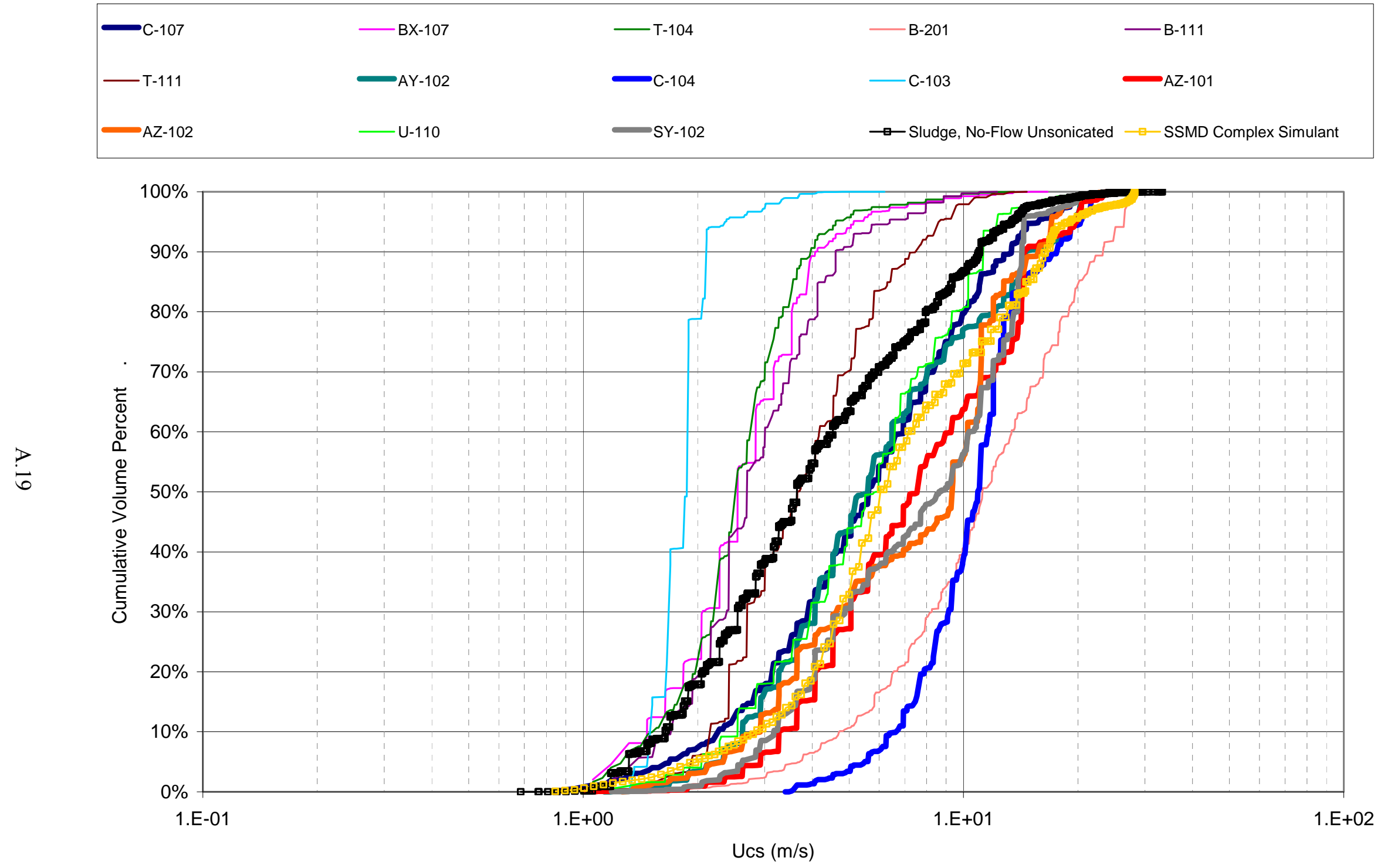

Figure A.18. PJM Critical Suspension Velocity for Non-Cohesive Solids Comparison. No-Flow, Unsonicated. (Same as Figure 4.6, Bottom). 


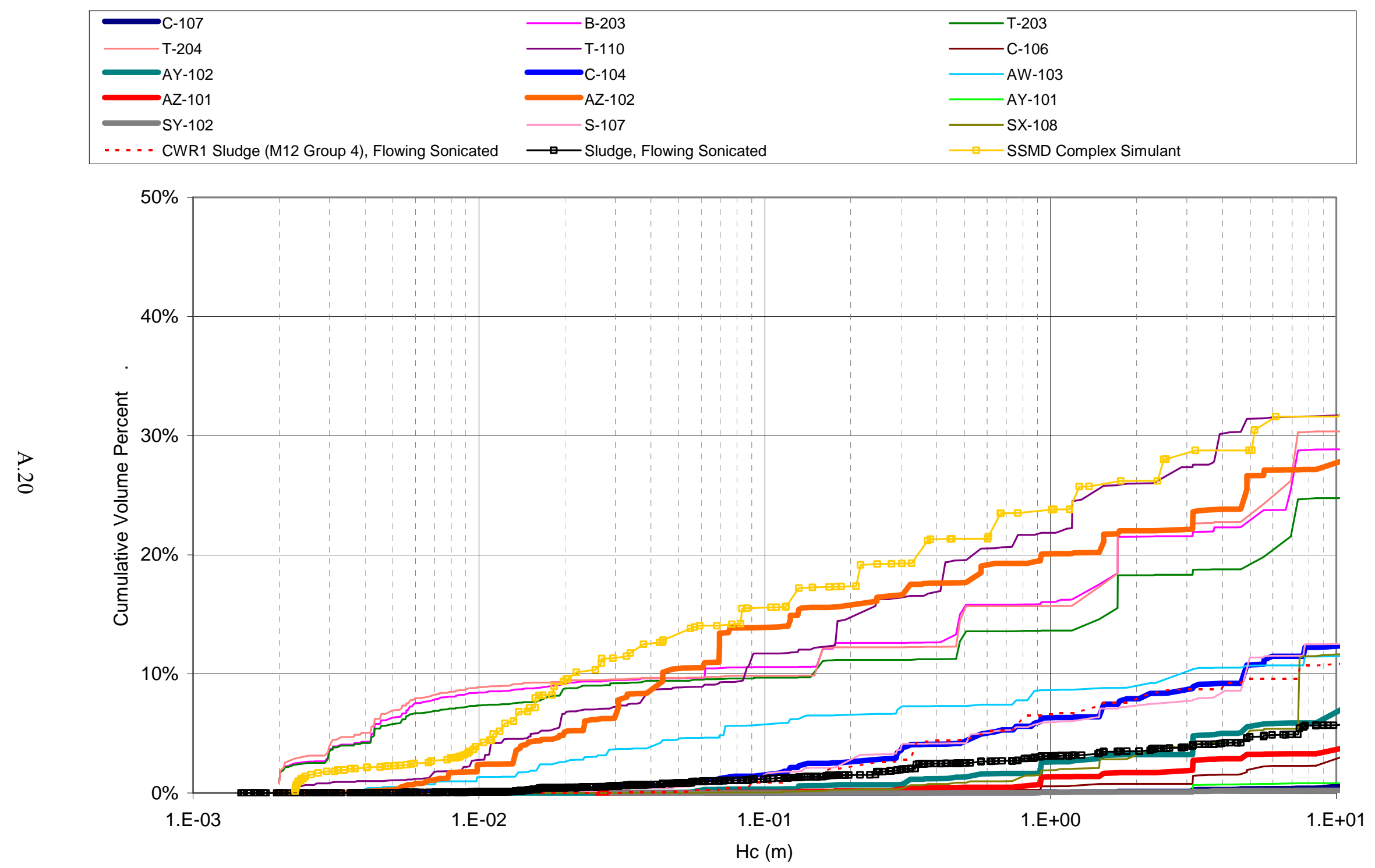

Figure A.19. PJM Cloud Height for Noncohesive Solids Comparison. Flowing, Sonicated. (Same as Figure 4.7, Top). 


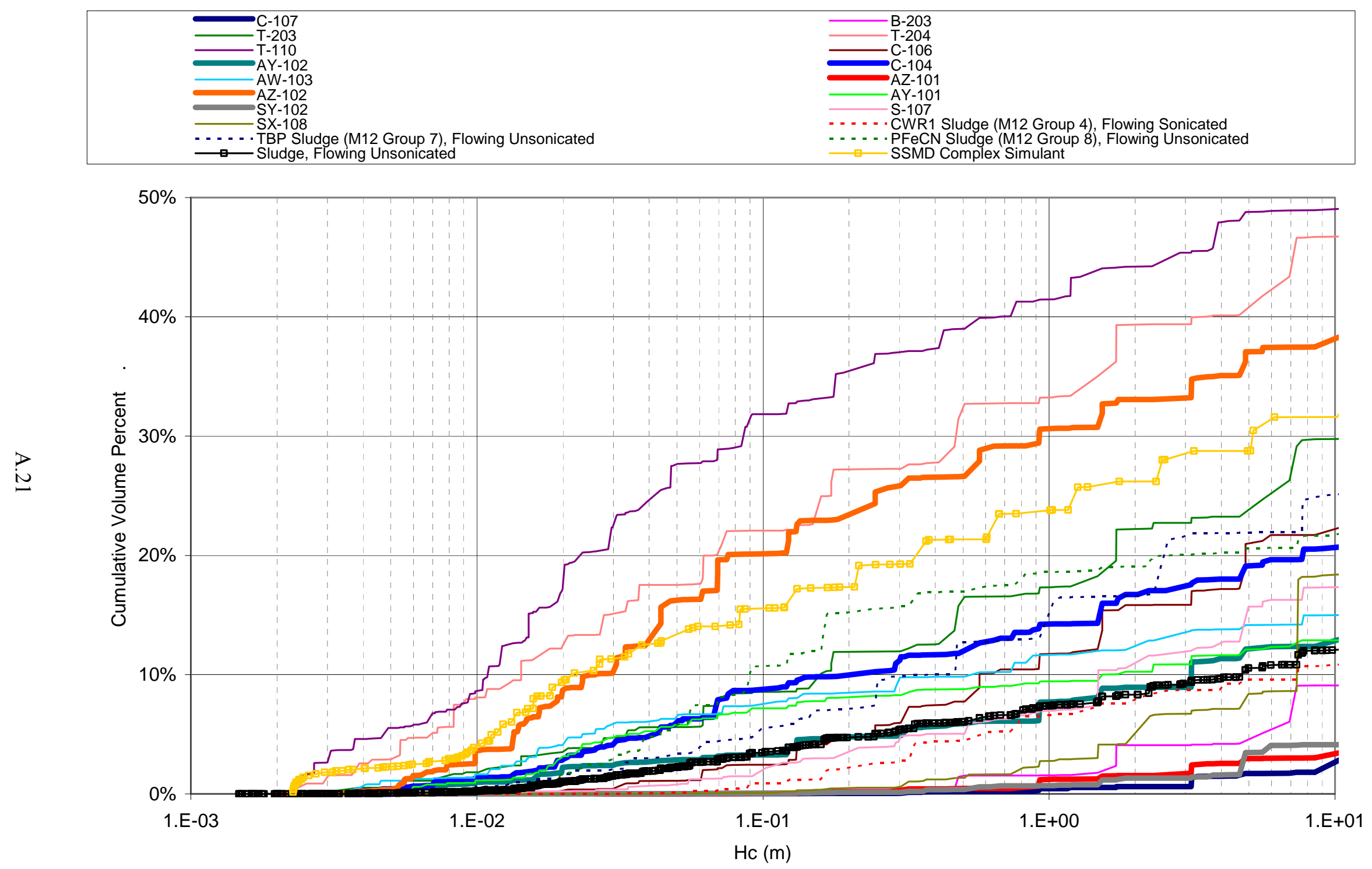

Figure A.20. PJM Cloud Height for Noncohesive Solids Comparison. Flowing, Unsonicated. (Same as Figure 4.7, Middle). 


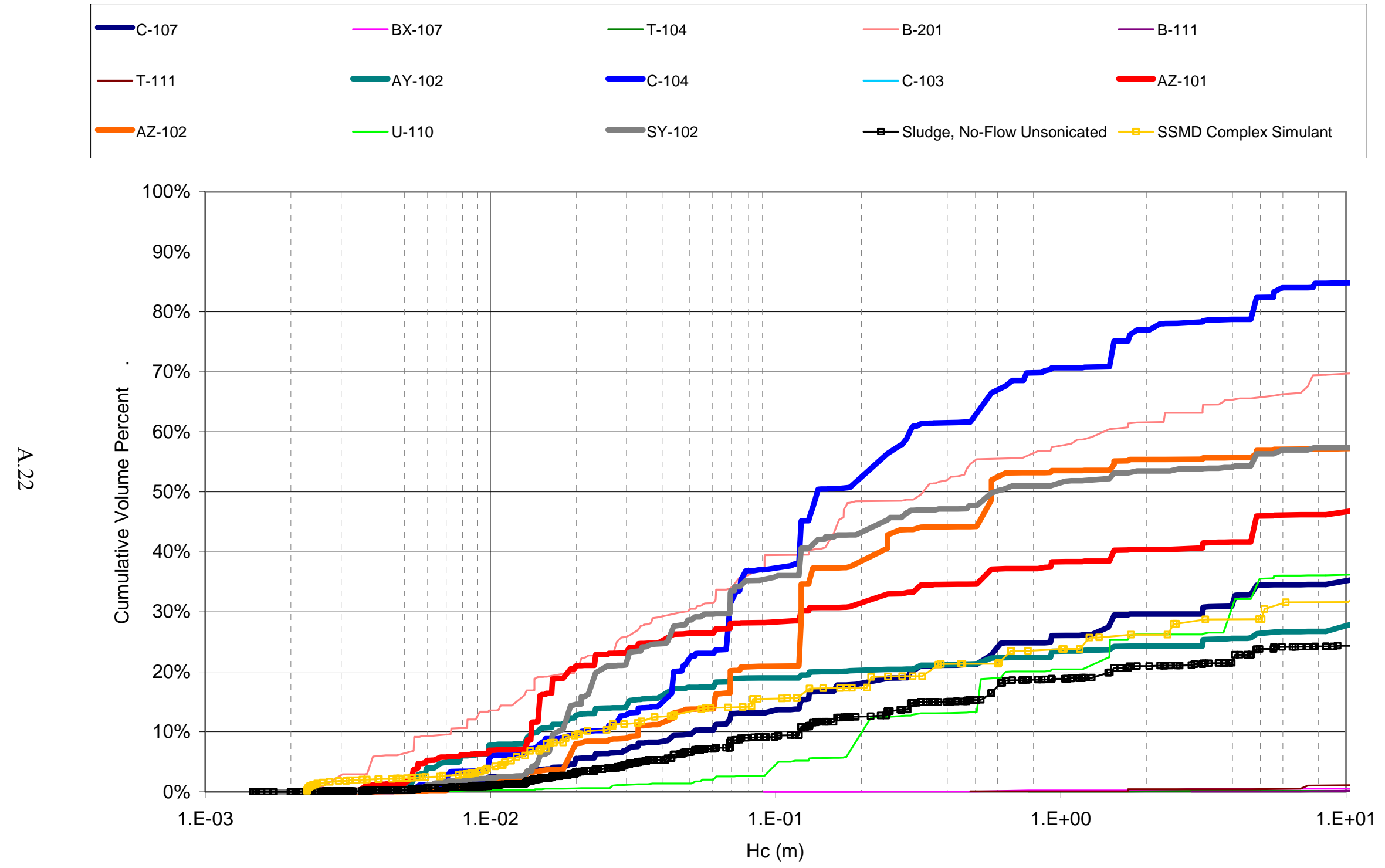

Figure A.21. PJM Cloud Height for Noncohesive Solids Comparison. No-Flow, Unsonicated. (Same as Figure 4.7, Bottom). 


\begin{tabular}{|c|c|c|}
\hline$C-107$ & B-203 & $-\mathrm{T}-203$ \\
\hline$-\mathrm{T}-204$ & $\longrightarrow \mathrm{T}-110$ & $\longrightarrow \mathrm{C}-106$ \\
\hline$A Y-102$ & $\longrightarrow \mathrm{C}-104$ & $-\mathrm{AW}-103$ \\
\hline$A Z-101$ & AZ-102 & $-\mathrm{AY}-101$ \\
\hline SY-102 & S-107 & SX-108 \\
\hline - - - - CWR1 Sludge (M12 Group 4), Flowing Sonicated & $\longrightarrow$ Sludge, Flowing Sonicated & $\square$ SSMD Complex Simulant \\
\hline
\end{tabular}

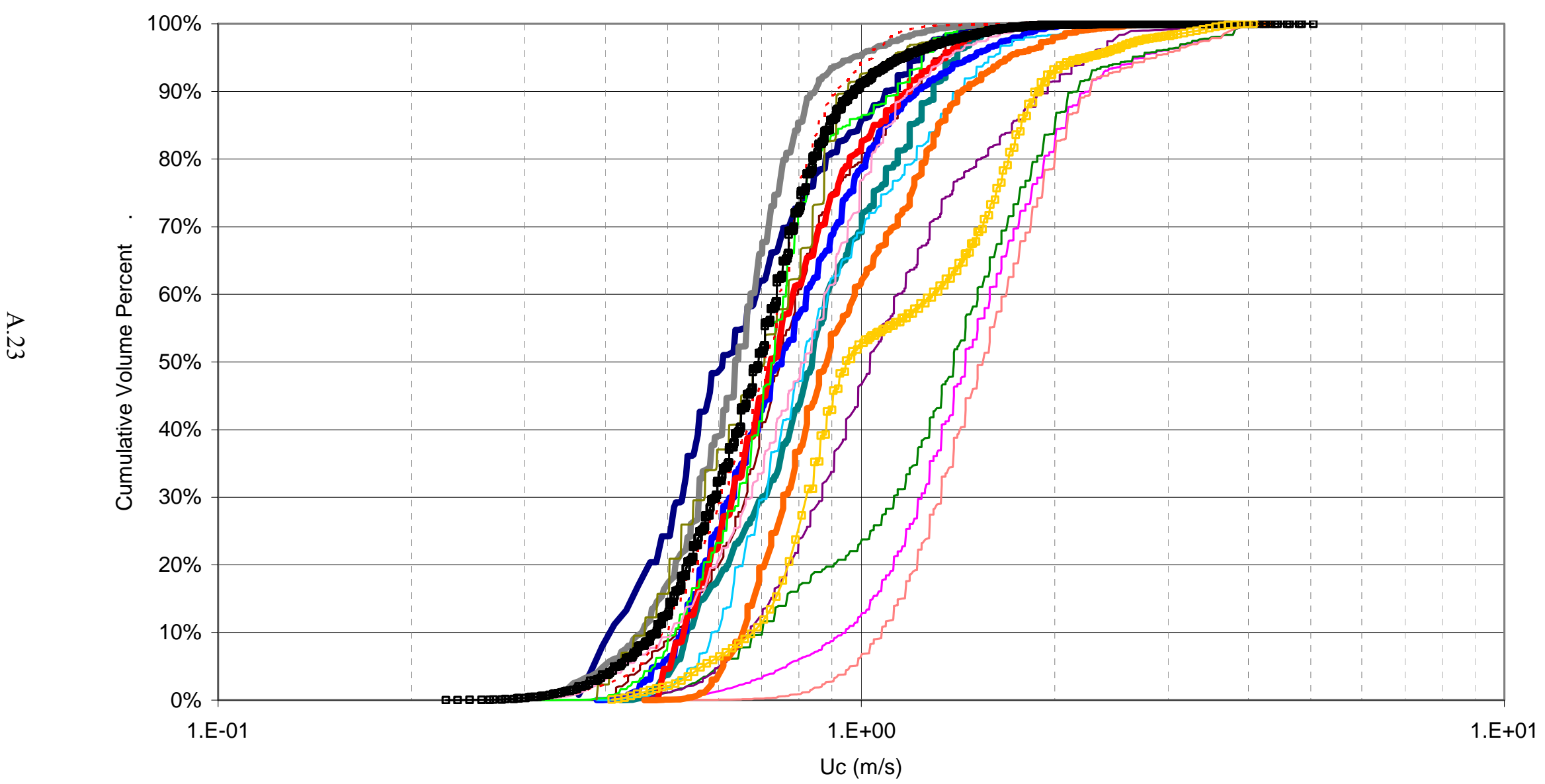

Figure A.22. Pipeline Critical Transport Velocity Comparison. Flowing, Sonicated. (Same as Figure 4.8, Top). 


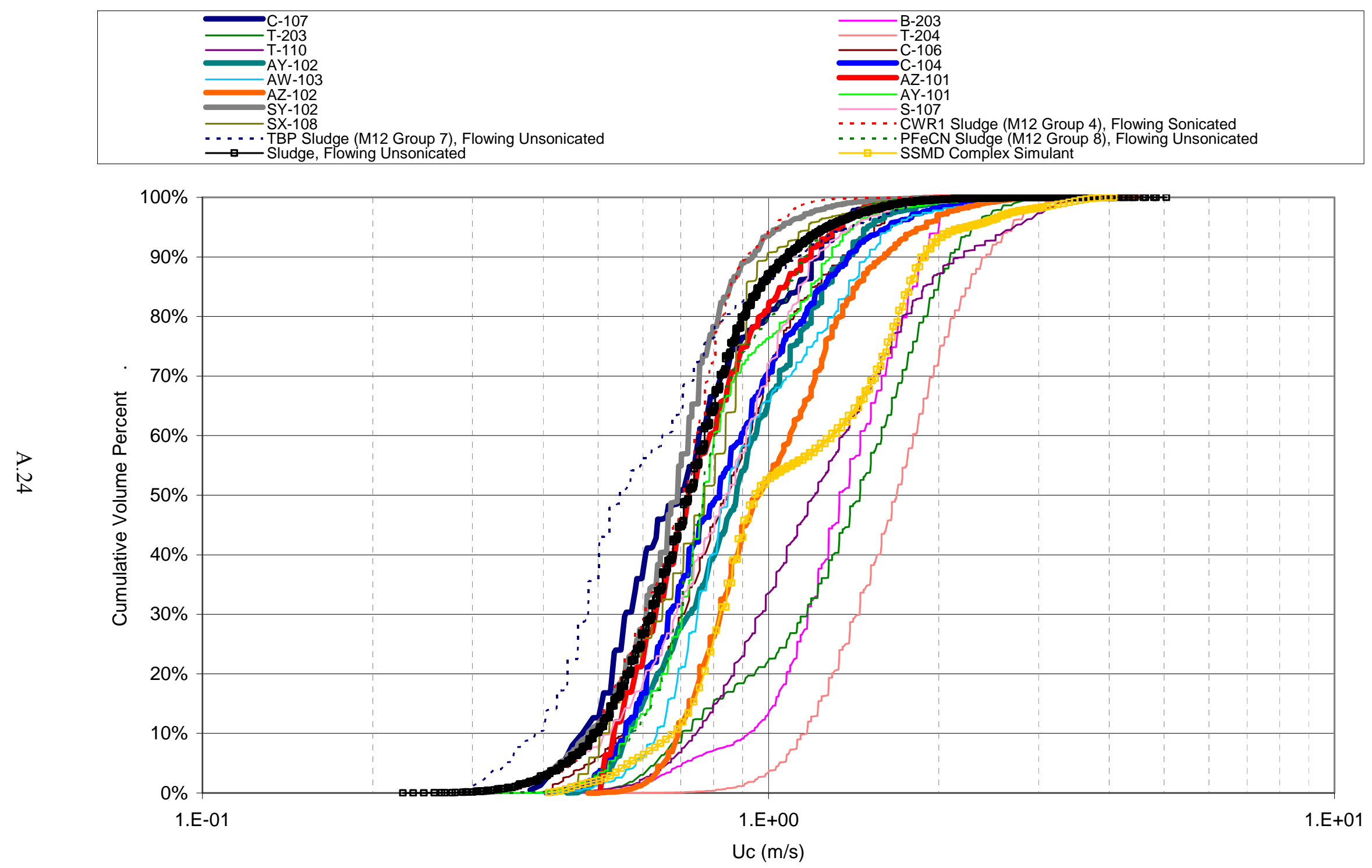

Figure A.23. Pipeline Critical Transport Velocity Comparison. Flowing, Unsonicated. (Same as Figure 4.8, Middle). 


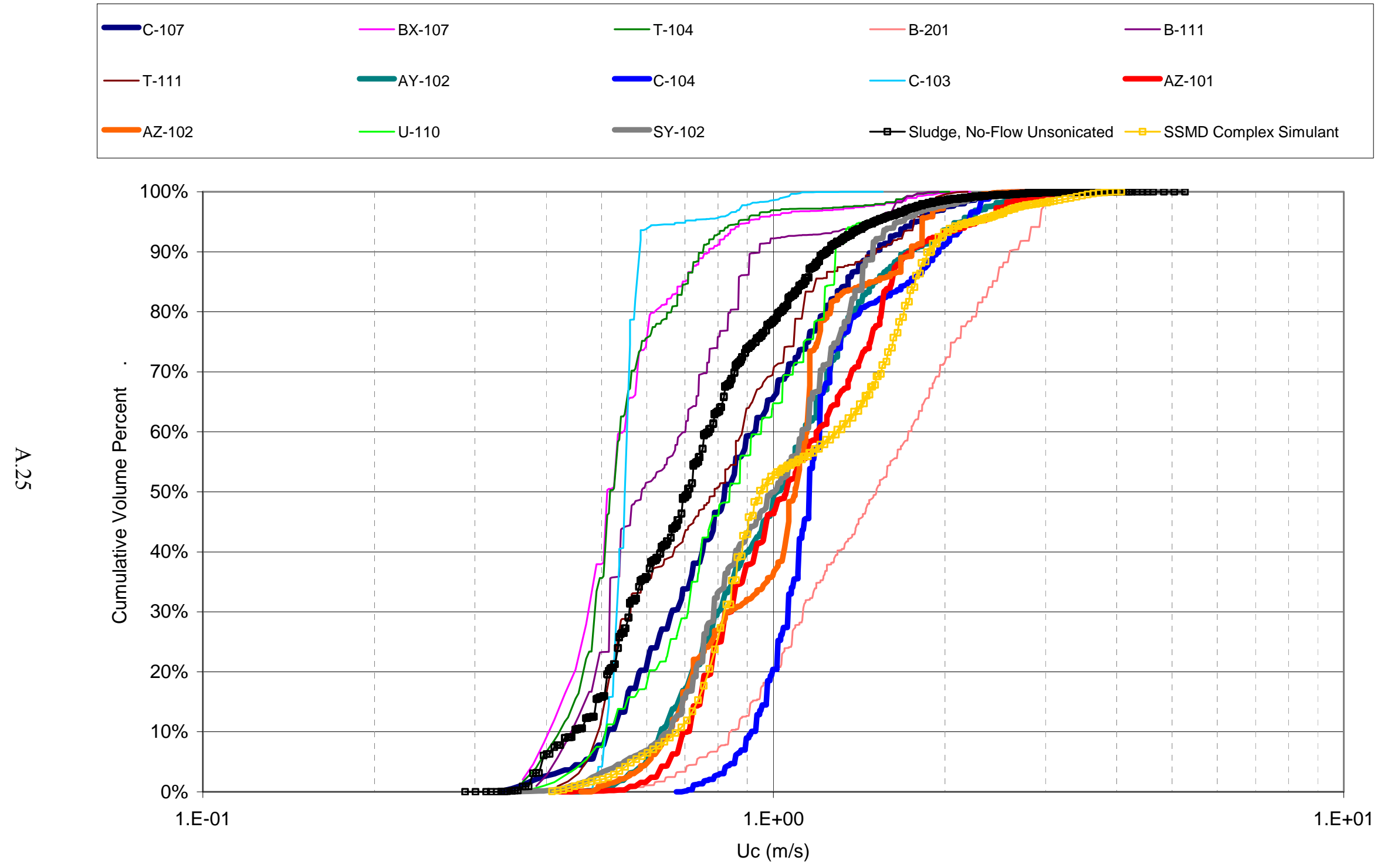

Figure A.24. Pipeline Critical Transport Velocity Comparison. No-Flow, Unsonicated. (Same as Figure 4.8, Bottom). 



\section{Distribution}

No. of

Copies

3 DOE Office of River Protection

RA Gilbert

JA Reddick

JS Shuen

H6-60

H6-60

H6-60

8 Washington River Protection Solutions

RL Garrett

VL Jackson

JG Reynolds

SA Saunders

M Thien (3)

TA Wooley

1 Bechtel National Inc.

P Keuhlen
No. of

\section{Copies}

9 Pacific Northwest National Laboratory

$\begin{array}{ll}\text { JA Fort } & \text { K7-15 } \\ \text { PA Gauglitz (5) } & \text { K7-15 } \\ \text { TE Michener } & \text { K7-15 } \\ \text { DR Rector } & \text { K7-15 } \\ \text { BE Wells } & \text { K7-15 }\end{array}$

JA Fort

K7-15

K7-15

K7-15

K7-15
MS4-A2

\section{Energy Solutions}

P Townson

2345 Stevens Dr

Richland, WA 99352

R2-58

B1-55

B1-55

B1-55

B1-55

B1-55 




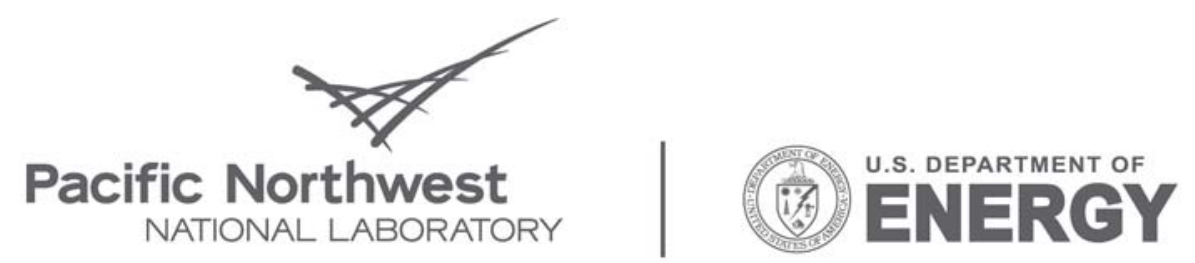

Proudly Operated by Battelle Since 1965

902 Battelle Boulevard

P.O. Box 999

Richland, WA 99352

1-888-375-PNNL (7665)

www.pnl.gov 